\title{
Effectiveness of Trek-21 model of professional development on changes in teacher practices with respect to instructional technology integration
}

Chifundo N. Lemani

West Virginia University

Follow this and additional works at: https://researchrepository.wvu.edu/etd

\section{Recommended Citation}

Lemani, Chifundo N., "Effectiveness of Trek-21 model of professional development on changes in teacher practices with respect to instructional technology integration" (2004). Graduate Theses, Dissertations, and Problem Reports. 2600.

https://researchrepository.wvu.edu/etd/2600

This Dissertation is protected by copyright and/or related rights. It has been brought to you by the The Research Repository @ WVU with permission from the rights-holder(s). You are free to use this Dissertation in any way that is permitted by the copyright and related rights legislation that applies to your use. For other uses you must obtain permission from the rights-holder(s) directly, unless additional rights are indicated by a Creative Commons license in the record and/ or on the work itself. This Dissertation has been accepted for inclusion in WVU Graduate Theses, Dissertations, and Problem Reports collection by an authorized administrator of The Research Repository @ WVU.

For more information, please contact researchrepository@mail.wvu.edu. 
Effectiveness of Trek-21 Model of Professional Development on Changes in Teacher Practices with Respect to Instructional Technology Integration

Chifundo N. Lemani

A Dissertation submitted to the College of Human Resources and Education

at West Virginia University

in Partial Fulfillment of the Requirements

for the degree of

Doctor of Education

in

Technology Education

John G. Wells, Ph.D., Chair

David L. McCrory, Ph.D.

Randall Wiesenmayer, Ph.D

Richard T. Walls, Ph.D

Frances Vanscoy, Ph.D

Department of Technology Education

Morgantown, West Virginia

2004 


\begin{abstract}
Effectiveness of Trek-21 Model of Professional Development on Changes in Teacher Practices with Respect to Instructional Technology Integration
\end{abstract}

\title{
Chifundo N. Lemani
}

The purpose of this study was to investigate the relationship between key factors of Trek-21 professional development model and resulting changes in teacher practices with respect to the integration of instructional technologies into participants' classrooms. The Trek 21 professional development was a three-year project designed to bring about a deep and lasting change in educators through the integration of instructional technologies. The project was funded as an implementation grant through the U.S. Department of Education’s Preparing Tomorrow's Teachers to Use Technology (PT3) grant program. The Trek-21 professional development was developed around research-based practices that enabled participants to develop IT skills necessary to integrate what they learned.

Participants included 27 PK-12 teachers from schools in West Virginia, who took part in the second year (2001) of Trek-21 professional development training from January 2001 to January 2002. Data were collected using the Stages of Concern Questionnaire, the Principles of Adult Learning Scale (PALS) Questionnaire, the Survey of Computer Use Questionnaire, the Final-Daily Evaluation Questionnaire, and Indicators of Instructional Change Instrument (also known as the Lesson Sweep Instrument). Three key factors of the Trek-21 model were considered as potential factors affecting integration of instructional technologies into the classroom. These three factors include duration of training, instructional design, and evaluation. Descriptive analysis, paired t- 
test, correlation analysis and simple regression analysis were the quantitative statistical procedures that were used to compile the results.

Crucial key factors of the model found to be significant in affecting the integration of ITs into the classroom included duration of training and evaluation. The results indicated that teachers did make significant gains in integrating ITs learned during training over the duration of training suggesting that the period of training was sufficient enough to facilitate change in teacher practice. The study did not find Instructional Design as a crucial key factor of the Trek-21 professional development model. 


\section{ACKNOWLEDGEMENTS}

I would like to express my sincere appreciation to those who have assisted and supported me in the completion of this challenging educational endeavor.

My sincere appreciation and gratitude to the members of my dissertation committee for their assistance and support in the completion of this dissertation. Special thanks to Dr. John G. Wells, Chairperson of my dissertation committee, for his pursuit of excellence and dedication to this project. His friendship and support were paramount to the completion of this challenging endeavor. Also thanks to Dr. Debbie Wells for being there to assist me when I needed help with instruments and data. Her compassion was important to the completion of this project. I also owe a great deal of thanks to Dr. Richard Walls for sharing with me his wealth of statistics knowledge. I am appreciative of his guidance and encouragement.

I would also like to thank all of my professors and colleagues at West Virginia University for providing a challenging educational experience.

Most important, I wish to thank my family for their love, support and encouragement. Special thanks to my brother, Blessings and my sisters Rhoda, Dinna, Loveness, Taukirana, and Asausyedye. Without their love, enthusiasm, and support, this accomplishment would not have been possible. Their help will never be forgotten.

Special thanks also to Michelle, my daughter, for her understanding, cooperation, and patience throughout this challenging educational endeavor. My greatest thanks, love and appreciation to my dearest friend and loving mother of my daughter, Dessie, who encouraged me from the very beginning and supported me all the way. Thank you for your patience and giving me the opportunity to fulfill this dream. 
Thank you to Dr. Randall Wiesenmayer, Dr. John G. Wells, and Dr. Jerry Fletcher for providing me with the assistantships necessary to meet the costs of tuition throughout my doctoral coursework. 


\section{TABLE OF CONTENTS}

Page

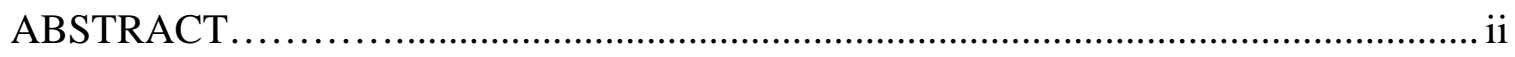

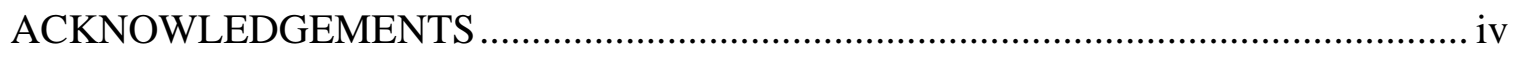

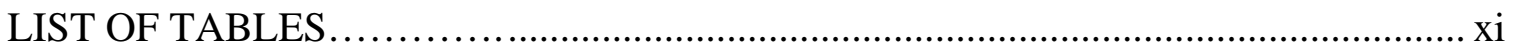

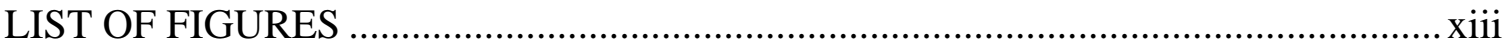

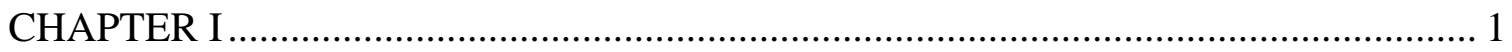

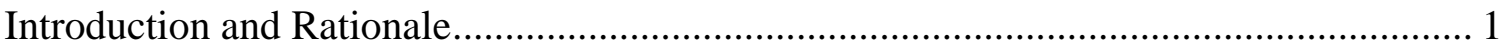

Statement of the Problem............................................................................... 2

Key Factors of Professional Development ................................................. 3

Research Questions............................................................................... 4

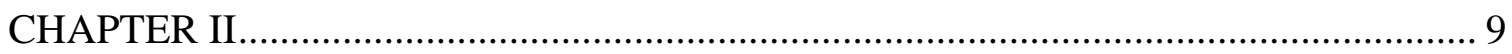

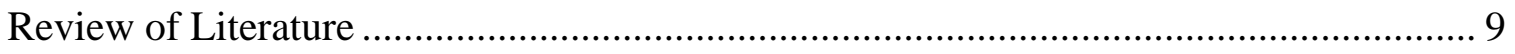

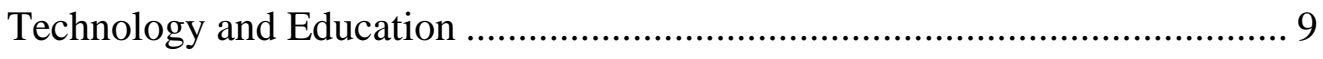

Impact on Education .................................................................... 9

Government Instructional Technologies Initiatives............................. 16

Instructional Technology and Professional Development .......................... 23

Traditional Approach to Professional Development.............................. 23

New Approach to Professional Development....................................... 25

Key Factors of Professional Development ............................................. 26

The Trek-21 Model of Professional Development .................................... 27

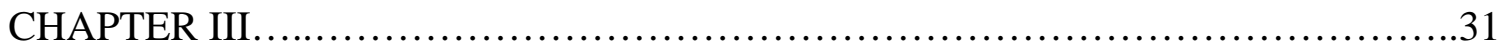

Methods........................................................................

Research Questions...................................................31 


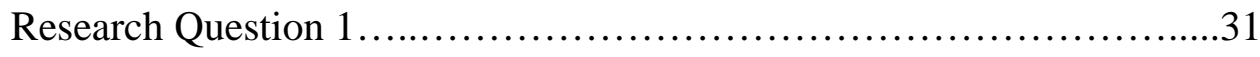

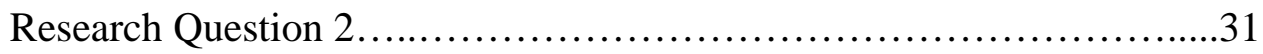

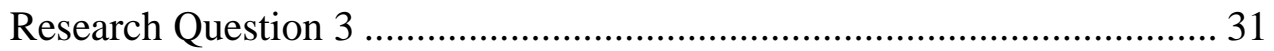

Research Question 4 ....................................................................... 32

Research Question 5 .................................................................... 32

Research Question 6 ..................................................................... 32

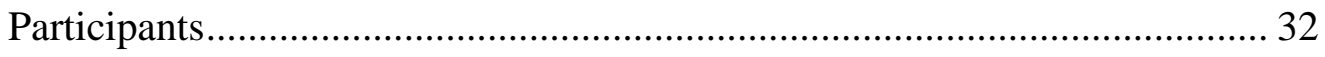

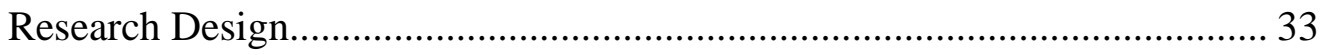

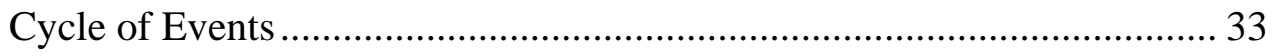

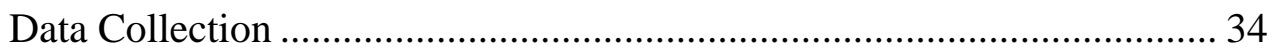

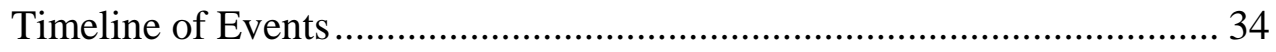

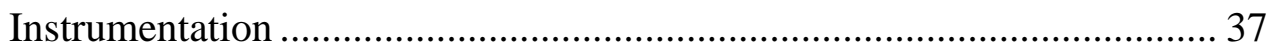

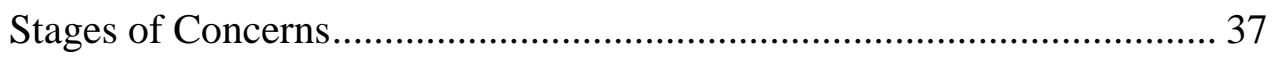

Principles of Adult Learning Scale ...................................................... 37

The Survey of Computer Use ......................................................... 38

Daily Training Evaluations and Final Training Evaluation..................... 38

Indicators of Instructional Change Instrument ................................... 39

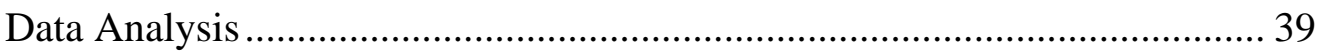

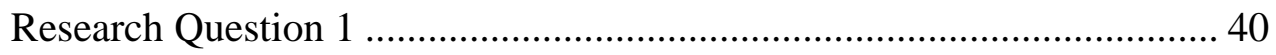

Research Question 2 .................................................................. 40

Research Question 3 ............................................................... 40

Research Question 4 ................................................................... 41

Research Question 5 .................................................................... 41

Research Question 6 ................................................................. 41

CHAPTER IV .............................................................47 


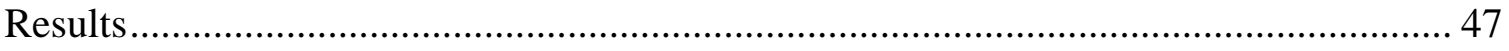

Description of the Participants.......................................................................... 47

Findings on the Research Questions................................................................ 48

Research Question 1 (RQ1) .......................................................................... 50

RQ1a - SoC vs. Duration of Training ............................................................ 51

All Participants............................................................................................ 56

Beginners Group Participants ................................................................... 57

Intermediate Group Participants .............................................................. 58

Advanced Group Participants ...................................................................... 60

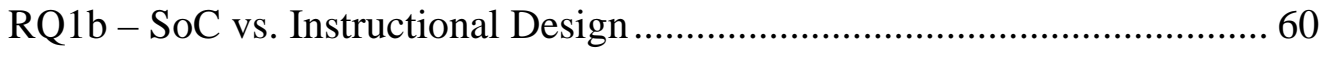

RQ1c - SoC vs. Evaluation ............................................................................ 63

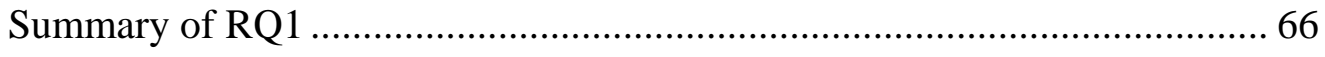

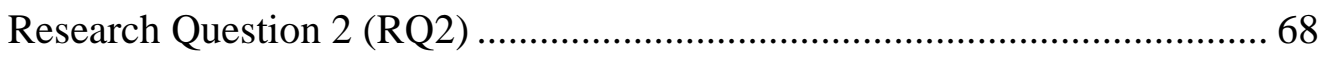

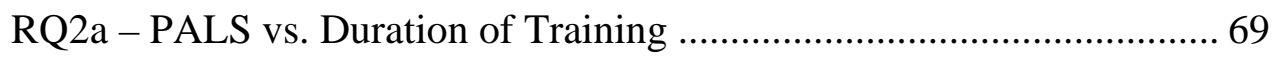

RQ2b - PALS vs. Instructional Design ..................................................... 70

RQ2c - PALS vs. Evaluation....................................................................... 71

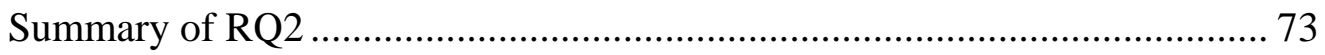

Research Question 3 (RQ3) ............................................................................ 75

RQ3a - Level of Computer Use vs. Duration of Training........................... 76

RQ3b - Level of Computer Use vs. Instructional Design ........................... 77

RQ3c - Level of Computer Use vs. Evaluation........................................... 79

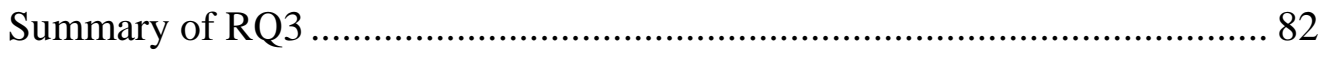

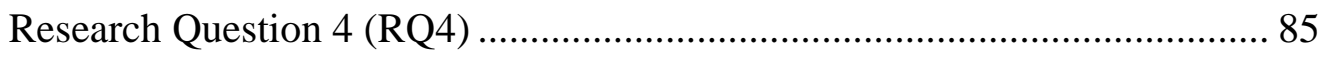

RQ4a - IT Integration vs. Duration of Training ......................................... 86

RQ4b - IT Integration vs. Evaluation........................................................ 87 


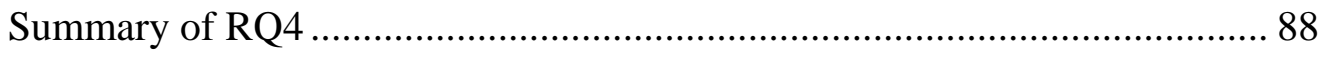

Research Question 5 (RQ5) ……………………….................................. 90

RQ5a - IT Knowledge vs. Duration of Training ........................................... 91

RQ5b - IT Knowledge vs. Instructional Design.......................................... 92

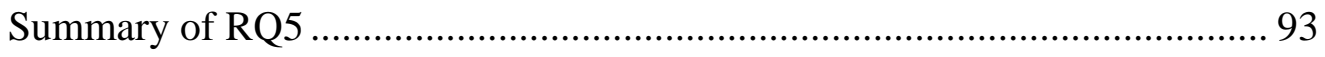

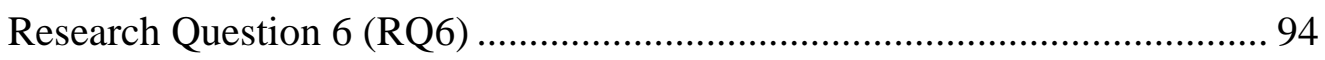

Duration of Training .................................................................................. 94

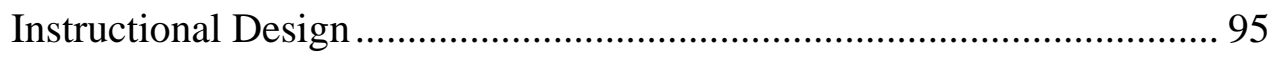

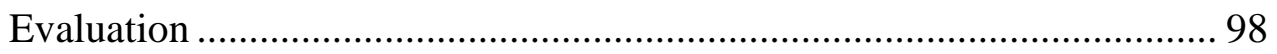

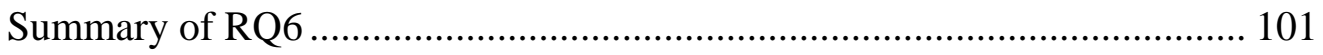

Duration of Training as a key factor ....................................................... 101

Instructional Design as a key factor.......................................................... 101

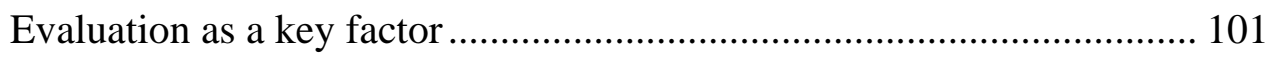

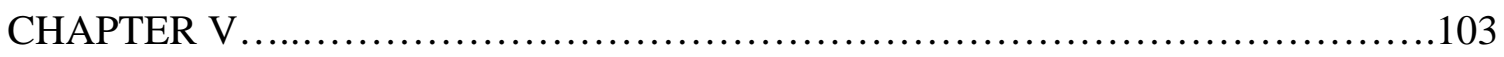

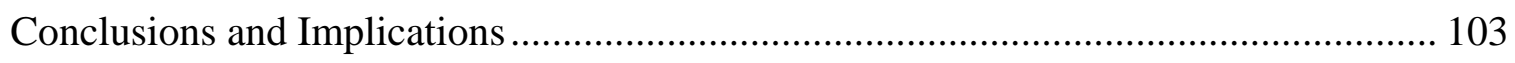

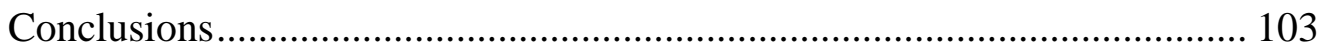

Summary of Conclusions............................................................................ 113

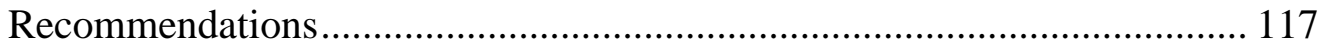

Future Research ………...................................................................... 118

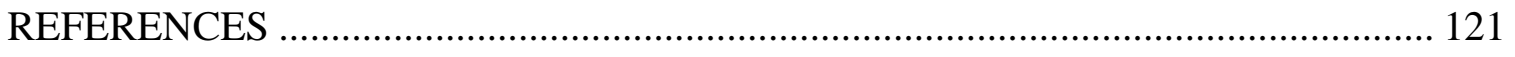

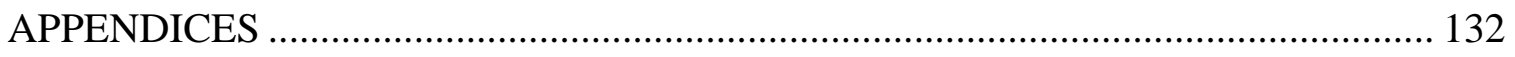

Appendix A: Stages of Concern Questionnaire A …………………………………….... 133

Appendix B: Principles of Adult Learning Scale (PALS) Questionnaire......................... 135

Appendix C: Survey of Computer Use Instrument.......................................................... 139

Appendix D: Lesson Sweep Instrument ................................................................... 149 
Appendix E: Final Daily Evaluation Form .......................................................... 152 


\section{LIST OF TABLES}

TABLE

Page

3.0 Demographic Characteristics of the 2001 Trek-21 PK-12 Participants............. 33

3.1 Research Design for the Study of Trek-21 PK-12 Teachers................................. 36

3.2 An illustration of Research Questions, Data Source, and Data Analysis

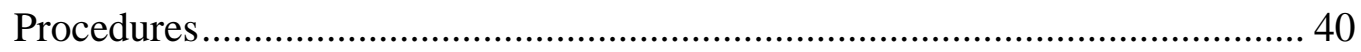

3.3 Dependent Variables versus Independent Variables........................................... 43

3.4 Research Question 1: Dependent and Independent Variables Interaction............... 44

3.5 Research Question 2: Dependent and Independent Variables Interaction............... 44

3.6 Research Question 3: Dependent and Independent Variables Interaction ............... 45

3.7 Research Question 4: Dependent and Independent Variables Interaction ............... 45

3.8 Research Question 5: Dependent and Independent Variables Interaction............... 46

4.0 Dependent Variables versus Independent Variables.......................................... 48

4.1 Dependent Variables and Independent Variables ............................................. 50

4.2 Stages of Concern Aggregate Data: Means and Standard Deviations .................... 51

4.3 Results of Paired t-Tests of the SoC Scores between the Pre and Post-1 ................ 54

4.4 Results of Paired t-Tests of the SoC Scores between the Pre and Post-2 ............... 54

4.5 Results of Paired t-Tests of the SoC Scores between the Post- 1 and Post-2 .......... 55

4.6 Simple Regression of Instructional Design on the Seven Levels of SoC ............... 61

4.7 Regression of Change in Evaluation Score on the Seven Levels of Concern ......... 64

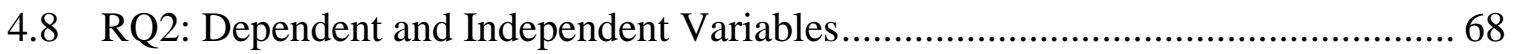

4.9 Comparison of Teaching Style Before and After Professional Development ......... 69

4.10 Trek-21 Participants: Predicting Pre-Teaching Style Scores................................ 70

4.11 Trek-21 Participants: Predicting Post-Teaching Style Scores ............................. 71

4.12 Trek-21 Participants: Predicting Pre-Teaching Style Scores ................................ 72 
4.13 Trek-21 Participants: Predicting Post-Teaching Style Scores .............................. 72

4.14 Trek-21 Participants: Predicting Change-in-Teaching Style Score ....................... 73

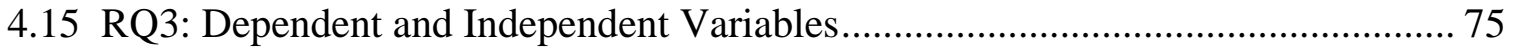

$4.16 t$-Value for Differences between Treatment Periods on Level of Computer ........... 76

4.17 Trek-21 Participants: Predicting Pre-Level of Computer Use Score ..................... 78

4.18 Trek-21 Participants: Predicting Post-Level of Computer Use Score .................... 78

4.19 Predicting Change in Level of Computer Use Scores ........................................ 79

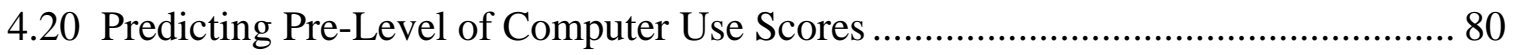

4.21 Predicting Post-Level of Computer Use Scores.............................................. 81

4.22 Predicting Change in Level of Computer Use Scores ....................................... 81

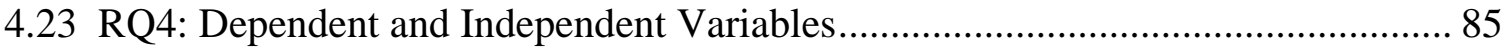

4.24 Comparison of IT Integration Score Before and After Professional Development. 86

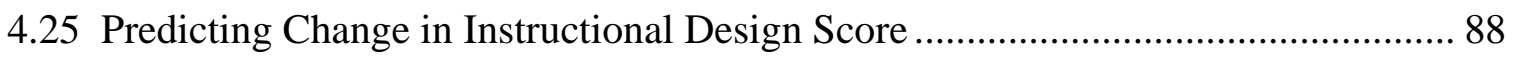

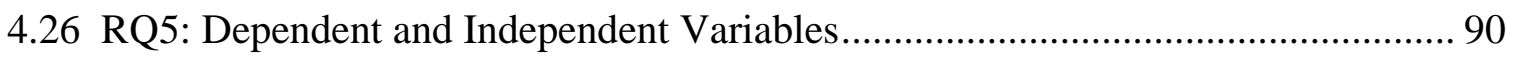

4.27 Comparison of IT Knowledge Score Before and After Professional Development 91

4.28 Predicting Change in Evaluation Score ....................................................... 92

4.29 Bivariate Correlations Between Stages of Concern and Instructional Design ........ 95

4.30 Bivariate Correlations Between Teaching Styles Score and Instructional

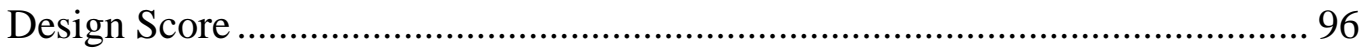

4.31 Bivariate Correlations Between Level of Computer Use and Instructional Design 97

4.32 Bivariate Correlations Between Stages of Concern and Evaluation Score.............. 98

4.33 Bivariate Correlations Between Level of Computer Use and Evaluation Score ... 100

4.34 Bivariate Correlations Between Change-in-Instructional Design and Evaluation 100 


\section{LIST OF FIGURES}

FIGURE $\quad$ Page

1. Stages of Concern Profiles for All Participants: Pre-, Post-1, and Post-2........... 56

2. Beginners Stages of Concern Profiles: Pre-, Post-1, and Post-2 ...................... 57

3. Intermediate Stages of Concern Profiles: Pre-, Post-1, and Post-2 $\ldots \ldots \ldots \ldots \ldots \ldots \ldots \ldots . . . . . . \ldots 8$

4. Advanced Stages of Concern Profiles: Pre-, Post-1, and Post-2......................... 59 


\section{CHAPTER I}

\section{Introduction and Rationale}

The availability of computers and the Internet has increased significantly in the nation's schools and classrooms (Williams, 2000). This increase has been coupled with initiatives aimed toward: (a) understanding how best to integrate instructional technologies (ITs) to improve teaching and learning and (b) training educators to integrate these technologies effectively through professional development programs.

Educators today agree (U.S. Department of Education, 2000a) that never before in education has there been greater recognition of the need for ongoing professional development. Professional development is a crucial component in nearly every modern proposal for educational reform, but many educators have various opinions as to what constitutes effective professional development. There is also wide-spread agreement (Kemp, 2002) that professional development practices for innovations have been historically constructed based on the values and beliefs of what policy makers thought was best for the system, instead of taking into consideration the needs and concerns of those implementing the innovation. The nation faces serious challenges in improving teacher quality and enhancing the teaching profession to meet the needs of all students. Teachers are expected to be able to integrate the latest instructional technologies into their classroom to help students meet new, more challenging standards.

A careful study of professional development models is therefore critical if policy makers and administrators are going to understand and promote the best practices for professional development. In an era of reform, policy makers need to be aware of the possibilities that professional development can provide for the adoption of innovations. This study focuses on key factors critical to effective models of professional development where the integration of 
instructional technologies is central to changing teaching practice. The Trek 21 project (Wells, 1999) presents a unique opportunity to study the impact of instructional technologies and professional development on teaching and learning. This study will be an effective means of complementing efforts of educators committed to professional development programs. An investigation into the Trek 21 model provides the research community with valuable information about change in teacher practice due to participating in a professional development program. Policy makers and administrators also will gain some specific information needed to carry out a successful implementation of innovations, and the various challenges of restructuring teaching and learning.

\section{Statement of the Problem}

A study by the Milken Exchange on Education Technology (1999) and International Society for Technology in Education found that, "in general, professional development programs do not provide future teachers with the kinds of experiences necessary to prepare them to use technology effectively in their classrooms.” Darling-Hammond and Berry (1998) noted that “Teacher quality is the factor that matters most for student learning,” therefore, professional development for teachers becomes the key issue in using instructional technology (IT) to improve the quality of learning in the classroom. Lack of professional development for technology use is one of the most serious obstacles to fully integrate technology into the curriculum (Fatemi, 1999; Office of Technology Assessment, 1995; Panel of Education Technology, 1997). But traditional sit-and-get training sessions or one-time-only workshops have not been effective in making teachers comfortable integrating instructional technologies into their lesson plans. Instead, a well-planned, ongoing professional development program that is tied to a school's curriculum goals, designed with built-in evaluation, and sustained technical 
support is essential if teachers are to integrate instructional technologies appropriately to promote learning in the classroom.

Professional development research (Fullan, 1996; Lewis et al., 1999; Mullens et al., 1996) suggests that teachers' opportunities to learn about instructional technologies during traditional professional development activities are often lacking. Often described as an important vehicle for school reform (Sprinthall, Reiman, \& Theis-Sprinthall, 1996), professional development activities in general have been widely criticized for being relatively ineffective. Specifically, they have been described as (a) short term, (b) devoid of continuity due to inadequate follow-up and the lack of ongoing feedback from experts, (c) isolated from participants' classroom and school contexts, and (d) characterized by too few opportunities to learn by doing and reflecting with colleagues (Fullan with Stiegelbauer, 1991). In fact, while a majority of teachers participate in such activities, only a small percentage of teachers report feeling very well prepared to integrate technology into instruction (Lewis et al., 1999).

In another study, it was found that teachers who spent more time in professional development activities were generally more likely than teachers who spent less time in such activities to indicate they felt well prepared or very well prepared to use computers and the Internet for instruction (Smerdon et al., 2000). The study found that teachers who spent more time in professional development on how to integrate technology into classrooms reported feeling better prepared than those who spent less time. As a result, teachers who reported feeling better prepared were more likely to use these technologies than their less prepared colleagues.

\section{Key Factors of Professional Development}

There are several key factors that are central to effective professional development training. (1) The first key factor is the duration of the professional development (Smerdon et al., 
2000). Duration of the Trek-21 institute was very important to the success of the training. A high-quality professional development program is conducted as an ongoing, iterative process, not a one-shot approach. Teachers need continued practice to become comfortable with and to implement the innovation, especially when the innovation is instructional technologies.

(2) The second key factor is instructional design, a scheme for preparing technologybased instruction. Prior to participating in the Trek 21 summer institute, teachers are provided with a thorough description of workshop content and goals including materials necessary for the institute. Pre-material development components included lesson templates. In designing effective instruction for the institute, the Trek 21 project's focus on curriculum design was combined with a series of practices to aid participating teachers in producing instructional technology-based units for their classrooms. Lesson templates, as an important component of instructional design, were furnished to the participants at the beginning of the institute to help guide teachers in their design of electronic web lessons. This was an important component in that it gave participants a head start in the design of their units, thereby saving on the time that would have taken to develop one from scratch. If technology is to be used to produce improvements in their teaching practice, teachers must see a direct link between the technology and the curriculum for which they are responsible (Byrom, 1998). Pre- and post-professional development lesson plans developed by teachers can be a good indicator of changes in teacher practice resulting from effective professional development. The best IT professional development for teachers does not simply show them how to add technology to projects "it helps them learn how to select digital content based on the needs and learning styles of their students, and infuse it into the curriculum rather than an end in itself,” (Fatemi, 1999). 
Another component of instructional design is modeling. Modeling of the Trek 21 project provided a framework that assured the success of the professional development. It also linked Trek 21's purposes with participants' professional and personal learning goals. If teachers are to be supported in their efforts to implement instructional technologies in ways that are aligned with the national standards on technology, then professional development will need to address the many knowledge and organizational issues that will be faced by teachers as they attempt to make an innovation like IT part of their everyday curriculum offerings in their curriculum.

(3) Evaluation is the third key factor. Effective professional development uses evaluation to ensure that each activity is meeting the needs of the participants and providing them with new learning experiences (Mullens et al., 1996). Evaluation is "the systematic investigation of merit or worth” (Joint Committee Of Standards for Educational Evaluation, 1994). Evaluation was built into the Trek 21 professional development program during the planning process, before the actual activities started. It consisted of two types: formative and summative evaluations. Both formative and summative evaluations can provide meaningful information that can be used to make thoughtful, responsible decisions about professional development processes and effects. Evaluation of instructional design assessed knowledge and skills gained by participants during the professional development training. In the Trek 21 model, evaluation consisted of three components: daily objective evaluations, daily open-ended feedback, and the overall evaluation of daily objectives. These were used during the Summer institute to assess achievement of daily objectives and overall impact of the professional development on participants’ instructional technology competencies.

(4) Application of the product is the fourth key factor of Trek 21 professional development. Not surprisingly, implementation plays a big part in the effectiveness of 
professional development. Professional development is not a one-time event, but ongoing process. The Trek-21 model incorporated research-based adult learning strategies that included hands-on, concrete activities that directly linked to a participant's everyday responsibilities. Ongoing support was built within the Trek-21 model, allowing participants to obtain clarifications and guidance.

(5) A fifth key factor of effective professional development for instructional technologies is support. Support for professional development is in two categories: technical support and instructional curriculum support. Teachers need technical support to help them trouble-shoot and fix technical problems. And because support with technology problems that inevitably arise is critical to the success of the professional development, teachers need to be assured that technical assistance will be provided to them in a thorough and timely way. Trek 21 professional development model provided technical support personnel who were responsible for troubleshooting and assistance when training teachers to integrate ITs. An effective professional development program provides sufficient time and follow-up support for teachers to master new content and strategies and integrate them into their practice (Corcoran, 1995).

An essential part of technical/curriculum support during an entire Trek 21 professional development cycle was the follow-up program. Two follow-up meetings (continuity meetings) were scheduled for the participants. The first continuity meeting was held in September following the summer institute, and the second continuity meeting was held the following January. The two meetings focused on participants improving their units and on data collection. These continuity meetings reinforced and built upon what was learned in the summer institute and provided support activities for the participants. Truly integrating technology into teaching and learning is a slow, time-consuming process that requires substantial levels of support and 
encouragement for participants. The model's two continuity meetings provided such support and encouragement to its participants.

Briefly, the five key factors for effective professional development training are (1)

duration, (2) instructional design, (3) evaluation, (4) application of the product, and (5) support. This research study is going to concentrate on three of the factors that were quantified, namely: duration of training, instructional design, and evaluation. The importance of investigating the relative impact of such key factors would provide insight into the effectiveness of a given professional development model. To this end, the problem of the study is to investigate the relationship among the above-mentioned key factors of the Trek-21 model of professional development and resulting changes in teacher practices with respect to the integration of instructional technologies (ITs).

\section{Research Questions}

To investigate the problem the following research questions will be addressed:

1. What is the relationship between changes in teacher concerns toward ITs and key factors (Duration, Instructional Design and Evaluation) of Trek-21 professional development model?

2. What is the relationship between changes in participant teaching/learning styles and key factors (Duration, Instructional Design and Evaluation) of Trek-21 professional development model?

3. What is the relationship between changes in teacher level of computer use and key factors (Duration, Instructional Design and Evaluation) of Trek-21 professional development model? 
$4 \quad$ What is the relationship between changes in teachers' extent of instructional technologies (ITs) integration into their units and key factors (Duration and Evaluation) of Trek-21 professional development model?

5 What is the relationship between changes in teachers' instructional technologies (ITs) knowledge and key factors (Duration and Instructional Design) of Trek-21 professional development model?

6. Which key factors of Trek 21 professional development model are crucial to facilitating changes in P-12 participants' instructional practices (adoption) with respect to integration of instructional technologies? 


\section{CHAPTER II - REVIEW OF LITERATURE \\ Technology and Education}

The evolution of technology and its infusion into education has happened at a much faster rate than any other tool for the classroom. The past decade has witnessed unprecedented and exponential changes in instructional technologies (ITs). With the rapid advances in IT, especially with the advent of the Internet in the late 1980s, the world is experiencing a new paradigm shift in which information power, and only those who are able to grasp the shift in paradigm are likely to excel in the new world. The pervasiveness of the impact of IT is apparent in every facet of society, including public schools and homes. In the information technology age, the classroom is simultaneously evolving along with the advances in instructional technologies. In the past, while education was solely based on traditional in-class teaching by instructors and from books, the new classroom involves the use of the Internet and advanced computer applications (Fatt, 2003). Technology represents a set of powerful tools that has become an essential part of everything teachers do. Education as an institution is embracing the change that technology brings, and many teachers are reinventing themselves in the process.

\section{Impact on Education}

Internet as an Instructional Technology. The following section of the review of literature explains the historical aspects of one component of instructional technology, namely the Internet and its facilities, and relates research findings about its integration by users in PK-12 classroom environments. Since the Internet is a global concept comprised of capabilities or facilities such as electronic mail (email), file transfer protocol (FTP), Telnet, USENet News, Gopher, WAIS (Wide Area Information Service), and World Wide Web (WWW), the review will cover all these 
types under one single term, the "Internet." Today, the Internet is the preferred technology to improve instruction, increase access, and raise productivity in education (Fatt, 2003).

Jamaludin Mohaiadin (1995) discussed the historical perspective of the Internet and its global use. He offers a definition of Internet referred to by Lane and Summerhill (1993a) as an existing system of communication linking many computers. Also described by Carrol (1993) as a “Global International network”, with vast uses for e-mail, FTP, and Telnet. Historically, Mohaiadin points out Internet started as a project to share data and by 1989, 28 universities had uplinking capabilities and distributions (Fahey, 1989). The scope of use has since increased from education to commercial users, with the number of users doubling each year.

A Profile of Internet Usage in Education. No recent technological development has transformed American society more profoundly than the integration of Internet technology into many aspects of public and private life. Despite this trend, the use of Internet as an educational tool in the classroom has been slow to develop. As a result, Internet usage in American schools is of increasing interest among both educators and the general public, and has become an important focus of instruction.

All personnel functions have a direct or indirect impact on school effectiveness, but none has a greater potential effect than professional development and training. By participating in professional development programs teachers can acquire new skills and attitudes that can lead to changes in the way they teach and in turn result in increased student achievement. HensleyMarschand (1996) studied the effects of a teacher training program called the Jason Project. Participants for this study consisted of eighty-five educators from elementary, middle/junior high and high schools in five states and one Canadian Province who had experienced Jason Project teacher training, classroom use of the Jason Project curriculum and visits with students to 
Primary Interactive Network Sites (PINS) to participate in live, interactive broadcasts of scientific research. The researcher used responses to a likert-scale questionnaire to provide the basis for a general analysis, while telephone and e-mail interview transcripts contributed to a descriptive narrative analysis. The results of the study indicated a need to increase awareness and exposure of PK-12 teachers to professional development using the Jason Project. HensleyMarshand's study yielded four dominant triggers to teacher participation and professional development: Jason teacher training, curriculum, technology, and the overall Jason experience. The implication of this study was that the motivating power of the Jason Project suggests that PK-12 schools and those who provide interactive programs for them, should increase teacher awareness of and exposure to Jason or other related programs and technologies.

The use of Internet in the classroom by teachers related to factors such as demographics and attitude of teachers has been widely documented in literature. Wallace Raymond (1998) investigated the relationship between innovativeness, Internet use, demographic variables, and the attitude of teachers towards use of the Internet. His results collaborated with other research findings (Jaber, 1997) that innovative adopters of an innovation such as the Internet are believed to possess higher overall positive attitudes towards new experiences. In addition to this, he also found that innovators had significantly higher mean attitude scores towards Internet use compared to laggards. The relationship between adopter type and Internet use in this PK-12 teacher population was that innovators and majority members were the ones who had used the Internet, while laggards had little experience. Additionally, age and gender differences in Internet use were noted among PK-12 teacher groups with male teachers showing significantly Internet use compared to female counterparts. 
Demographics and teacher beliefs also have an impact on teacher Internet usage. Roberts (1998) used an on-line survey instrument and telephone interviews to gather information regarding demographics, influence of the Internet on instruction, reasons for continued use, and needs. This exploratory study examined the attributes of PK-12 educators using an Educational Internet Network to support instruction. The study examined educators who had used the Internet for more than a year to determine any commonalities in demographics, their perceptions of the Internet, reasons for continued use and their perceived needs. Roberts data analysis identified 90 $\%$ of the educators in his study as teachers with six or more years of experience and within the age range of 40 to 49 years. The respondents identified themselves as self-taught Internet users, who were personally motivated to use the technology, with more than half identifying themselves as resources and facilitators for other colleagues. The study also reviewed the benefits and reasons for continued use of the Internet, along with the Internet's influence on teaching methods. The study found that the described changes in teaching methods indicated a transition from a teacher-centered classroom to a student-centered environment with collaborative, project-based instruction.

During the last decade of the $20^{\text {th }}$ century, there was a revival of calls for education to meet the needs of society, schools and colleges and under increasing pressure from society and from advancements in technology sweeping across the country. At the center of this, was technology, notably the computers and the Internet. Research studies have shown that lack of or limited technology can undermine the use of technology in the classroom by teachers. Wheeler Robert (1996) carried out a descriptive, exploratory study to describe the current status of a sample of rural Northeast Kansas (PK-12) public schools in relationship to the availability, access and use of local area networks, telecommunications and the Internet. In this study, 79 
percent of the sampled schools participated including ten elementary, nine middle or junior high schools and 12 high schools (totaling 387 teachers). His research analysis showed that high school teachers were the most frequent users of Internet and on-line services, with middle school teachers being the next most frequent users and elementary school teachers using them the least. The study also revealed that early adopters (users) of on-line technologies tended to have more positive attitudes toward using the communication age technologies to construct more authentic, meaningful instruction for students and had adoption concerns that were, developmentally, more mature including management, collaboration and refocusing.

Shoemaker (1997) examined current and planned use of the Internet, and identified inhibitors and factors that encouraged Internet use by PK-12 school districts in Michigan. The study also attempted to identify methods of Internet access being used in Michigan's PK-12 schools, and a description of who is managing the use of Internet, the technical resources, the planning, and the policies relating to technology use in these districts. The participants included technology directors, assistant superintendents, superintendents, principals and other building administrators, teachers and media specialists. Shoemaker found that factors that encouraged Internet use included an existing technology plan, a single user and a technology director. Inhibiting factors included lack of training, lack of a long-term plan for Internet use or management by districts. He presented the following top recommendations for districts attempting to implement Internet technology: (1) develop a long range plan for both the use and management of the Internet; (2) appoint a district technology director to oversee the long-range planning; (3) allocate adequate funding for teacher training; (4) consider the use of technology a district-wide goal and support the teachers and other staff members serving as change agents in their buildings. 
Along with improvements in infrastructure, computers with improved Internet capability and access can lead to increased frequency of classroom use for teaching and learning purposes. Payne (1998) focused on frequency and ways of use of interactive technology by students and teachers. Payne also examined whether the teachers believed the technology helped them in preparing for and conducting classroom activities, and whether the students believed the technology enhanced their learning. The study showed that teacher indicated that computers with Internet capability were valuable for preparing and conducting classroom activities, while the majority of the students felt that computers helped them learn better. Analysis of Payne's data suggested the following major conclusions about schools, teachers, and students in the study: (a) schools are in the initial stages of using technology as an educational tool; (b) technology is still being used in a traditional sense -- for teacher instructional preparation and for individualizing student instruction; (c) students use computers more for drill practice than for inquiry-based learning; (d) there is a gap between teachers' personal use of computers and the use of computers in the classroom; (e) students are ready to use computers to the fullest extent, but teachers are under-prepared for it; and (f) teachers are using technology at their own comfort levels, but have not made the transition to a technology infused curriculum.

Davenport (1995) examined factors that influence PK-12 educators to use Internet in classroom activities or in their own professional development. He surveyed a random sample of 325 selected from a population of Tennessee PK-12 educators of which 198 educators returned their surveys. Educators were asked to respond to a 23 likert-type statements regarding their beliefs about technology, training, and the educational use of the Internet. Davenport's results determined that the Internet is being used by educators who have attended workshops or 
seminars. Educators indicated a need to receive more training on how to the Internet for both classroom activities and professional development.

Another important factor identified as affecting the use of Internet by teachers is administrative and technical support. Research studies have found that teachers need dynamic leadership and administrative support as well as technical support so they can advance their teaching. Therefore, a well-planned, ongoing professional development program that is tied to the school's curriculum goals, designed with built-in evaluation, and sustained by adequate financial and staff support is essential if teachers are to use technology appropriately to promote learning for all students in the classroom. Marlene Ann Kohn (1995) examined whether educators use and disseminated Internet skills to others at their site. The results indicated that educators learned to use the Internet when access is consistently available and technical support from an outside agency is on going. Sites that had supportive administrators accelerated learning and dissemination of the technology to others.

The collaborative factor becomes increasingly important as new ITs are adopted for use in the classroom by teachers. Foley (1996) examined how the Internet affects communication among PK-12 teachers. Foley believes that "The Internet, integrated as a communications innovation, has tremendous potential to improve connections among PK-12 teachers by increasing their potential to share content, pedagogy, classroom management, materials and more.” In this research study, teachers received equipment and home access to the Internet, along with training and support to eliminate previously identified barriers of time, access, leadership and money. Foley used the Concerns-Based Adoption Model (CBAM) as a conceptual framework to introduce teachers to the Internet through face-to-face training sessions, written instructions and electronically-delivered optional activities and assistance. The results showed 
decreased isolation and a positive view of Internet potential. Foley (1996) concludes that Internet integration is a revolutionary in opportunity, but requires an evolutionary approach for success. The study suggested that teachers need dynamic leadership and support from administrators so they can advance their work "personally, professionally and pedagogically."

From these profiles a general understanding of how Internet is accessed and how it is being integrated into the curriculum can be gained. These profiles indicate that accessibility, improved infrastructure, and administrative and technical support affect Internet usage and organization of professional development training. What was needed for advances in the use of ITs by teachers was a large-scale support at the federal level.

\section{Government Instructional Technologies Initiatives}

High-quality, sustained professional development means adequate funding and more money. Often schools or districts rely on special funding sources, such as state, federal, or foundation grant programs. A number of federal programs have been involved in providing funding initiatives that targeted connectivity, technology planning, IT in the classroom, technology literacy, and professional development. The following are some of the major federal initiatives in the past decade that address education and instructional technologies.

National Science Foundation Grants (NSF). NSF was handed a mandate from Congress to help improve science and math education. The agency was convinced that technology can be a "powerful, liberating tool with the potential to engender fairly radical pedagogical changes." The successful Statewide and Rural Systemic Initiatives launched in 1991 demonstrate the reliance on state and locally centered models to provide actual connectivity for PK-12 schools. In 1994, the NSF, co-funded with ARPA, awarded 19 planning grants, 11 multi-year projects, and 10 supplements. West Virginia is one of the states that benefited from these NSF grants. 
The Federal Communications Commission (FCC). The FCC is an independent federal regulatory agency responsible directly to Congress. Established by the Communications Act of 1934, it is charged with regulating interstate and international communications by radio, television, wire, satellite, and cable (FCC, DOC-229127A1). Traditionally the FCC insures universal telephone service, taking measures even today to increase penetration of phone service above the current level of 94 percent. The FCC regulates charges for public National Information Infrastructure (NII) access and determines spectrum usage. This kind of regulation led to increase in educational Internet access over the years aided by the allocation of funds through such programs as the Education Rate Program (E-rate). The E-rate program was established in 1996 and approved by the FCC in 1997 to make services, Internet access, and internal connections available to schools and libraries at discounted rates based upon the income level of the students in their community and whether their location is urban or rural. As of February 28, 2001, \$ 5.8 billion had been committed to E-rate applications throughout the nation (Catttagni \& Westat, 2001).

U.S. Department of Education. Under the Goals 2000: Educate America Act and the Improve America's Schools Act which was signed into law by president Clinton on March 31, 1994, Congress charged the U.S. Department of Education (DoE) with providing a long term national technology plan. This charge was met with enthusiasm as the DoE believed that technology plays an integral role in education reform and can enable a citizenry equipped for life-long learning. Of the \$372 million allocated to Goals 2000 in fiscal year 1995, \$5 million was earmarked to encourage each state to develop comprehensive educational technology plans.

Challenge Grants. The Challenge Grants for Technology in Education program was an effort to "support state-of-the-art technology projects in twenty low-income rural and urban 
school districts.” In 1995, grants were awarded "to further the use of technology in classrooms or library media centers, promote the integration of technology into the curriculum, and ensure the successful, effective, and sustainable use of the acquired technologies.” This program issued a challenge to communities across the country to bring together a consortium of schools, educators, parents, industry partners and others to transform our factory era schools into information age learning centers. The Challenge Grants program dependent on cooperative endeavors between schools, local businesses, and higher education institutions to define how innovative technologies would be employed to meet national education goals as outlined in Goals 2000.

No Child Left Behind Act. Another federal technology initiative is the 'No Child Left Behind Act' (NCLB) which requires more staff training in technology skills and better assessment of these skills (Education Testing Service, 2002). The main program for technology funding through NCLB is Enhancing Education Through Technology (Ed Tech) formely the Technology Literacy Challenge Fund (Teacher Quality Bulletin, 2002). The Enhancing Education through Technology (Ed Tech) program (ESEA Title II, Part D, Subpart 1) consolidates the current Technology Literacy Challenge Fund program and the Technology Innovative Challenge Grant program into a single program and provides the consolidated funds to states as a block grant. Ed Tech primary goal is to improve student academic achievement through use of technology in schools. Ed Tech also assist students in becoming technology literate by the end of the eight grade and encourages the effectiveness integration of technology with teacher training and curriculum development to establish successful research-based instructional methods. 
Need for Professional Development. Traditionally, teacher professional development has been woefully under-funded, at the pre-service and in-service levels. This is true even with most current professional development in the use of instructional technologies because education policy makers typically work within fixed technology budgets and are inclined to give priority to hardware and software acquisition over teacher professional development (OTA, 1995). However, without training, teachers will not sustain their use of instructional technology. The result of under-funding teacher professional development is that much of the technology provided to schools is never used. Instead, it sits in boxes or closets gathering dust and becoming obsolete. It is more than a loss of potential learning and skills acquisition. It is a waste of scarce resources used to procure technology in the first place.

It has been well documented over the past several years that upon completion of their professional development, teachers are inadequately prepared to integrate instructional technologies they learned (Wenglinsky, 1998). Although recent studies confirm that this is still the case (Moursound \& Bielefeldt, 1999; Willis et al., 1999), there are many professional development programs across the country that are integrating instructional technologies very well into their curriculum in their efforts to help teachers learn to effectively integrate (Downs, Clark, \& Bennett, 1995; Hoffman, Green, \& Swearngen, 1994).

Great inroads in arranging access to technology in schools and preparing teachers in basics of instructional technologies have been made. However, the next step is to help teachers move beyond the basics toward real teaching with instructional technologies. In recent years, elementary schools, middle schools and high schools have acquired computers and Internet connections (Becker, 1999), and teachers and administrators have been trained in the basics of technology use. However, the mere inclusion of technology in schools is not sufficient (Coley, 
Crandler, \& Engel, 1999). What matters is how technology is used to enhance student learning (Merisotis \& Phipps, 1999). Proper use of technology in schools requires additional professional development aimed at creating teachers who fully integrate technology into their instructional programs.

While computer technology offers much promise for education, achieving this potential requires teachers who are skilled in its use. According to a recent report from the National Center for Education Statistics, 99\% of all full-time teachers now have access to technology in their schools, and two-thirds of these report using technology for classroom instruction. Still, twothirds of the teachers surveyed also indicate that they are not well prepared to use computers and Internet technology in the classroom (Smerdon et al., 2000).

In a 1998 survey by the U.S. Department of Education (1999), 78 percent of teachers reported that they had participated in professional development about integrating technology into the grade or subject taught during the last twelve months. Yet despite this level of participation, only 20 percent said they felt very well prepared to integrate technology into classroom instruction, and another 37 percent said they were moderately well prepared. The figures were only slightly higher for teachers with three years or fewer experiences; 24 percent of the group said they felt very well prepared.

\section{Professional development has a greater potential effect on the integration of instructional technologies in schools. Professional development provides opportunities for teachers to acquire new skills and attitudes that can lead to changes in behavior leading to increased student achievement (Seyfath, 1996).}

Adopting the new roles and learning ways of teaching that go hand-in-hand with technology integration requires that teachers have opportunities to participate in an extended process of professional development. Teachers need time to acquire technology skills and develop new teaching strategies for integrating technologies into the classroom. Professional 
development time is especially important when teachers are learning new technology skills (Renyi, 1996). The integration of technology into curriculum will not succeed without giving teachers ample time to practice, explore, conceptualize, and collaborate. "Many teachers hunger for time to translate new ideas and strategies into practical classroom lessons and unit plans," states McKenzie (1998).

Over the years, there has been an emphasis on the need for teachers to continue to learn through professional development. Almost every school district in the country provides some form of professional development for teachers. Most studies agree that professional development for teachers is a necessary activity. However, professional development has been unsatisfactory in its current form. Research studies have argued that professional development in U.S. public schools is misguided in both policy and practice (Stout, 1996).

Sparks and Hirsh (1997) stated that professional development has been undergoing profound changes as traditional approaches fall short of current needs and teachers encounter new challenges. Sparks and Hirsh further stated that if schools are to adequately prepare students for life in the world that is becoming increasingly complex, professional development of school public school teachers and significant changes in the organizations in which they worked are both required. Their study also stated that in the past, professional development had been an afterthought as school systems initiated major innovations. Districts then realized that they could not educate students to high levels without well-designed professional development initiatives.

Bull and Buechler (1996) stated that traditionally, professional development for teachers has consisted of one-shot training workshops (Crawford, 2003; Lewis et al., 1999) delivered by outside consultants with no follow-up.

According to Guskey and Huberman (1995), professional development has been crucial for educational improvement. Efforts must be made to correct deficiencies if the educational institutions are to meet the demands of the ever increasingly complex society. Guskey and Huberman further stated that education was a dynamic, professional field with constant discovery of new knowledge about teaching and leaning processes. New types of skills are 
required of teachers, and teachers must be prepared to use this new knowledge base to continually refining their teaching skills. Professional development, like change, is a process not an event. Professional development and change go hand-in-hand (Loucks-Horsley, 1989). Showers, Joyce, and Bennett (1987) described professional development as the foundation for a successful learning environment.

But the need for high-quality professional development keeps increasing, not only because of the teaching Standards and because of new instructional technologies but also because of the benefits that can be realized and growing concern about improving students’ performance and achievement. In order for educators to use instructional technology to its fullest potential, and students to reap the greatest educational benefits, teachers need professional development. Without such professional training, the educational system is doing a disservice in preparing young people for their futures. Teachers also need to take responsibility for staying abreast of new methodologies and trends in pedagogy. A teacher's interest and vision are critical to the integration of instructional technology or any new form of pedagogy. Without the teacher there is no starting point. Teachers need to embrace technology and actively seek out technology training in order to get started.

\section{Instructional Technology and Professional Development}

\section{Traditional Approach to Professional Development}

For many years, teachers and other educators have used district-sponsored staff development or university course work to improve individual skills, qualify for salary increases, and meet certification requirements. Professional development rewarded educators with personal and professional growth, greater job security, and career advancement (Abdal-Haqq, 1996). Prior to 1999 the integration of technology within the field of professional development programs was 
not emphasized. Participants were required to participate in educational technology class, but there was no real coordination between what students were learning in the class and what they were doing in their methods experiences. Thus participants were learning discrete technology skills as web page design, PowerPoint, and basic technology literacy without opportunities to apply technology in authentic teaching situations.

Professional development programs must meet the challenge of training participants for effective use of instructional technologies. Lately, technology potential has been recognized. Various approaches have been utilized to get teachers use technology. From workshops, and seminars to using students of technology to help teachers adopt technology increasing effort in being expanded to encourage teachers to be an active part of this trend in educational institutions.

A 1999 study by the Milken Exchange on Education Technology and the International Society for Technology in Education found that, “in general, teacher-training programs do not provide future teachers with the kinds of experiences necessary to prepare them to use technology effectively in their classrooms.” It emphasized that since the United States will need a projected 2.2 million new teachers over the next decade, "the time to examine and re-engineer our teacher preparation programs is now.” The most important recommendation of the Milken Exchange study is to integrate technology training into the entire teacher education program, since instructional time spent in other classes, such as methods and curriculum courses, is much more useful for educating student teachers about computer use than are formal stand-alone technology courses.

The Federal Office of Technology Assessment (1995) recommended that school districts devote at least 30 percent of their technology budgets to teacher training and support. However, only 6 percent of the $\$ 4.2$ billion that PK-12 schools spent on technology in 1996 went towards 
training (U.S. Dept. of Education, 2000b). That figure increased to 17 percent for public school teacher technology training for the 1999-2000 school year, but it is still far below the recommended amount (Market Data Retrieval, 1999).

A Presidential Panel report recommended that teachers needed in-depth, sustained assistance to integrate computer use into the curriculum and reconcile new methods of instruction which use technology extensively with traditional methods (President's Committee, 1997). One program that offered such training was the Teacher Led Technology Challenge (TLTC) in Berkeley, California, funded by the U.S. Department of Education's Technology Innovation Challenge Grant Program; it provided teachers with extensive support, tools, and professional development.

With traditional professional development phasing out, the need for new approaches to professional development is great and growing with great expectations. To meet these new expectations, teachers need to deepen their content knowledge and learn new methods of teaching. They need more time to work with colleagues, to critically examine the new standards, and to revise curriculum. They need opportunities to develop, master and reflect on new approaches to working with children with regards to instructional technologies. All of these activities lead to under the new approaches to professional development.

New Approach to Professional Development

In the past few years, new approaches to professional development that take advantage of the newer Internet technologies have been taking place. These approaches have a number of characteristics that support what research has found to be essential for quality teacher development with respect to instructional technologies. Research evidence shows that quality teacher development is cumulative and sustained. Future teachers need an "attitude" that is 
fearless in the use of technology, encourages them to take risks, and inspires them to become lifelong learners. By spending more time in effective professional development, teachers will feel more prepared and more likely to integrate technology into the classroom.

One key factor that has to be considered in the new approaches to professional development is the duration of the training (Smerdon et al., 2000). A high-quality professional development program is conducted as an ongoing, iterative process, not a one-shot approach. Teachers need continued practice to become comfortable with and to implement the innovation, especially when the innovation is instructional technologies. A second factor for the new approaches is instructional design, a scheme for preparing technology-based instruction. A third factor that has to exist in a professional development model is evaluation. An effective professional development model uses evaluation to ensure that each activity is meeting the needs of the participants and providing them with new learning experiences (Mullens et al., 1996). Evaluation is the systematic investigation of merit or worth of a program (Joint Committee of Standards for Educational Evaluation, 1994). Application of the product is the fourth key factor of professional development. Not surprisingly, implementation plays a big part in the effectiveness of professional development. Professional development is not a one-time event, but ongoing process.

Finally, teachers need a great deal of support to help them trouble-shoot, and fix technical problems during training. For support to effective, it must exist in two forms: technical support and instructional curriculum support. And because support with technology problems that inevitably arise is critical to the success of the professional development, teachers need to be assured that technical assistance will be provided to them in a thorough and timely way. A good model of professional development must provide technical support personnel who can be 
responsible for troubleshooting and assistance when training teachers to integrate ITs. An effective professional development program provides sufficient time and follow-up support for teachers to master new content and strategies and integrate them into their practice (Corcoran, 1995).

In summary, reviews of research on instructional technology and professional development agreed that duration of training, instructional design, evaluation, application of the product and support play a vital role in increasing effective integration of instructional technologies into the classroom by PK-12 teachers. These key factors are central to the effectiveness of the training and can be addressed by being incorporated into the model of professional development.

\section{Key Factors of Professional Development}

(1) The first key factor is the duration of the professional development (Smerdon et al., 2000) itself that is very important to the success of the training.

(2) The second key factor is instructional design, a scheme for preparing technologybased instruction. Prior to participating in the summer institute, teachers were provided with a through description of workshop content and goals including materials necessary for the institute.

(3) Evaluation is the third key factor. Effective professional development uses evaluation to ensure that each activity is meeting the needs of the participants and providing them with new learning experiences (Mullens et al., 1996).

(4) Application of the product is the fourth key factor of Trek 21 professional development. The Trek-21 model incorporated research-based adult learning strategies that 
included hands-on, concrete activities that directly linked to a participant's every day responsibilities.

(5) A fifth key factor of effective professional development for instructional technologies is support. Support for professional development is in two categories: technical support and instructional curriculum support. Trek 21 model provided technical support personnel who were responsible for troubleshooting and assistance when training teachers to integrate ITs.

\section{The Trek-21 Model of Professional Development}

The Trek 21 professional development was a three-year project designed to bring about a deep and lasting change in educators through the integration of instructional technologies (Wells, 1999). The project was funded as an implementation grant through the U.S. Department of Education's Preparing Tomorrow's Teachers to Use Technology (PT3) grant program. PT3 is built on the premise that teachers should learn how to effectively integrate technology during their in-service training. Grants from the PT3 initiative provided funding for innovative programs to develop technologically proficient educators who are well prepared to meet the needs of $21^{\text {st }}$ century learner. The College of Human Resources and Education at West Virginia University (WVU) was a PT3 implementation grant in 1999. The design of the Trek 21 cycle of professional Development was based on the principle belief that in order for professional development to be effective, it must be sustainable and must result in long-term change in teacher practice.

A primary goal of Trek 21 model was to facilitate sustained use of instructional technologies by P-12 teachers, resulting in a lasting change in teacher practice (Wells, 1999). The Trek 21 professional development model was designed to achieve a sustained change in teacher practice where integration of instructional technologies was central to the learning 
environment. Instructional technology integration can play an important part in motivating teachers to modify their roles from deliverers of information to facilitators of learning (Roblyer, 2003). This modification of roles promotes a significant change in teacher practice, where their instructional focus shifts from a teacher-centered to learner-centered, resulting in increased active student engagement.

The Trek-21 professional development was developed around research-based practices that enabled participants to develop IT skills necessary to integrate what they learned (Joyce \& Showers, 2002; Wells, 1999). In designing effective instruction, the Trek 21 project's focus on curriculum design was combined with a series of practices to aid participating teachers in producing instructional technology-based units for their classrooms. Lesson templates were provided to the participants at the beginning of the institute to help guide teachers in their design of electronic web lessons. The Trek-21 training gave an opportunity to participants to learn new IT skills in the context within which those IT skills would be used more effectively and be able to see the link between the technology and the curriculum for which they were responsible (Byrom, 1998).

To be effective, the Trek 21 model used evaluation as a means to ensure that each activity met the needs of the participants and provided them with new learning experiences (Muller et al., 1996). Evaluation is the "the systematic investigation of merit or worth" (Joint Committee of Standards for Educational, 1994). Evaluation was built into the Trek 21 professional development model during the planning process, long before the actual activities started. It consisted of two types: formative and summative evaluations. The Trek 21 model consisted of three components: daily objective evaluations, daily open-ended feedback, and the overall evaluation of daily objectives. These were used during the Summer institute to assess 
achievement of daily objectives and overall impact of the professional development on participants’ instructional technology competencies.

The training also focused on delivery of proven IT strategies. The Trek 21 model incorporated research-based adult learning strategies that included hands-on, concrete activities that directly linked to participants' every day responsibilities. On going support was also built within the model allowing participants to obtain clarifications and guidance.

In summary, literature on new professional development models suggests there are key factors that are important for successful IT integration to be adopted and sustained by teachers. The Trek-21 professional development was shaped by these factors, all of which must be considered within the larger context of the teaching environment. Having in place certain kinds of structures and services makes it possible to increase the success of professional development efforts within this context and help in the sustainability of IT integration over time. Therefore, the importance of investigating the relative impact of these factors would provide insight into the effectiveness of the Trek-21 model, thereby helping to answer the problem of the study which is to investigate the relationship between the model's key factors of professional development and resulting changes in teacher practices with respect to the integration of instructional technologies into participants' classrooms. 


\section{CHAPTER III - METHOD}

This research study sought to investigate the Trek-21 professional development's key factors that are crucial to facilitating changes in PK-12 participants' instructional practices with regards to integration of instructional technologies. Hence a number of instruments were used to gather specific data pertinent to this study. This chapter describes the research questions, participants, research design, the cycle of events, data collection procedures, and instrumentation and data analysis.

\section{Research Questions}

With respect to the integration of instructional technologies by Trek-21 PK-12 participants, the design of the study seeks answers to the following research questions: Research Question 1

What is the relationship between changes in teacher concerns toward instructional technologies (ITs) and key factors (Duration, Instructional Design and Evaluation) of the Trek21 professional development model?

\section{Research Question 2}

What is the relationship between changes in participant teaching/learning styles and key factors (Duration, Instructional Design and Evaluation) of Trek-21 professional development model?

Research Question 3

What is the relationship between changes in teacher level of computer use and key factors (Duration, Instructional Design and Evaluation) of Trek-21 professional development model? 


\section{Research Question 4}

What is the relationship between changes in teachers' extent of instructional technology (IT) integration into their units and key factors (Duration and Evaluation) of the Trek-21 professional development model?

Research Question 5

What is the relationship between changes in teachers' instructional technologies (ITs) knowledge and key factors (Duration and Instructional Design) of the Trek-21 professional development model?

Research Question 6

Which key factors (Duration, Instructional Design and Evaluation) of the Trek 21 professional development are crucial to facilitating changes in P-12 participants' instructional practices (adoption) with respect to integration of instructional technologies?

\section{Participants}

The subjects in this study were West Virginia P-12 public teachers who completed the 2001/02 Trek-21 project professional development institute. Twenty-seven educators participated in the program from a pool of West Virginia teachers from more than twenty-one schools in 5 West Virginia counties that participate in the West Virginia University (WVU) professional development (PDS) program.

This study population included 25 female and two male participants. Of the 27 teachers, 24 taught General Education classes and 3 were Special Education teachers. As for grade levels, two teachers taught pre-school, 17 elementary, 4 middle, and 4 high school. 
Table 3.0

Demographic Characteristics of the 2001 Trek 21 P-12 Participants

\begin{tabular}{llc}
\hline Sample Size & Grade Level & Subject Area \\
\hline (N=27) & 17 Elementary School & 24 General Education \\
AY2001 Participants & 4 Middle School & 3 Special Education \\
& 4 High School & \\
& 2 Pre-School & \\
\hline
\end{tabular}

\section{Research Design}

The purpose of this study was to investigate the relationship among the key factors of the Trek-21 model of professional development and resulting changes in P-12 teacher practices with respect to instructional technologies integration. This research study used quantitative statistics in a descriptive and correlation research design. Five dependent variables were correlated with five independent variables. The five dependent variables were stages of concerns, teacher styles, computer use score, change in IT integration, and change in IT knowledge. The independent variables will be the three key factors of professional development: duration, instructional design, evaluation, application of the product, and support.

Cycle of Events

Designed to achieve a sustained change in teacher practice when integrating instructional technologies, the Trek 21's professional development cycle of events begins each year with PK12 participants submitting teaching/instructional units that they successfully used in the past. Each participant used his/her paper-based unit to develop a web-based unit during the next event in the Trek 21 project cycle, the Summer Institute (see Table 3.1). During this three-week Summer institute, participants gained pedagogical knowledge and technical skills needed to integrate ITs into their teaching units. After the three-weeks, the Trek 21 cycle continued with 2 
Continuity Meetings where teachers came together to revisit and refine their technologyenhanced units. The first meeting was held in September 2001, followed by a second continuity meeting in January 2002. Site visits, where Trek 21 staff visited the teachers in their schools and help desk services provided ongoing technical support and helped to remove any technical barriers to implementation.

\section{Data Collection Procedures}

To investigate the Trek-21 professional development key factors, the study used extant data that was collected by the Trek-21 research team which included this researcher. Treatment for this study was participation in the one year of Trek-21 professional development. The data collection points were aligned with the following four stages: pre-institute, summer institute, post-institute I, and post-institute II. Initial data collection for the study was done prior to participants arriving for the Summer Institute (i.e. January 2001) when a packet of preliminary materials was sent to all participants. Completed preliminary materials were collected prior to the first day of training (see Timeline of Events). All materials were checked for completeness. During the institute, participant data were gathered through on-line and/or hard copy surveys. Following the summer institute, additional data were gathered during the two continuity meetings (one in September 2001 and another in January 2002). The gathered data (Table 3.1) will be entered in a Microsoft Access database and later be exported to Microsoft Excel and SPSS software packages for further data analysis.

\section{Timeline of Events}

December 2000: Pre-institute materials packet that included a letter of commitment and responsibility, pre-institute surveys (SoC, PALS, Computer Use), and 
unit/lesson template was mailed to prospective Trek-21 participants. The deadline for the materials was set as March 16, 2001.

January 2001: Completed pre-institute materials started arriving.

March 2001: All pre-institute surveys were completed and returned by 38 teachers prior to the set deadline of March 15, 2001. Pre-institute data were collected from the unit/lesson templates using the Lesson Sweep instrument.

June 2001: Three-week Trek-21 Summer Institute took place from June 18 to July 13 (with July $4^{\text {th }}$ week off). Daily Training evaluations were administered on-line at the end of each day of training. The final training objective evaluation was administered (on-line) on the last day of the training (July 13, 2001) together with the Post-I institute Stages of Concerns survey.

August 2001: Post-institute data from teacher units were collected using the Lesson Sweep instrument.

September 2001: The first continuity meeting was held on September 28, 2001. No surveys were administered during this event.

January 2002: The second continuity meeting was held on January 18, 2002. The following surveys were administered (on-line), SoC (Post-institute II), PALS (Postinstitute), and Computer Use (Post-institute). 
Table 3.1

Research Design for the Study of Trek-21 P-12 Teachers

\begin{tabular}{|c|c|c|c|c|}
\hline Period & January 2001 ------ $\rightarrow$ & $\leftarrow---J u n e ~ 2001----\rightarrow$ & $\leftarrow$ August $2001---\rightarrow$ & $\leftarrow---$ January 2002 \\
\hline Event Cycle & Cycle I: Pre-Institute & Cycle II: Summer Institute & Cycle III: Post-Institute I & Cycle IV: Post-Institute II \\
\hline Treatment & $\begin{array}{l}\text { Pre-Institute Material } \\
\text { Development }\end{array}$ & 3 Week Summer Institute & $\begin{array}{l}\text { (August-December) } \\
1 \text { Day Continuity Meeting }\left(1^{\text {st }}\right) \\
4 \text { Months implementation }\end{array}$ & 1 Day Continuity Meeting $\left(2^{\text {nd }}\right)$ \\
\hline $\begin{array}{l}\text { Surveys } \\
\text { Administered }\end{array}$ & $\begin{array}{l}\text { I1--Stages of Concern } \\
\text { I2--PALS } \\
\text { I3--Computer Use } \\
\text { I5--Lesson Sweep }\end{array}$ & $\begin{array}{l}\text { During Institute: } \\
\text { I4--Daily Evaluations } \\
\text { At the end of institute: } \\
\text { I1--Stages of Concerns }\end{array}$ & $\begin{array}{c}\text { None } \\
\text { I5--Lesson Sweep }\end{array}$ & $\begin{array}{l}\text { I1--Stages of Concern } \\
\text { I2--PALS } \\
\text { I3--Computer User }\end{array}$ \\
\hline $\begin{array}{l}5 \text { Dependent } \\
\text { Variables }\end{array}$ & \multicolumn{4}{|c|}{ Stages of Concerns, teaching Styles, Computer Use Score, Change in IT Integration, and Change in IT Knowledge. } \\
\hline $\begin{array}{c}3 \text { Independent } \\
\text { Variables }\end{array}$ & \multicolumn{4}{|c|}{ Duration of Training, Instructional Design, and Evaluation. } \\
\hline
\end{tabular}




\section{Instrumentation}

This research study's instrumentation will consist of five major instruments: (1) A Concerned-Based Assessment Model’s Stages of Concern Questionnaire (SoCQ), (2) a Principles of Adult Learning Scale (PALS) questionnaire, (3) A Survey of Computer Use questionnaire, (4) Daily Training Objective Evaluations and Final Training Objective Evaluation questionnaire, and (5) A Indicators of Instructional Change Instrument - Random Sweep and Comprehensive Evaluation 37-item instrument.

\section{Instrument 1: The Stages of Concern about IT integration Questionnaire}

Stages of Concerns Questionnaire (SoCQ) used in this research study is based on the Stages of Concern Questionnaire developed by Hall, George and Rutherford (1977) as illustrated by Appendix A. The SoCQ contains 35 items measured using an eight-point scale. The SoCQ consists of 35 Likert scale questions: 5 questions for each of the 7 stages related concerns (Hall et al., 1979). The stages are divided into two groups: internal concerns (awareness, informational, personal and management) and external concerns (consequence, collaboration, and refocusing). This instrument was administered three times during training: pre-training, posttraining I, and post-training II.

Instrument 2: Principles of Adult Learning Scale (PALS) Questionnaire

The Principles of Adult Learning Scale (PALS) questionnaire was used to collect data to provide a measure of participants' teaching styles (Appendix B). Developed and validated by G.J. Conti in 1978, the instrument measures the degree of practitioner support and adherence to the collaborative teaching-learning mode. Originally developed for application with adult educators (Conti, 1982), the instrument has been adapted for use with P-12 educators as well to measure their teaching style preference as either teacher-centered or learner-centered. In addition 
to measuring an overall pattern behavior, the instrument contains several constructs: learnercentered activities, personalizing instruction, relating to experience, assessing student needs, climate building, participation in the learning process, and flexibility for personal development.

Instrument 3: The Survey of Computer Use Questionnaire

A Survey of Computer Use questionnaire administered to Trek-21 participants is based on four separate instruments - the Technology Needs Assessment, developed by Chip Kimball as part of his doctoral dissertation; the CODE 77 Self-Evaluation Rubrics for basic Teacher Computer Use, the CODE 77 Self-Evaluation Rubrics for Advanced Teacher Computer Use, and the CODE 77 Internet Skills Rubrics for Teachers, developed by Doug Johnson (Appendix C). Administered pre- and post-institute, scores can be compared to evaluate the efficacy of instruction as related to the constructs in the rubrics (Johnson, 1997). Edmin and Johnson both granted permission to Trek-21 to alter and use their instruments to meet the specific needs of the project.

\section{Instrument 4: Daily Training Evaluations and Final Daily Training Evaluation Questionnaire}

Daily Training Evaluations were administered on a daily basis of the three-week institute (June 17-21; 24-28, July 8-12 of 2002), while Final Daily Training evaluations were administered on the final day (July 12, 2002) of the Trek-21 Summer institute (Appendix D). The daily training evaluations were designed to collect formative data regarding the immediate achievement of training objectives, while the final daily training evaluation questionnaire was designed to collect data describing participants' sustained achievement of training objectives. The daily training evaluation instruments combined several (minimum of 2 and maximum of 6) Likert-scale, forced-choice items related to the content of each training session and several (minimum of 3 and maximum of 5) open-ended prompts asking participants to describe the impact of the training in greater depth and to make suggestions for improvements. The final daily 
training instrument combined 24 Likert-scale, forced-choice items assessing participants’ durability of daily training objectives.

\section{Instrument 5: Indicators of Instructional Change Instrument - Random Lesson Sweep}

The Indicators of Instructional Change Instrument - Random Lesson Sweep instrument was developed by Trek-21's evaluation team to assess pre- and post-institute units developed by participating PK-12 teachers (Appendix E). It was first used to assess units developed in the first year (2000) of the Trek-21 project. The purpose of the instrument was to assess various indicators of instructional change by comparing pre- and post-institute participants' units. These indicators included active student engagement, increased integration of instructional technologies, and the inclusion of instructional variables. Each item on the instrument can take the following values: $0=$ absence of the variable; 1 = presence of the variable; $2=$ assessment is linked to objectives/extension involves IT; 3 = each objective is assessed; + = active student engagement. In the initial assessment, the instrument categorized participants' units by grade level i.e. preschool, elementary, middle, and high etc. The instrument evaluates three main areas namely, instructional procedures with 7 items, instructional strategies with 13 items, and IT integration with 13 items.

\section{Data Analysis}

The data from each individual survey instrument were given a unique numeric participant identification number for easy processing. A printout of the database was then verified to make sure that what is available on the instruments is exactly the same as what will be 
RQ1 What is the relationship between changes in teacher concerns toward instructional technologies and key factors of the Trek-21 professional development model?

RQ2 What is the relationship between changes in participant teaching/learning styles and key factors of the Trek-21 professional development model?

RQ3 What is the relationship between changes in teacher level of computer use and key factors of the Trek-21 professional development model?

RQ4 What is the relationship between changes in teachers' extent of IT integration and key factors of the Trek-21 professional development model?

RQ5

What is the relationship between changes in teachers' IT Knowledge and key factors of the Trek-21 professional development model?

RQ6 Which key factors of the Trek-21 professional development are crucial to facilitating changes in P-12 participants' instructional practices (adoption) with respect to integration of instructional
Stages of Concerns questionnaire

(Appendix A)

Principles of Adult Learning Scale (PALS)

(Appendix B)

Survey of Computer Use questionnaire

(Appendix C)

Indicators of Instructional Change Instrument (Appendix D)

Final Daily Evaluations (Appendix E)

All of the above instruments

(Appendices A to D)
Raw scores will be translated into percentiles \& graphed for formative evaluation. Percentile scores will be analyzed using repeated Paired ttest and Simple Regression Analysis.

Descriptive Analysis, Correlation Analysis, Simple Regression Analysis. The dependent variables will be the Teaching Style score.

Descriptive Analysis, Correlation Analysis and Simple regression.

Descriptive Analysis. Simple frequency \& percent of participants will be compiled and analyzed. Correlation Analysis and Simple Regression.

Descriptive Analysis. Simple frequency \& percent of participants will be compiled and analyzed. Correlation Analysis and Simple Regression will be used.

Descriptive Analysis, Correlation Analysis will be used. 
technologies?

Table 3.2

An illustration of Research Questions, Data Sources, and Data Analysis Procedures 
in the database. A final review of the data was performed to check for inaccuracies and errors. This involved pulling out an instrument one at a time randomly and checking the data against the final database. The completed database was then exported to a SPSS statistical package on Windows XP platform. The statistical package used was responsible for the generation of statistical analyses, charts, and graphs for this study (Table 3.2).

Descriptive and inferential statistics were used in this study. Means, standard deviations, t-tests, and correlations were calculated with all descriptive data. Hence relationships and direction of the relationships were determined using Pearson Product Moment Correlation Coefficients and point bi-serial correlations depending on data type (continuous-continuous or continuous-dichotomous).

Research Question 1. What is the relationship between changes in teacher concerns toward ITs and key factors (Duration, Instructional Design and Evaluation) of the Trek-21 professional development model? Stages of Concern raw scores will be converted to percentile scores. Matched pair t-test analysis for the pre-test, post-test, and post1-test surveys will be performed. Correlations of the seven stages of concerns will be run.

Research Question 2. What is the relationship between changes in participant teaching/learning styles and key factors (Duration, Instructional Design and Evaluation) of Trek21 professional development model? A simple-regression analysis was used to determine the relationships between dependent and independent variables.

Research Question 3: What is the relationship between changes in teacher level of computer use and key factors (Duration, Instructional Design and Evaluation) of Trek-21 professional development model? A correlation analysis will be used to deal with this question. 
Research Question 4: What is the relationship between changes in teachers' extent of instructional technologies (ITs) integration into their units and key factors (Duration and Evaluation) of the Trek-21 professional development model? A correlation analysis and simple regression analyses were used to answer this question.

Research Question 5: What is the relationship between changes in teachers' instructional technologies (ITs) knowledge and key factors (Duration and Instructional Design) of the Trek21 professional development model? A correlation analysis and simple regression analyses were used to answer this question.

Research Question 6: Which key factors of the Trek-21 professional development are crucial to facilitating changes in P-12 participants' instructional practices (adoption) with respect to integration of instructional technologies?

To simplify the data organization and analysis, a list of variable structures was developed and is presented on the next page. This list depicts the dependent and independent variables of the research study. The structures consist of details of the variables including that data ranges for each dependent/independent variable. 


\section{A List of Dependent (DV) and Independent (IV) Variables}

Independent Variables:

1. Duration of Training (Testing Period):

Pre-Treatment, PostI-Treatment, and PostII-treatment

2. Instructional Design:

IT integrations (Total ITs) and Total Active Range: 0 - 13

3. Evaluation:

(1) Total Final Evaluation Pre-Treatment (24 items)

Range: 0 - 120

(2) Total Final Evaluation Post-Treament (24 items)

Range: 0 - 120

Dependent Variables:

1. Stages of Concern score (Pre -, PostI-, and PostII-Treament)

1. Awareness, 5 items

2. Informational, 5 items

Range: $0-35$

3. Personal, 5 items

Range: $0-35$

4. Management, 5 items

5. Consequences, 5 items

Range: $0-35$

Range: 0 - 35

6. Collaboration, 5 items

Range: 0 - 35

7. Refocusing, 5 items

Range: $0-35$

8. Internal Concerns $(1+2+3+4)$, Average of 20 items

Range: 0 - 35

9. External Concerns $(5+6+7)$, Average of 15 items

Range: $0-35$

Range: $0-35$

2. Teaching Styles score: (Pre- and PostII-Treament)

42 items

Range: 0 -210

3. Computer Use score

Part I: Sections $(\mathrm{A}+\mathrm{B}+\mathrm{C}+\mathrm{D})$

Range: $55-220$

Part II: Sections $(A+B+C+D)$

Range: $27-108$

4. Change in IT integration

1. Post minus Pre Total Procedures (Paper template) Range: $0-12$

2. Post minus Pre Total ActiveProc (Paper template) Range: 0 - 7

3. Post minus Pre Total Strategies (Paper template) Range: $0-13$

4. Post minus Pre Total Active Strategies (Paper template)

Range: $0-13$

5. $\quad$ Post minus Pre Total ITs (Paper template)

Range: $0-13$

6. Post minus Pre Total ITs Active (Paper template)

Range: $0-13$

5. Change in IT Knowledge

15 Daily Evaluation (Begin - End of Day)

Range: $0-450$ 
The preceding list of variables does not show the interaction between dependent and independent variables. To show overall interaction, Table 3.3 was created to display a matrix of all variables.

Table 3.3

Dependent Variables versus Independent Variables

\begin{tabular}{|c|c|c|c|c|}
\hline \multirow{6}{*}{ 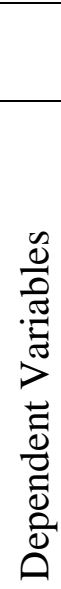 } & & \multicolumn{3}{|c|}{ Independent Variables } \\
\hline & & $\begin{array}{l}\text { Duration of Training } \\
\text { (Testing Period) }\end{array}$ & $\begin{array}{l}\text { Instructional } \\
\text { Design }\end{array}$ & Evaluation \\
\hline & $\begin{array}{l}\text { Stages of } \\
\text { Concern }\end{array}$ & $\mathrm{X}$ & $\mathrm{X}$ & $\mathrm{X}$ \\
\hline & $\begin{array}{l}\text { Teaching } \\
\text { Styles }\end{array}$ & $\mathrm{X}$ & $\mathrm{X}$ & $\mathrm{X}$ \\
\hline & Computer use & $\mathrm{X}$ & $\mathrm{X}$ & $\mathrm{X}$ \\
\hline & $\begin{array}{l}\text { Change IT } \\
\text { Integration }\end{array}$ & $\mathrm{X}$ & $\Theta$ & $\mathrm{X}$ \\
\hline & $\begin{array}{l}\text { Change in IT } \\
\text { Knowledge }\end{array}$ & $\mathrm{X}$ & $\mathrm{X}$ & $\Theta$ \\
\hline
\end{tabular}

$\mathrm{X}$ - denotes analysis will be performed; $\Theta$ - denotes No Analysis

From the overall matrix above, separate tables have been generated for each of the research questions to indicate how each dependent variable will interact with each of the three independent variables. Each row (dependent variable) has been expanded by adding a hypothesis by which the interaction will be tested. Tables 3.4 through 3.8 have been incorporated to further clarify the research design of the study. 
Table 3.4

Research Question 1: Dependent and Independent Variables Interaction

RQ1: What is the relationship between changes in teacher concerns toward instructional technologies and key factors of the Trek-21 professional development model?

\begin{tabular}{|c|c|c|}
\hline $\begin{array}{l}\text { Independent } \\
\text { variable }\end{array}$ & Data Sources & Hypothesis \\
\hline $\begin{array}{c}\text { vs. } \\
\text { Duration of } \\
\text { Training }\end{array}$ & Stages of Concern & $\begin{array}{l}\mathrm{H}_{0} \text { : Duration of training does not affect stages of } \\
\text { concerns of teachers? }\end{array}$ \\
\hline $\begin{array}{c}\text { vs. } \\
\text { Instructional } \\
\text { Design }\end{array}$ & Stages of Concern & $\begin{array}{l}\mathrm{H}_{0} \text { : Instructional Design does not affect teachers' } \\
\text { stages of concern? }\end{array}$ \\
\hline $\begin{array}{l}\text { vs. } \\
\text { Evaluation }\end{array}$ & Stages of Concern & $\begin{array}{l}\mathrm{H}_{0} \text { : Evaluation does not affect teachers' stages of } \\
\text { concern? }\end{array}$ \\
\hline
\end{tabular}

Table 3.5

Research Question 2: Dependent and Independent Variables Interaction

RQ2: What is the relationship between changes in participants' teaching/learning styles and key factors (Duration, Instructional Design and Evaluation) of the Trek-21 professional development model?

\begin{tabular}{|c|c|c|}
\hline $\begin{array}{l}\text { Independent } \\
\text { variable }\end{array}$ & Data Sources & Hypothesis \\
\hline $\begin{array}{c}\text { vs. } \\
\text { Duration of } \\
\text { Training }\end{array}$ & $\begin{array}{l}\text { Principles of Adult } \\
\text { Learning Scale }\end{array}$ & $\begin{array}{l}\mathrm{H}_{0} \text { : Duration of training does not affect } \\
\text { teaching/learning styles of participants }\end{array}$ \\
\hline $\begin{array}{c}\text { vs. } \\
\text { Instructional } \\
\text { Design }\end{array}$ & $\begin{array}{l}\text { Principles of Adult } \\
\text { Learning Scale }\end{array}$ & $\begin{array}{l}\mathrm{H}_{0}: \text { Instructional Design does not affect } \\
\text { teaching/learning of participants }\end{array}$ \\
\hline $\begin{array}{l}\text { vs. } \\
\text { Evaluation }\end{array}$ & $\begin{array}{l}\text { Principles of Adult } \\
\text { Learning Scale }\end{array}$ & $\begin{array}{l}\mathrm{H}_{0} \text { : Evaluation does not affect teaching/learning of } \\
\text { participants }\end{array}$ \\
\hline
\end{tabular}


Table 3.6

Research Question 3: Dependent and Independent Variables Interaction

RQ3: What is the relationship between changes in level of computer use and key factors (Duration, Instructional Design and Evaluation) of the Trek-21 professional development model?

\begin{tabular}{|c|c|c|}
\hline $\begin{array}{l}\text { Independent } \\
\text { variable }\end{array}$ & Data Sources & Hypothesis \\
\hline $\begin{array}{l}\text { vs. } \\
\text { Duration of } \\
\text { Training }\end{array}$ & Survey of Computer Use & $\begin{array}{l}\mathrm{H}_{0} \text { : Duration of training does not affect participants' } \\
\text { level of computer use }\end{array}$ \\
\hline $\begin{array}{c}\text { vs. } \\
\text { Instructional } \\
\text { Design }\end{array}$ & Survey of Computer Use & $\begin{array}{l}\mathrm{H}_{0} \text { : Instructional Design does not affect participants' } \\
\text { level of computer use }\end{array}$ \\
\hline $\begin{array}{l}\text { vs. } \\
\text { Evaluation }\end{array}$ & Survey of Computer Use & $\begin{array}{l}\mathrm{H}_{0} \text { : Evaluation does not affect participants' level of } \\
\text { computer use }\end{array}$ \\
\hline
\end{tabular}

Table 3.7

Research Question 4: Dependent and Independent Variables Interaction

RQ4: What is the relationship between changes in teachers' extent of instructional technologies (ITs) integration into their units and key factors (Duration and Evaluation) of the Trek-21 professional development model?

\begin{tabular}{ll}
\hline $\begin{array}{l}\text { Independent } \\
\text { variable }\end{array}$ & Data Sources
\end{tabular}

\begin{tabular}{ccc}
$\begin{array}{c}\text { vs. } \\
\begin{array}{c}\text { Duration of } \\
\text { Training }\end{array}\end{array}$ & $\begin{array}{c}\text { Indicators of } \\
\text { Instructional Change }\end{array}$ & $\begin{array}{c}\mathrm{H}_{0}: \text { Duration of training does not affect participants' extent } \\
\text { of ITs in their units }\end{array}$ \\
$\begin{array}{c}\text { vs. } \\
\text { Evaluation }\end{array}$ & $\begin{array}{c}\text { Indicators of } \\
\text { Instructional Change }\end{array}$ & $\begin{array}{c}\mathrm{H}_{0}: \\
\text { Evaluation does not affect participants' extent of ITs in } \\
\text { their units }\end{array}$ \\
\hline
\end{tabular}


Table 3.8

Research Question 5: Dependent and Independent Variables Interaction

RQ5: What is the relationship between changes in participants' IT knowledge and key factors (Duration, Instructional Design and Evaluation) of the Trek-21 professional development model?

\begin{tabular}{|c|c|c|}
\hline $\begin{array}{l}\text { Independent } \\
\text { variable }\end{array}$ & Data Sources & Hypothesis \\
\hline $\begin{array}{l}\text { vs. } \\
\text { Duration of } \\
\text { Training }\end{array}$ & Final Daily Evaluation & $\begin{array}{l}\mathrm{H}_{0} \text { : Duration of training does not affect participants' } \\
\text { change in IT knowledge }\end{array}$ \\
\hline $\begin{array}{c}\text { vs. } \\
\text { Instructional } \\
\text { Design }\end{array}$ & Final Daily Evaluation & $\begin{array}{l}\mathrm{H}_{0} \text { : Instructional Design does not affect participants' } \\
\text { change in IT knowledge }\end{array}$ \\
\hline
\end{tabular}

This chapter has presented the research design which included the data collection and analysis sections. The results of these analyses will be presented in the following chapter. 


\section{CHAPTER IV - RESULTS \\ Introduction}

The following chapter describes the results obtained from the various quantitative instruments used throughout this study. The data sources of the results came from the following five instruments: (1) Stages of Concern Questionnaire, (2) Principles of Adult Learners Scale Questionnaire, (3) Survey of Computer Use, (4) Lesson Sweep, and (5) the Final Daily Evaluation Questionnaire. The results from these surveys are reported for each research question. This chapter includes various tables and figures to present the results of analyzed data and simplify the narrative. Other data, as noted, will be included in the Appendix of this document.

\section{Description of the Participants}

Participants of this study came from the Year 2001, of the Trek-21 Project, West Virginia University’s US Department of Education PT3 grant for integrating instructional technologies. A total of 27 P-12 teachers participated in the second year, Year 2001, of the Trek-21 Professional Development. Of the 27 participants, 25 were female and two were male. Of the 27 teachers, 24 taught General Education classes and three were Special Education teachers. As for grade levels, two teachers taught pre-school, 17 elementary, four middle, and four high school. Participants self-reported their computer skills in the survey of Computer Use before they began the Year 2001 professional development where they learned to integrate technologies into their teaching. The selfreported responses of the participants’ computer levels are the following: 11 teachers indicated that they were Beginners (Low level), 14 Intermediate, and 2 Experts. 


\section{Findings on the Research Questions}

This chapter begins by presenting the results of the study in six sub-sections. The description of the results will follow the interaction between dependent and independent variables displayed in Table 4.0 below. From this overall matrix, separate tables have been generated for each of the research questions to indicate how each dependent variable will interact with each of the three independent variables. Each row (dependent variable) has been expanded by adding a hypothesis by which the interaction will be tested.

Table 4.0

Dependent Variables versus Independent Variables

\begin{tabular}{ccccc}
\hline & Dependent Variable & \multicolumn{3}{c}{ Independent Variables } \\
\cline { 3 - 5 } & & Duration & $\begin{array}{c}\text { Instructional } \\
\text { Design }\end{array}$ & Evaluation \\
\hline RQ1 & Stages of Concern & $\mathrm{X}$ & $\mathrm{X}$ & $\mathrm{X}$ \\
RQ2 & Teaching Styles & $\mathrm{X}$ & $\mathrm{X}$ & $\mathrm{X}$ \\
RQ3 & Computer use & $\mathrm{X}$ & $\mathrm{X}$ & $\mathrm{X}$ \\
RQ4 & Change in IT Integration & $\mathrm{X}$ & $\Theta$ & $\mathrm{X}$ \\
RQ5 & Change in IT Knowledge & $\mathrm{X}$ & $\mathrm{X}$ & $\Theta$ \\
\hline
\end{tabular}

$\mathrm{X}$ - denotes analysis will be performed; $\Theta$ - denotes no analysis

The first section will present the results relevant to Research Question 1 (RQ1): examining the relationship between changes in teachers concerns toward instructional technologies (ITs) and the key factors (Duration of Training, Instructional Design, and Evaluation) of the Trek-21 professional development model. The second section will summarize the results of Research Question 2 (RQ2): examining the relationship between 
changes in participant teaching/learning styles and key factors (Duration, Instructional Design, and Evaluation) of the Trek-21 professional development model. The third section will summarize the findings of Research Question 3 (RQ3): examining the relationship between teachers’ level of computer use and key factors (Duration, Instructional Design, and Evaluation) of the Trek-21 professional development model. Section four will answer Research Question 4 (RQ4): examining the relationship between changes in teachers' extent of instructional technologies integration into their units and key factors (Duration and Evaluation) of the Trek-21 professional development model. The fifth section will summarize the results of Research Question 5 (RQ5): examining the relationship between teachers' instructional technologies knowledge and key factors (Duration and Instructional Design) of the Trek-21 professional development model. The sixth and final section will summarize the results of Research Question 6 (RQ6): which key factors of the Trek-21 professional development are crucial to facilitating changes in P-12 participants’ instructional practices with respect to integration of ITs. 


\section{Research Question 1(RQ1)}

RQ1 asks: What is the relationship between changes in teachers concerns toward instructional technologies (ITs) and key factors (Duration, Instructional Design, and Evaluation) of the Trek-21 professional development model?

Table 4.1

RQ1: Dependent and Independent Variables

$$
\begin{aligned}
& \text { RQ1: What is the relationship between changes in teacher concerns toward } \\
& \text { instructional technologies and key factors of the Trek-21 professional } \\
& \text { development model? }
\end{aligned}
$$

\begin{tabular}{|c|c|c|}
\hline $\begin{array}{l}\text { Independent } \\
\text { variable }\end{array}$ & Dependent Variable & Hypothesis \\
\hline $\begin{array}{l}\text { Duration of } \\
\text { Training }\end{array}$ & Stages of Concern & $\begin{array}{l}\mathrm{H}_{0} \text { : Duration of training does not affect } \\
\text { stages of concerns of teachers }\end{array}$ \\
\hline $\begin{array}{l}\text { Instructional } \\
\text { Design }\end{array}$ & Stages of Concern & $\begin{array}{l}\mathrm{H}_{0} \text { : Instructional Design does not affect } \\
\text { teachers' stages of concern }\end{array}$ \\
\hline Evaluation & Stages of Concern & $\begin{array}{l}\mathrm{H}_{0} \text { : Evaluation does not affect teachers' } \\
\text { stages of concern }\end{array}$ \\
\hline
\end{tabular}

This question included one dependent variable with seven levels of concern from the Stages of Concern Questionnaire (SoCQ) and three independent variables from the Lesson Sweep and the Final Daily Evaluation Questionnaire. Participants’ Stages of Concern score, represented by the seven levels of concern toward instructional technologies, will be the dependent variables. The independent variables are (1) three durations of training (pre, post-1, and post-2 treatment periods), and (2) two continuous variables (instructional design score and evaluation score). The Pearson ( $r$ ) correlation coefficient was computed when the dependent variable and independent variables were 
both continuous. However, when the independent variable was categorical, the $t$-test was used to investigate the differences between the means of the treatment periods so that the correlations between the independent variables and dependent variable could be explained. Table 4.2 represents the means and standard deviations for each of the seven levels of Stages of Concern from pre, post-1, and post-2 periods.

Table 4.2

Stages of Concern Aggregate Data: Means and Standard Deviations

\begin{tabular}{|c|c|c|c|c|c|c|c|}
\hline Stage & Level of concern & \multicolumn{2}{|c|}{ Pre- PD Level } & \multicolumn{2}{|c|}{ Post1- PD Level } & \multicolumn{2}{|c|}{ Post2- PD Level } \\
\hline \multirow{5}{*}{ 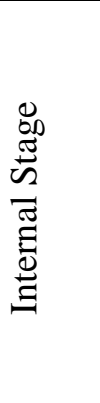 } & & mean & $\mathrm{SD}$ & mean & $\mathrm{SD}$ & mean & $\mathrm{SD}$ \\
\hline & 0-Awareness & 58 & 31.9 & 55 & 21.7 & 48 & 29.1 \\
\hline & 1-Informational & 86 & 14.4 & 72 & 25.7 & 73 & 18.4 \\
\hline & 2-Personal & 76 & 20.5 & 71 & 31.6 & 68 & 22.4 \\
\hline & 3-Management & 67 & 32.8 & 53 & 33.1 & 57 & 32.1 \\
\hline \multirow{3}{*}{ 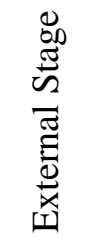 } & 4-Consequence & 46 & 28.2 & 49 & 26.9 & 49 & 21.9 \\
\hline & 5-Collaboration & 64 & 24.4 & 71 & 18.7 & 72 & 24.5 \\
\hline & 6-Refocusing & 82 & 17.2 & 83 & 21.3 & 90 & 7.0 \\
\hline
\end{tabular}

PD = Professional Development

RQ1a - SoC vs. Duration: What is the relationship between changes in teachers concerns toward instructional technologies (ITs) and Duration of training, a key factor of the Trek-21 professional development model?

A series of seven sets of pre, post- 1 , and post- $2 t$-test analyses were conducted to investigate the relationship between teachers' concerns toward integrating ITs and duration of training. Seven sets of paired (within subjects) $t$-tests were conducted to investigate teachers' concerns from the Stages of Concern Questionnaire (SoCQ). Teachers' concerns were the dependent variables in this question, and included the 
following: (0) Awareness, (1) Informational, (2) Personal, (3) Management, (4)

Consequences, (5) Collaboration, and (6) Refocusing (Range $=0$ to 100 for each). The SoCQ instrument divides the seven levels of concern into Internal Stage Concerns (variables 0 through 3), and External Stage of Concerns (variables 5 through 7). Duration of training is the only independent variable of this question. Below, the results of these ttests are reported on each dependent variable in text and tabulated in Table 4.3, Table 4.4, and Table 4.5 .

Awareness. The Awareness concern represents Level 0 in the SoCQ. The pre to post- 1 t-test analysis indicated $t(26)=.54, p>.05$, non-significant. The comparison between the pre to post- 2 result was $t(26)=1.71, p>.05$, non-significant and between post-1 to post- 2 was $t(26)=1.27, p>.05$, non-significant.

Informational. The Informational concern represents Level 1 in the SoCQ. The pre to post- 1 -test analysis indicated $t(26)=8.07, p<.05$, significant. The comparison between the pre to post-2 yielded $t(26)=-3.27, p<.05$, significant and between post- 1 to post-2 $t(26)=-3.27, p<.05$, significant.

Personal. The Personal concern represents Level 2 in the SoCQ. The pre to post$1 t$-test analysis indicated $t(26)=4.51, p<.01$, significant. The comparison between the pre to post-2 yielded $t(26)=1.86, p>.05$, non-significant and between post- 1 to post-2 $t(26)=-2.42, p<.05$, significant.

Management. The Management concern represents Level 3 in the SoCQ. The pre to post- 1 -test analysis indicated $t(26)=2.31, p<.05$, significant. The comparison between the pre to post- 2 yielded $t(26)=2.12, \quad p<.05$, significant and between post -1 to post-2 $t(26)=-.52, p>.05$, non-significant. 
Consequences. The Consequences concern represents Level 4 in the SoCQ. The pre to post- 1 -test analysis indicated $t(26)=-.72, p>.05$, non-significant. The comparison between the pre to post-2 yielded $t(26)=-.58, p>.05$, non-significant and between post-1 to post-2 $t(26)=.16, p>.05$, non-significant.

Collaboration. The Collaboration concern represents Level 5 in the SoCQ. The pre to post- 1 -test analysis indicated $t(26)=-1.61, p>.05$, non-significant. The comparison between the pre and post- 2 yielded $t(26)=-1.57, p=.13$, a trend toward significance and between post-1 to post-2 $t(26)=-.15, p>.05$, non-significant.

Refocusing. The Refocusing concern represents Level 6 in the SoCQ. The pre to post- 1 t-test analysis indicated $t(26)=-.25, p>.05$, non-significant. The comparison between the pre and post- 2 yielded $t(26)=-2.78, p<.05$, significant and between post-1 and post- $2 t(26)=-3.79, p<.05$, significant.

These results indicate that the Trek-21 participants' Informational and Management concerns changed significantly from the time they began the summer institute (pre-test) and the time they finished IT implementation (post-2, six months later). This means that, as the participants learned more about the ITs, both their Internal concerns regarding IT integration decreased as expected. Their External concerns also changed, but not significantly.

$T$-test values for periods between pre to post-1, pre and post-2, and post- 1 to post2 are presented in the consecutive Tables 4.3, 4.4, and 4.5. 
Table 4.3

Results of Paired t-Tests of the SoC Scores between the Pre and Post-1 t-test

\begin{tabular}{|c|c|c|c|c|c|c|c|}
\hline \multirow[t]{2}{*}{$\begin{array}{l}\text { Level of } \\
\text { Concern }\end{array}$} & Mean & Std & Post1-Survey & \multicolumn{2}{|c|}{$\begin{array}{l}\text { 95\% Confidence } \\
\text { Interval of Diff. }\end{array}$} & \multirow[b]{2}{*}{$t(26)$} & \multirow[b]{2}{*}{$p$} \\
\hline & Diff. & Deviation & Std. Error & Lower & Upper & & \\
\hline $\begin{array}{l}\text { 0-Awareness } \\
\text { Pre-Post1 }\end{array}$ & 3.11 & 29.9 & 5.70 & -8.7 & 14.92 & .54 & .59 \\
\hline $\begin{array}{l}\text { 1-Informational } \\
\text { Pre-Post1 }\end{array}$ & 30.96 & 19.9 & 3.83 & 23.08 & 38.85 & $8.07 * *$ & .01 \\
\hline $\begin{array}{l}\text { 2-Personal } \\
\text { Pre-Post1 }\end{array}$ & 23.11 & 26.6 & 5.13 & 12.57 & 33.65 & $4.51 * *$ & .01 \\
\hline $\begin{array}{l}\text { 3-Management } \\
\text { Pre-Post1 }\end{array}$ & 13.41 & 30.2 & 5.80 & 1.48 & 25.34 & $2.31 *$ & .03 \\
\hline $\begin{array}{l}\text { 4-Consequence } \\
\text { Pre-Post1 }\end{array}$ & -3.3 & 23.7 & 4.55 & -12.66 & 6.06 & -.72 & .48 \\
\hline $\begin{array}{l}\text { 5-Collaboration } \\
\text { Pre-Post1 }\end{array}$ & -6.78 & 21.9 & 4.22 & -15.45 & 1.89 & $-1.61^{\dagger}$ & .12 \\
\hline $\begin{array}{l}\text { 6-Refocusing } \\
\text { Pre-Post1 }\end{array}$ & 0.81 & 17.2 & 3.30 & -7.61 & 5.976 & -.25 & .81 \\
\hline $\begin{array}{l}\text { Diff. }=\text { Mean Dif } \\
* p<.05, * * p< \\
\text { Table } 4.4 \\
\text { Results of Pairec }\end{array}$ & $\begin{array}{l}\text { ference } \\
.01, * * * \\
\text { t-Tests }\end{array}$ & $\begin{array}{l}<.001, \dagger \\
\text { the SoC sC }\end{array}$ & $\begin{array}{l}\text { trend }(.05<p \\
\text { es between th }\end{array}$ & Pre anc & $s t-2 t$ & & \\
\hline Level of Concern & Mean & Std & Post1-Survey & $\begin{array}{l}95 \% \mathrm{C} \\
\text { Interva }\end{array}$ & $\begin{array}{l}\text { idence } \\
\text { f Diff. }\end{array}$ & & \\
\hline & Diff. & Deviation & Std. Error & Lower & Upper & $t(26)$ & $p$ \\
\hline $\begin{array}{l}\text { 0-Awareness } \\
\text { Pre-Post2 }\end{array}$ & 10.52 & 32.05 & 6.17 & -2.16 & 23.20 & $1.71^{\dagger}$ & .10 \\
\hline $\begin{array}{l}\text { 1-Informational } \\
\text { Pre-Post2 }\end{array}$ & 13.07 & 13.80 & 5.48 & -29.15 & -6.63 & $-3.27 * *$ & .01 \\
\hline $\begin{array}{l}\text { 2-Personal } \\
\text { Pre-Post2 }\end{array}$ & 8.26 & 23.13 & 4.45 & -0.88 & 17.41 & $1.86^{\dagger}$ & .08 \\
\hline $\begin{array}{l}\text { 3-Management } \\
\text { Pre-Post2 }\end{array}$ & 10.04 & 24.56 & 4.72 & 0.32 & 19.75 & $2.12 *$ & .03 \\
\hline $\begin{array}{l}\text { 4-Consequence } \\
\text { Pre-Post2 } \\
\end{array}$ & -2.63 & 23.65 & 4.55 & -11.99 & 6.73 & -0.58 & .58 \\
\hline $\begin{array}{l}\text { 5-Collaboration } \\
\text { Pre-Post2 }\end{array}$ & -7.44 & 24.69 & 4.75 & -17.21 & 2.32 & $-1.57^{\dagger}$ & .13 \\
\hline $\begin{array}{l}\text { 6-Refocusing } \\
\text { Pre-Post2 }\end{array}$ & -8.07 & 15.07 & 2.90 & -14.03 & -2.11 & $-2.78 * *$ & .01 \\
\hline
\end{tabular}

Diff. $=$ Mean Difference, ${ }^{\dagger}=$ trend $(.05<p<.15)$.

$* p<.05,{ }^{* *} p<.01, * * * p<.001{ }^{\dagger}{ }^{\dagger}=$ trend $(.05<p<.15)$ 
Table 4.5

Results of Paired t-Tests of the SoC Scores between the Post-1 and Post-2 t-test

\begin{tabular}{|c|c|c|c|c|c|c|c|}
\hline $\begin{array}{l}\text { Level of } \\
\text { Concern }\end{array}$ & Mean & Std & Post1-Survey & $\begin{array}{l}95 \% \mathrm{C} \\
\text { Interva }\end{array}$ & $\begin{array}{l}\text { idence } \\
\text { f Diff. }\end{array}$ & & \\
\hline & Diff. & Deviation & Std. Error & Lower & Upper & $t(26)$ & $p$ \\
\hline $\begin{array}{l}\text { 0-Awareness } \\
\text { Post1-Post2 }\end{array}$ & 7.41 & 30.33 & 5.84 & -4.59 & 19.41 & 1.27 & .22 \\
\hline $\begin{array}{l}\text { 1-Informational } \\
\text { Post1-Post2 }\end{array}$ & -17.89 & 28.45 & 5.48 & -29.15 & -6.63 & $-3.27 * *$ & .01 \\
\hline $\begin{array}{l}\text { 2-Personal } \\
\text { Post1-Post2 }\end{array}$ & -14.85 & 31.93 & 6.14 & -27.48 & -2.22 & $-2.42 *$ & .02 \\
\hline $\begin{array}{l}\text { 3-Management } \\
\text { Post1-Post2 }\end{array}$ & -3.37 & 33.87 & 6.52 & -16.77 & 10.03 & -0.52 & .61 \\
\hline $\begin{array}{l}\text { 4-Consequence } \\
\text { Post1-Post2 }\end{array}$ & .67 & 22.19 & 4.27 & -8.11 & 9.44 & 0.16 & .88 \\
\hline $\begin{array}{l}\text { 5-Collaboration } \\
\text { Post1-Post2 }\end{array}$ & .67 & 23.74 & 4.56 & -10.06 & 8.72 & -0.15 & .89 \\
\hline $\begin{array}{l}\text { 6-Refocusing } \\
\text { Post1-Post2 }\end{array}$ & -7.26 & 9.94 & 1.91 & -11.19 & -3.33 & $-3.79 * *$ & .01 \\
\hline
\end{tabular}

To further interpret the SoC Questionnaire, an overall view of the relative intensity of different levels of concern was developed among the participants. The participants were grouped into three different groups according to their level of computer use and skills at the beginning of the professional development training. The three groups were Beginners, Intermediate, and Advanced. These groups helped to expose the increasing and decreasing patterns as well as trends of participants' Stages of Concern scores throughout the duration of the training. Aggregate mean percentile scores are presented in Figures 1, 2, 3, and 4 as a graphic representation of the data in Table 4.2. Stages of Concern data are frequently presented in the literature in this graphic format (Hall et al., 1998; Hord et al., 1987). Figure 1 represents the Stages of Concern profiles of all participants in the pre, post-1, and post-2 tests. Figures 2, 3, and 4 represent the Stages of Concern profiles for the Beginners, Intermediate, and Advanced groups, 
respectively. Interpretation of the scores is based on guidelines contained in Measuring Stages of Concern about the Innovation: A Manual For Use of the SoC Questionnaire (Hall, George, \& Rutherford, 1998). When scores were considered and viewed by individual technology groups (Beginner, Intermediate, and Advanced), trends and patterns of the data were more obvious and easily interpreted over the course of the training duration.

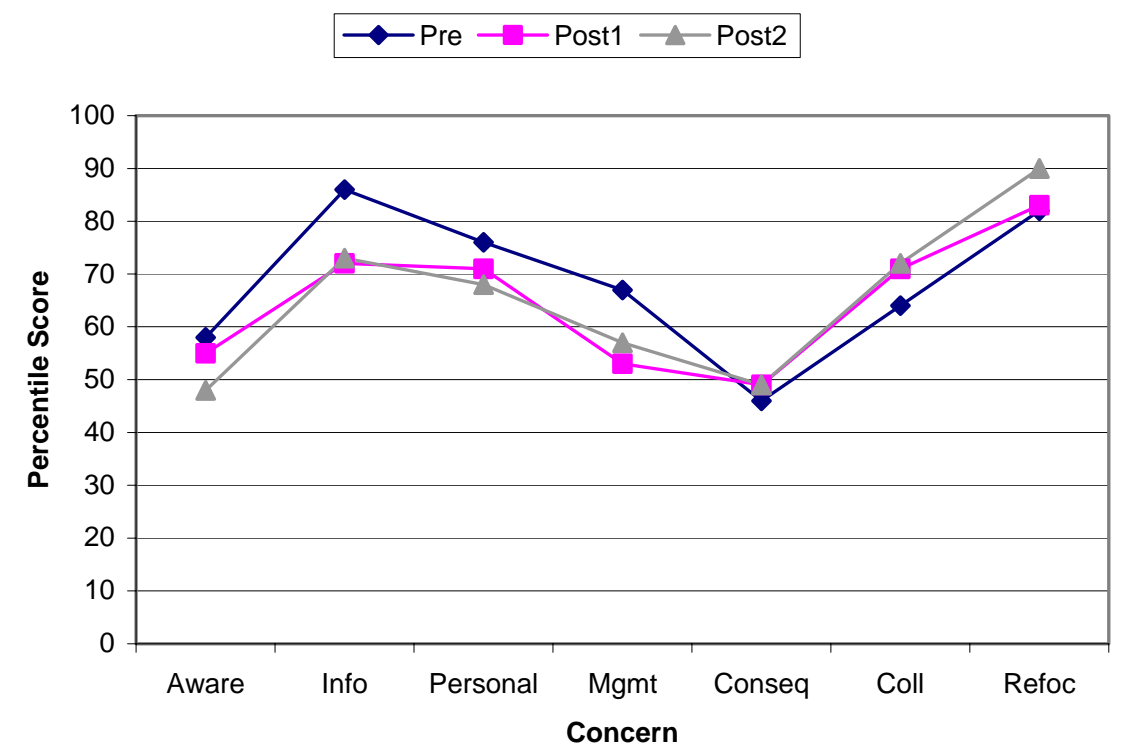

Figure 1: Stages of Concern Profiles for All Participants: Pre-, Post-1, and Post-2 Scores

Note: Aware $=$ Awareness, Info $=$ Information, Mgmt $=$ Management, Conseq $=$ Consequences, Coll $=$ Collaboration, Refoc $=$ Refocusing .

All participants. Figure 1 depicts the aggregate profiles of the changes in the concerns of all 27 participants before the training (pre), after the training (post-1), and after implementation (post-2). As shown in Figure 1, participants’ Internal concerns changed significantly from pre to post and post- 1 to post- 2 as expected. This indicated that participant teachers learned about the innovation during the training and their Internal concerns decreased as they found out more about IT integration. Participants' 
External concerns increased after the training as indicated in the directions of post-1 and post-2 tests. This meant as participants learned about the innovation and implemented their web-based unit with their students, they became concerned about the effects of IT integration on their practice and learners. Although the changes in the External concerns were not significant, the increasing direction of External concerns was in the right direction as expected following an effective training.

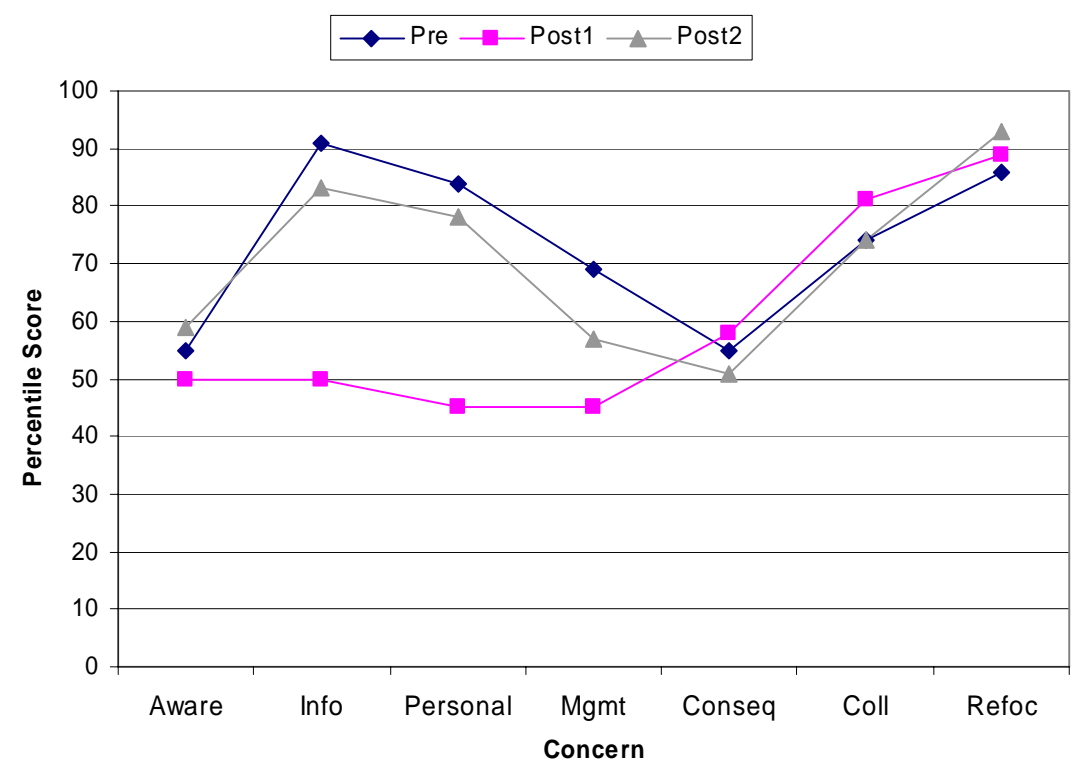

Figure 2: Beginners’ Stages of Concern Profiles: Pre-, Post-1, and Post-2 Scores.

Beginners Group Participants. Figure 2 illustrates that the concerns of teachers who reported to be beginners (Computer Use Score) were the highest at the Informational concern and followed by Refocusing. The profile for Beginner Group had very high Internal concerns when they began the training. Their Internal concerns significantly decreased as expected following an effective training. This group of participants’ Internal concerns bounced back after implementation of their web-based units in their classrooms. This meant as participants implemented the innovation, they experienced the effect of the innovation and realized they needed to learn more about IT integration. The 
Beginners' had high External concerns before they began the training. Their External concerns increased significantly after the training (post-1) and almost dropped down to the pre-test level at the end of training (post-2). This meant following an effective training, the beginning level participants had increasing concerns in regards to the effects of IT integration on their practice and learners as expected. Their External concerns, however, decreased after the implementation in an unexpected direction. This may be due to the fact that Beginners realized they needed more training to be able to fully observe the effects of IT implementation on their practice.

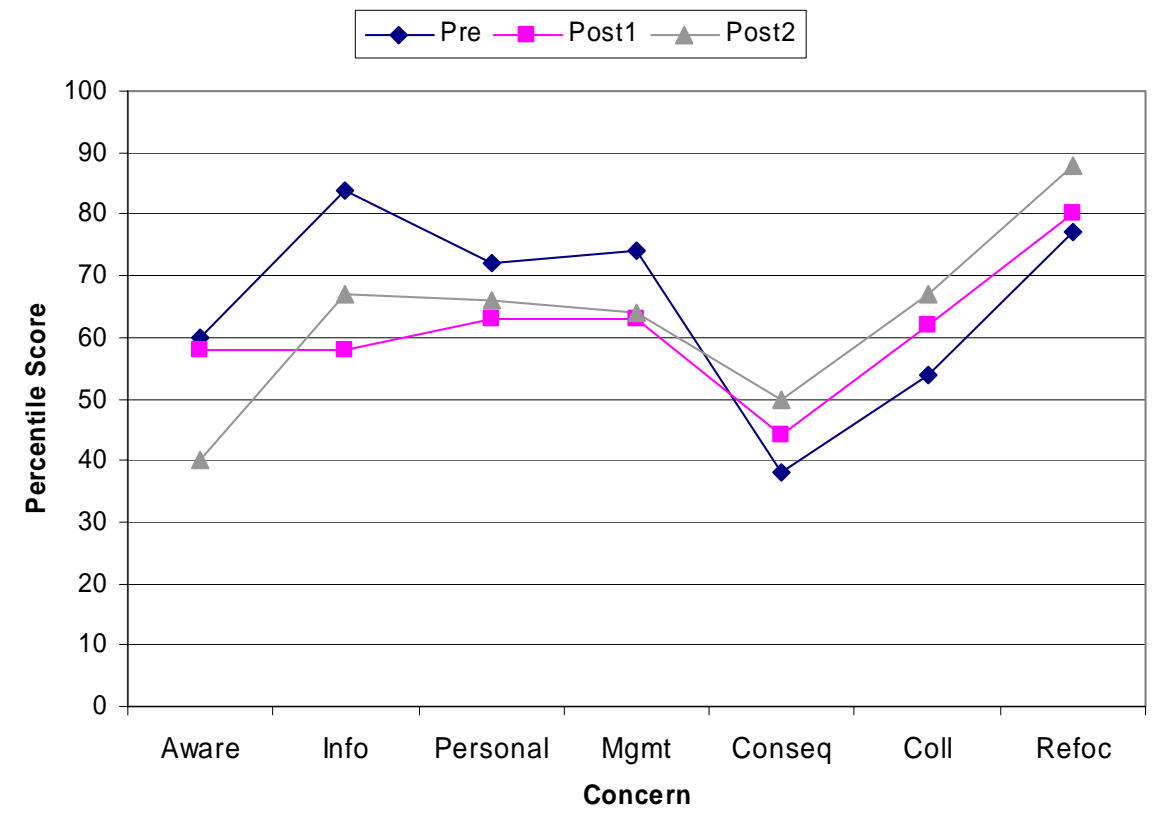

Figure 3: Intermediate Groups' Stages of Concern Profiles: Pre-, Post-1, and Post-2 Scores.

Intermediate Group Participants. The concerns of the Intermediate group were the highest at the Informational (Level-1) and followed by Management (Level-3) at the pre-test period. A high Informational concern indicated that teachers wanted more information about the ITs. Concerns were lowest at the Consequences and Collaboration levels of concern. Low Consequences and Collaboration concerns suggested some lack of 
concern about consequences for learners. After the summer institute, the two highest concerns were Refocusing and Collaboration while Consequences and Informational were the lowest. The second peak at Level 5 -Collaboration suggested that teachers were transitioning to logistics, time, and management concerns and this clearly indicated a progression from Internal Stage (Levels 0, 1, 2, and 3) to External Stage concerns (Levels 4, 5 and 6).

The Intermediate group had very high Internal concerns when they began the training. Their Internal concerns decreased as expected following effective training and implementation in general. This meant participant teachers were satisfied with what they learned during the training. The Intermediate group's External concerns progressively increased following the training and implementation as expected. This meant participant teachers were able to be externally concerned about the effects of IT on their teaching practices both after the training and increasingly after the implementation as expected.

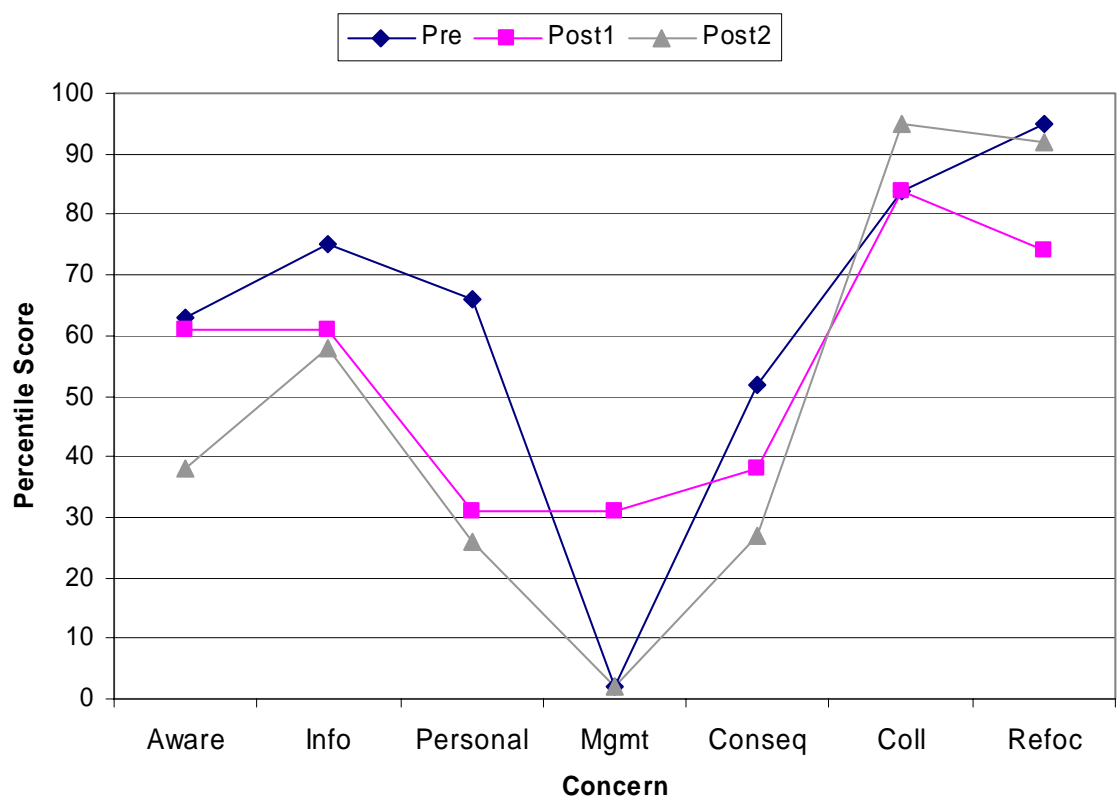

Figure 4: Advanced Groups' Stages of Concern Profiles: Pre-, Post-1, and Post-2 Scores. 
Advanced Group of Participants. At the pre-test period the concerns of the Advanced group were highest at Refocusing, followed by Collaboration. The lowest concerns were at Level-3, Management concerns. After the summer institute, the two highest concerns remained at Refocusing and Collaboration with Personal and Management as the lowest two concerns. Refocusing and Collaboration remained as the two highest concerns throughout training while Management remained as the lowest for the advanced group. The SoCQ profile for Advanced participants suggested a slight spin on the interpretation than typically expected indicating differences in response pattern than the first two groups. A high Level 6 -Refocusing indicated established users were no longer particularly concerned about ITs, but were concerned about refocusing, indicating that teachers had ideas about how to improve integrating ITs into the classroom.

The Advanced group’s Internal concerns decreased following an effective training. Their External concerns indicated unpredicted directions after the training and implementation. This may be due to the fact that there were only three people in this group and changes in the direction of their concerns cannot be explained meaningfully.

In summary, Duration of training was sufficient enough to have significantly affect participants' SoC scores during the course of the professional development training. The Duration of the professional development was a key factor in lowering participants’ Internal Concerns and increasing External Concerns soon after 4-week training, and at the end of training.

$R Q 1 b-S o C$ vs. Instructional Design: What is the relationship between changes in teachers concerns toward instructional technologies (ITs) and Instructional Design, a key factor of the Trek-21 professional development model? 
A series of seven sets of pre, post-1, and post-2 simple regression analyses (seven by three) were conducted to investigate the relationship between teachers' concerns toward integrating ITs and the Instructional Design score (Range $=0$ to 26). Teachers' concerns were determined as being the dependent variables of this question, and they included the following concern levels: (0) Awareness, (1) Informational, (2) Personal, (3) Management, (4) Consequences, (5) Collaboration, and (6) Refocusing (Range $=0$ to 100 for each). The Instructional Design score was the independent variable in this question. The Instructional Design score was derived from the Lesson Sweep instrument. Seven sets of regression analysis were computed between a dependent variable and an independent variable. $T$-test values for pre, post-1, and post-2 are reported in Table 4.6 below.

Table 4.6

Simple Regression of Instructional Design Score on the Seven Levels of Concern

\begin{tabular}{lcccccc}
\hline & \multicolumn{5}{c}{ Instructional Design } \\
\hline Level of Concern & $t(26)$ & $\mathrm{p}$ & $t(26)$ & $p$ & $t(26)$ & $p$ \\
\hline 0 - Awareness & -1.13 & .27 & -0.24 & .81 & 0.63 & .53 \\
\hline 1 - Informational & 1.43 & .17 & -0.24 & .81 & $2.23^{*}$ & .04 \\
\hline 2 - Personal & $1.62^{\dagger}$ & .12 & -0.74 & .46 & 1.05 & .30 \\
\hline 3 - Management & -0.24 & .81 & -0.74 & .46 & $-1.66^{\dagger}$ & .11 \\
\hline 4 - Consequence & $2.13^{*}$ & .04 & $3.25^{* *}$ & .01 & $1.78^{\dagger}$ & .09 \\
\hline $5-$ Collaboration & 0.84 & .41 & $1.51^{\dagger}$ & .14 & 0.65 & .52 \\
\hline $6-$ Refocusing & 1.04 & .31 & $3.88^{* *}$ & .01 & 0.80 & .43 \\
\hline$* p<.05, * * p<.01, * * * p<.001, \dagger$ & $=$ trend $(.05<p<.15)$ & &
\end{tabular}

Note: For Stages of Concern, Range $=0$ to 100, Means and SDs are in Table 4.1. For Instructional Design, Range $=0$ to 26, Mean $=20.70, S D=7.43$.

Awareness. There was no significant relationship found between gains in Instructional Design and Awareness at any point in the treatment. The pre regression 
analysis indicated $t(26)=-1.13, p=.27$, non-significant. The post-1 regression analysis indicated $t(26)=-0.24, p=.81$, non-significant and post-2 regression yielded $t(26)=-$ $0.63, p=.53$, non-significant.

Informational. There was no significant relationship found between Instructional Design and the Informational concern at the pretest stage, $t(26)=1.43, p=.17$, or at the post-1 stage, $t(26)=-.24, p=.81$. A significant positive relationship was found at the post-2 stage $t(26)=2.23, p=.04$. Those with higher gains in Instructional Design tended to have higher Informational concerns after the Trek-21 summer institute.

Personal. No significant relationship was found between Instructional Design and Personal concerns, at pre-test $t(26)=1.62, p=.12$, post- 1 test stage $t(26)=-.24, p=.81$, and post-2 test $t(26)=1.05, p=.30$. However, there was a relationship between Instructional Design gain and Personal concerns that approached significance at pre treatment $t(26)=1.62, p=.12($ See Tables 4.6$)$.

Management. There was no significant relationship found between Instructional Design and Management concerns before the treatment, at pre-test $t(26)=-0.24, p=.81$; at the post-1test point, $t(26)=-0.74, p=.46$; or post- 2 test $t(26)=-1.66, p=.11$. Prior to training, participants’ gains in instructional design did not affect their Management concerns at all. A negative relationship between Instructional Design gains and Management concerns that approached significance was found at the end of the project (post-2test), $t(26)=-1.66, p=.11$. Those participants with higher gains in instructional design tended to have lower management concerns after the implementation period, i.e. six months after the summer institute. (See table 4.6) 
Consequence. There was a significant relationship between Instructional Design and Consequence concerns at pretest stage, $t(26)=2.13, p=.04$ and post- 1 test point $t(26)=3.25, p=.01$. These data show that participants’ Instructional Design tended to be related to higher Consequence concerns at the beginning of the training and soon after summer institutes. However, after implementation, a positive relationship was found between Instructional Design gains and Consequence concerns that approached significance, $t(26)=1.78, p=.09$. This indicated that those participants with more gains in their instructional design score tended to have higher consequence concerns at the end of the Trek-21 project.

Collaboration. There was no significant relationship found between Instructional Design and collaboration concerns before the training, $t(26)=.84, p=.41$; at the post- 1 test point, $t(26)=1.51, p=.14$; or at post-2 test $t(26)=.65, p=.52$. (See table 4.6)

Refocusing. There was no significant relationship found between Instructional Design and Collaboration concerns before the training, $t(26)=1.04, p=.31$; but, there was a significance positive relationship at the post-1test point between the two variables, $t(26)=3.88, p=.01$. At the end of program, no significant relationship was found, $t(26)$ $=.80, p=.43$.

The above findings indicate that participants who integrated more ITs in their web units also had higher External concerns during the course of the professional development training.

RQ1c-SoC vs. Evaluations: What is the relationship between changes in teachers concerns toward ITs and the Evaluation score, a key factor of the Trek-21 professional development model? 
A series of seven sets of pre, post-1, and post-2 simple regression analyses (seven by three) were conducted to investigate the relationship between teachers' concerns toward integrating ITs and the Evaluation score (Range $=0$ to 252). Teachers' concerns were determined as being the dependent variables of this question, and they included the following levels: (0) Awareness, (1) Informational, (2) Personal, (3) Management, (4) Consequences, (5) Collaboration, and (6) Refocusing (Range $=0$ to 100 for each). The Evaluation score was determined as being the independent variable in this question. The Evaluation score comes from the Final Daily Evaluation Questionnaire. Seven sets of simple regression analysis were run between a dependent variable and an independent variable. Below $t$ values for pre, post-1, and post-2 are reported in Table 4.7.

\section{Table 4.7}

Simple Regression of Change in Evaluation Score on the Seven Levels of Concern

\begin{tabular}{lcccccc}
\hline & \multicolumn{3}{c}{ Change in Evaluation Score (Post - Pre) } \\
\hline Level of Concern & \multicolumn{2}{c}{ Pretest } & \multicolumn{2}{c}{ Post-1 test } & \multicolumn{2}{c}{ Post-2 test } \\
& $t(26)$ & $p$ & $t(26)$ & $p$ & $t(26)$ & $p$ \\
\hline 0 - Awareness & $2.13^{*}$ & .04 & .57 & .57 & 1.84 & $.08^{\dagger}$ \\
\hline 1 - Informational & $2.75^{*}$ & .01 & .57 & .57 & .91 & .37 \\
\hline 2 - Personal & 1.11 & .28 & .81 & .42 & .22 & .83 \\
\hline 3 - Management & 0.87 & .39 & .81 & .42 & -.45 & .66 \\
\hline 4 - Consequence & 0.05 & .96 & 1.45 & .16 & -.68 & .50 \\
\hline $5-$ Collaboration & -0.14 & .89 & .64 & .53 & -.71 & .48 \\
\hline $6-$ Refocusing & -0.60 & .55 & 1.30 & .21 & -1.91 & $.07 \dagger^{\dagger}$ \\
\hline$*<.05, * * p<.01, * * * p<.001, \dagger$ & $\dagger$ & $=$ trend $(.05<p<.15)$ & &
\end{tabular}

Note: For Stages of Concern, Range $=0$ to 100, Means and SDs are in Table 4.1.

For Evaluation, Range $=0$ to 252, Mean $=57.52, S D=26.75$.

Awareness. There was a significant positive relationship found between change in Evaluation score and Awareness concerns at pretest stage, $t(26)=2.13, p=.04$. There 
was also a positive relationship that approached significance at the end of the post-2 test point, $t(26)=1.84, p=.078$ (See table 4.7).

Informational. There was a significant relationship found between the changes in Evaluation score and Information concerns at pretest stage, $t(26)=2.75, p=.01$. No significant relationships were found between evaluation change score and information concerns at both post1test point, $t(26)=0.57, \mathrm{p}=.57$, and post 2 test $t(26)=0.91, p=.37$.

Personal. There was no significant relationship found between evaluation-change score and personal concerns before the treatment, $\mathrm{t}(26)=1.11, p=.28$; at the post-1 point, $\mathrm{t}(26)=.81, \mathrm{p}=.42$; or post $-2 \mathrm{t}(26)=0.22, p=.83$. Prior to training, after training, and six month after training (after implementation) participants' changes in the evaluation score did not affect their Personal concerns at all.

Management. There was no significant relationship between Change-inEvaluation change score and Management concerns pretreatment, $t(26)=.87, p=.39$; post-1 point, $t(26)=.81, p=.42$; or post-2 test, $t(26)=-0.45, p=.66$. Prior to training, after training, and six month after training (after implementation) participants’ changes in the Evaluation score did not affect their Management concerns at all.

Consequences. There was no significant relationship found between Change-inEvaluation score and Consequences concerns before the treatment, $t(26)=.05, p=.96$; at the post-1 point, $t(26)=1.45, p=.16$; or post- $2 t(26)=-0.68, p=.50$. Prior to training, after training, and six month after training (after implementation) participants’ changes in the Evaluation score did not affect their Consequences concerns at all.

Collaboration. There was no significant relationship found between Change-inEvaluation score and Collaboration concerns before the treatment, $t(26)=-.14, p=.89$; at 
the post-1test point, $t(26)=.64, p=.53$; or post- $2 t(26)=-0.71, p=.48$. Prior to training, after training, and six month after training (after implementation) participants' changes in the Evaluation score did not affect their Collaboration concerns at all.

Refocusing. There was no significant relationship found between Change-inEvaluation score and Refocusing concerns before the treatment, $t(26)=-0.60, p=.55$ at the post-1test point, $\mathrm{t}(26)=1.30, p=.21$; or post- 2 test $t(26)=-1.91, p=.07$. Prior to training, participants’ changes in the evaluation score did not affect their Refocusing concerns at all. A negative relationship between positive change in Evaluation score and Refocusing concerns that approached significance was found at the end of the project (post-2test), post-2 test $t(26)=-1.91, p=.07$. Those participants with a larger change in Evaluation score tended to have lower Refocusing concerns after the implementation period (six months after the summer institute).

\section{Summary of RQ1}

The analysis of data supported the implications of the Trek-21 professional development project on the stages of concern (SoCQ) related to Duration of Training, Instructional Design, and Evaluation.

SoC vs. Duration. This research question was designed to answer if the duration of the training was a key factor in teachers' concerns toward IT integration. Results of the SoCQ for all 27 teachers indicated that both Internal and External concerns of the participants moved to the direction excepted after an effective training (post-1). The changes in their concerns were not as significant after implementation as they were after training. This may be due to differences of IT implementation experiences of the participants in the contexts of their teaching practices. 
Findings for RQ1a indicate that duration of training was a key factor in the changes of teachers' concerns toward IT integration. Following a four-week-long training, participant teachers' concerns changed in expected directions. After implementation, however, participant teachers' scores did not change significantly, perhaps, due to their IT implementation experiences in their teaching context.

SoC vs. Instructional Design. This study found that Instructional Design score was positively related to Consequences concerns and Refocusing concerns at the Post-1 period. A significant positive relation was also found between Informational concerns and Instructional Design score at the end of implementation period.

The above findings indicate that participants who integrated more ITs in their web units also had higher External concerns during the course of the professional development training.

SoC vs. Change in Evaluation. This study found that Change in Evaluation score was significantly related to Awareness and Informational at the Post- 1 period. There were no other significant relationships between Change in Evaluation score and with five other levels of concern toward IT integration. This indicates that the participants who were beginning to learn how to integrate ITs into the curriculum self-rated their learning higher at the end of the training compared to those who were more knowledgeable.

The findings indicate that participants who were more concerned internally during the professional development training were more likely to gain more IT knowledge than participants who were less concerned coming into the training. 


\section{Research Question 2 (RQ2)}

RQ2 for this study was: What is the relationship between changes in participants' teaching/learning styles and key factors (Duration of training, Instructional Design, and Evaluation) of Trek-21 professional development model?

Table 4.8

RQ2: Dependent and Independent Variables

RQ2: What is the relationship between changes in participants' teaching/learning styles and key factors (Duration, Instructional Design and Evaluation) of the Trek-21 professional development model?

\begin{tabular}{|c|c|c|}
\hline $\begin{array}{l}\text { Independent } \\
\text { variable }\end{array}$ & Data Sources & Hypothesis \\
\hline $\begin{array}{l}\text { Duration of } \\
\text { Training }\end{array}$ & $\begin{array}{l}\text { Principles of Adult } \\
\text { Learning Scale }\end{array}$ & $\begin{array}{l}\mathrm{H}_{0} \text { : Duration of training does not affect } \\
\text { teaching/learning styles of } \\
\text { participants }\end{array}$ \\
\hline $\begin{array}{l}\text { Instructional } \\
\text { Design }\end{array}$ & $\begin{array}{l}\text { Principles of Adult } \\
\text { Learning Scale }\end{array}$ & $\begin{array}{l}\mathrm{H}_{0} \text { : Instructional Design does not affect } \\
\text { teaching/learning of participants }\end{array}$ \\
\hline Evaluation & $\begin{array}{l}\text { Principles of Adult } \\
\text { Learning Scale }\end{array}$ & $\begin{aligned} \mathrm{H}_{0}: & \text { Evaluation does not affect } \\
& \text { teaching/learning of participants }\end{aligned}$ \\
\hline
\end{tabular}

This question included one dependent variable, the Teaching Style score and three independent variables, Duration of Training, Instructional Design score, and Evaluation score. The dependent variable, Teaching Style, came from the Principals of Adult Learning Scale (PALS) instrument (Range $=0$ to 220). The independent variables are (1) three durations of training (pre and post treatment periods), and (2) two continuous variables Instructional Design score (from the Lesson Sweep instrument, with Range $=0$ to 26), and Evaluation score (from the Final Daily Evaluation questionnaire, with Range $=0$ to 252). The PALS instrument measures the practitioner support of and adherence to collaborative teaching and learning mode and was collected at the pre and post-institute 
periods. The PALS Scores range between 0 and 220 with a mean score being 146 and a standard deviation of 20. Scores above 146 indicate a preference toward learner-centered mode of instruction; scores below 146 show a preference toward a teacher-centered style. RQ2-a asks: What is the relationship between participants' teaching/learning styles and Duration of training, a key factor of the Trek-21 professional development model?

Paired $t$ - tests were computed to investigate the differences in the mean scores between the pre and post-test of the participants' Teaching Styles. The Duration of Training was determined as being the independent variable in this question. Below $t$ values for pre and post-tests are reported in Table 4.9.

Participants' pre-test results were 19 points, below the PALS established mean of 146. This indicated a teacher-centered style of instruction before the participants began the summer institute. Their post-test results were 14 points below the established mean, indicating a significantly slight movement towards weaker teacher-centered mode of instruction. This indicated a significant statistical difference in teaching style toward learner-centered mode of instruction at the end of the professional development.

Table 4.9

Comparison of Teaching Style Before and After Professional Development

\begin{tabular}{cccccc}
\hline Year & $\begin{array}{c}\text { Pre-Test } \\
\text { Mean (SD) }\end{array}$ & $\begin{array}{c}\text { Post-Test } \\
\text { Mean (SD) }\end{array}$ & t-Value & df & $\begin{array}{c}\text { p-value } \\
(2-\text {-tailed) }\end{array}$ \\
\hline 2001 & $127.07(19.80)$ & $132.85(18.35)$ & $3.06^{* *}$ & 27 & .01 \\
\hline$* * p<.01$ & & & & &
\end{tabular}

The significant difference in participants teaching styles from the beginning to the end of the professional training indicates that duration of training was sufficient enough 
to significantly increase participants’ teaching style scores. Duration of training positively influenced participants Teaching Style scores indicating a positive relationship between Teaching styles scores and Duration of training of professional development.

RQ2-b asks: What is the relationship between participants' teaching/learning styles score and Instructional Design, a key factor of the Trek-21 professional development model?

A series of six simple regression analyses was conducted between the pre and post-test to investigate the relationship between teachers’ Teaching Styles and the Instructional Design score. The Instructional Design score came from the Lesson Sweep instrument. Six simple regression analyses were conducted between a dependent variable and an independent variable. Tables 4.10 and 4.11 below present $t$-test values for pre and post tests.

There was no significant relationship between the Pre-Teaching Style score with any of the three independent variables: Pre-Instructional Design score $t(26)=.58, p=$ .57 , Post-Instructional Design score $t(26)=.36, p=.72$, and Change-in-Instructional Design score $t(26)=-.115, p=.91$.

Table 4.10

Trek-21 Participants: Predicting Pre-Teaching Style Scores

\begin{tabular}{lccccc}
\hline & \multicolumn{5}{c}{ Criterion Variable: Pre-Teaching Style Score } \\
\cline { 2 - 6 } Variable & $B$ & SE B & $\beta$ & $t(26)$ & Sign. \\
\hline Pre-Instructional Design Score & .37 & .64 & .12 & .58 & .57 \\
Post-Instructional Design Score & .18 & .50 & .07 & .36 & .72 \\
Change-in-Instructional Design Score & -.07 & .63 & -.02 & -.12 & .91 \\
\hline$* p<.05, * * p<.01, * * * p<.001, \dagger=$ trend $(.05<p<.15)$ & & &
\end{tabular}


Table 4.11

Trek-21 Participants: Predicting Post-Teaching Style Scores

\begin{tabular}{lccccc}
\hline & \multicolumn{5}{c}{ Criterion Variable: Post-Teaching Style Score } \\
\cline { 2 - 6 } Variable & $B$ & $S E B$ & $\beta$ & $t(26)$ & Sign. \\
\hline Pre-Instructional Design Score & .05 & .63 & .02 & .08 & .94 \\
Post- Instructional Design Score & .06 & .49 & .02 & .12 & .91 \\
Change-in-Instructional Design & .04 & .62 & .01 & .07 & .94 \\
\hline
\end{tabular}

$* p<.05, * * p<.01, * * * p<.001,{ }^{\dagger}=$ trend $(.05<p<.15)$

There was no significant relationship between the dependent variable, PostTeaching Style score and any of the three independent variables: Pre-Instructional Design score $t(26)=.08, p=.94$, Post-Instructional Design score $t(26)=.12, p=.91$, and Change-in-Instructional Design score $t(26)=-.07, p=.94$.

The above findings reveal that teachers' teaching styles were independent of the extent to which participants integrate ITs into their web units.

RQ2c-SoC vs. Evaluation: What is the relationship between participants' Teaching Styles score and Evaluation score, a key factor of the Trek-21 professional development model?

A series of nine simple regression analyses was conducted to investigate the relationship between teachers' Teaching Styles and the Evaluation score. The Evaluation score was the independent variable in this question. The Evaluation score comes from the Final Daily Evaluation Questionnaire. Nine simple regression analyses were conducted between the dependent variable and the independent variable. Below, $t$ values for pre and post tests are reported in Table 4.12, 4.13, and 4.14.

There was no significant relationship between the dependent variable, PreTeaching Style score, and any of the three independent variables: Pre-Evaluation score 
$t(26)=-.61, p=.55$, Post-Evaluation score $t(26)=-.29, p=.79$, and Change-in-

Evaluation score $t(26)=.41, p=.69$.

Table 4.12

Trek-21 Participants: Predicting Pre-Teaching Style Scores

\begin{tabular}{lccccc}
\hline & \multicolumn{5}{c}{ Criterion Variable: Pre-Teaching Style Score } \\
\cline { 2 - 6 } Variable & $B$ & $S E B$ & $\beta$ & $t(26)$ & Sign. \\
\hline Pre-Evaluation Score & -.07 & .12 & -.12 & -.61 & 0.55 \\
Post-Evaluation Score & -.04 & .13 & -.06 & -.29 & 0.79 \\
Change-in-Evaluation Score & .06 & .14 & .08 & .41 & 0.69 \\
\hline
\end{tabular}

$* p<.05, * * p<.01, * * * p<.001,^{\dagger}=$ trend $(.05<p<.15)$

There was no significant relationship between the dependent variable, Post-

Teaching Style score, and any of the three independent variables: Pre-Evaluation score $(t(26)=-1.22, p=.23)$, Post-Evaluation score $(t(26)=-1.27, p=.22)$, and Change-inInstructional Design score $(t(26)=.05, p=.96)$.

Table 4.13

Trek-21 Participants: Predicting Post-Teaching Style Scores

\begin{tabular}{lccccc}
\hline & \multicolumn{5}{c}{ Criterion Variable: Post-Teaching Style Score } \\
\cline { 2 - 6 } Predictor Variable & $B$ & SE B & $\beta$ & $t(26)$ & Sign. \\
\hline Pre-Evaluation Score & -.14 & .11 & -.24 & -1.22 & 0.23 \\
Post-Evaluation Score & -.15 & .12 & -.25 & -1.27 & 0.22 \\
$* p<.05, * * p<.01,{ }^{* * *} p<.001,+{ }^{\dagger}=$ trend $(.05<p<.15)$ &
\end{tabular}

There was no significant relationship between the dependent variable, Change-inTeaching/Learning Style score, and the three independent variables: Pre-Evaluation score $(t(26)=-.61, p=.55)$, Post-Evaluation score $(t(26)=-.29, p=.79)$, and Change-inEvaluation score $(t(26)=-.49, p=.63)$. 
Table 4.14

Trek-21 Participants: Predicting Change in Teaching Scores

\begin{tabular}{llcccc}
\hline & \multicolumn{4}{l}{ Criterion Variable: Change in Teaching Style Score } \\
\cline { 2 - 6 } Predictor Variable & $B$ & $S E ~ B$ & $\beta$ & $t(26)$ & Sign. \\
\hline Pre-Evaluation Score & $-7.2 \mathrm{E}-02$ & .12 & -.12 & -.61 & 0.55 \\
Post-Evaluation Score & $-3.6 \mathrm{E}-02$ & .13 & -.06 & -.29 & 0.79 \\
Change-in-Evaluation Score & $-5.0 \mathrm{E}-02$ & .10 & -.10 & -.49 & 0.63 \\
\hline
\end{tabular}

$* p<.05, * * p<.01, * * * p<.001,{ }^{\dagger}=$ trend $(.05<p<.15)$

Since there was no significant relationship between Teaching Style (PALS) score and Evaluation score this means that the amount of IT knowledge the participants gained during the professional development was not related to their teaching styles, indicating that integration of new instructional technology tools into web units did not change the way these teachers teach.

\section{Summary RQ2}

PALS vs.Duration. After a $t$-test was used to investigate the differences between PALS score means of the treatment periods over the course of the training, and to trace the correlation between the independent variable and the dependent variable, the results (Table 4.9) indicate a significant statistical difference in teaching style slightly toward learner-centered at the end of the professional development.

PALS vs.Instructional Design. The independent variables Instructional Design and Evaluation were regressed against the Teaching Style scores, the dependent variable.

(i) When PALS Score were regressed against Pre-Instructional Design Score, there was no significant relationship between Pre-instructional Design score and Principle of Adult learning scores at either the pre-treatment stage, or the post-treatment stage. 
(ii) When PALS Score were regressed against Post-Instructional Design Score, there was no significant relationship between Post-instructional Design score and Principle of Adult learning scores at either the pre-treatment stage, or the post-treatment stage. When PALS Score were regressed against Post-Instructional Design Score there was no significant relationship between Change-in-instructional Design score and Principle of Adult learning scores at either the pretreatment stage, or the post- 1 treatment stage.

The findings therefore, reveal that teachers' teaching styles were independent of the extent to which participants integrate ITs into their web units.

PALS vs. Evaluation. When each of the independent variables (Pre-, Post-, and Change-in) Evaluation scores was regressed against the Teaching Styles score, the dependent variable as displayed in Table 4.14. No significant relationship was found between any of the Evaluation score variables and Teaching Styles score. The findings indicate that the amount of IT knowledge the participants gained during the professional development was not related to their teaching styles, indicating that integration of new instructional technology tools into web units did not change the way these teachers teach. 


\section{Research Question 3 (RQ3).}

RQ3 addressed in this study was: What is the relationship between changes in teacher level of computer use and key factors (Duration of training, Instructional Design and Evaluation) of Trek-21 professional development model? In answering this question, teacher responses to the Survey of Computer Use Questionnaire were collected for the pre- and post-institute periods. The Survey of Computer Use was used to measure teacher's level of computer use before training (pre-test) and six months after training (Post-test). Its score was used as the dependent variable for this question. The Duration of the Training, Computer Use score and Evaluation score were the three factors used as the independent dependent variables.

\section{Table 4.15}

RQ3: Dependent and Independent Variables

RQ3: What is the relationship between changes in level of computer use and key factors (Duration, Instructional Design and Evaluation) of the Trek-21 professional development model?

\begin{tabular}{|c|c|c|}
\hline $\begin{array}{l}\text { Independent } \\
\text { variable }\end{array}$ & Data Sources & Hypothesis \\
\hline $\begin{array}{l}\text { Duration of } \\
\text { Training }\end{array}$ & Survey of Computer Use & $\begin{array}{l}\mathrm{H}_{0} \text { : Duration of training does not affect participants' } \\
\text { level of computer use }\end{array}$ \\
\hline $\begin{array}{l}\text { Instructional } \\
\text { Design }\end{array}$ & Survey of Computer Use & $\begin{array}{l}\mathrm{H}_{0} \text { : Instructional Design does not affect participants } \\
\text { level of computer use }\end{array}$ \\
\hline Evaluation & Survey of Computer Use & $\begin{array}{l}\mathrm{H}_{0} \text { : Evaluation does not affect participants' level of } \\
\text { computer use }\end{array}$ \\
\hline
\end{tabular}


RQ3a - Level of Computer Use vs. Duration: What is the relationship between participants' changes in teacher's level of computer use and Duration of training, a key factor of the Trek-21 professional development model?

Paired $t$-tests were computed to investigate the differences in the mean scores between the pre and post-test of the Level of Computer Use. The Duration of Training was determined as being the independent variable in this question. Below, $t$ values for pre, post-tests are reported in Table 4.16.

Mean scores were computed for each period (Pre- and Post-test) on participants Computer Use scores. Participants' pre- and post-test mean scores were compared using paired t-tests and analyzed for significant at an alpha level of .05 (Table 4.16). The results indicate a significant increase in the participants' Level of Computer Use score from the beginning (pre) to the end of the Trek 21 training (post). Pre-test mean was 43.26 $(S D=15.87)$ and post-test mean was $54.48(S D=16.49)$ with $t(26)=-5.11, p<.05$ indicating increased Level of Computer Use.

Table 4.16

t-Value for Differences between Treatment Periods (Pre and Post) on Level of Computer Use

\begin{tabular}{|c|c|c|c|c|c|}
\hline & $\begin{array}{c}\text { Pre-Test } \\
\text { Mean }(S D) \\
\end{array}$ & $\begin{array}{c}\text { Post-Test } \\
\text { Mean }(S D) \\
\end{array}$ & $t$-Value & $d f$ & $\begin{array}{c}p \text {-value } \\
\text { (2-tailed) }\end{array}$ \\
\hline $\begin{array}{l}\text { Computer } \\
\text { Use Score }\end{array}$ & 43.26 (15.87) & 54.48 (16.49) & $-5.11 * *$ & 26 & .01 \\
\hline
\end{tabular}

Table 4.16 indicates the $t$-test value that was computed to investigate the differences between means of the treatment periods based on the scores of participants' Level of Computer Use. It is noted from the table that there was a significant statistical difference in the Level of Computer Use score from the beginning of the training to the 
end of the Trek-21 professional development. Therefore, Trek-21 professional development model of training was effective in improving participants' level of computer use and skills.

$R Q 3 b$ - Level of Computer Use vs. Instructional Design: What is the relationship between participants' changes in teacher level of computer use score and Instructional Design score, a key factor of the Trek-21 professional development model?

A series of nine simple regression analyses was conducted between the pre and post-test to investigate the relationship between teachers’ Level of Computer Use score and the Instructional Design score. The Instructional Design score came from the Lesson Sweep instrument. Nine regression analyses were calculated between a dependent variable and an independent variable. Below $t$ values for pre and post tests are reported in Table 4.17, 4.18, and 4.19.

In Table 4.14 below, the regression analyses indicated $p$-values that were greater than alpha $=.05$ for both the pretest and posttest. Therefore, there was no significant relationship between the participant's Pre-Computer Use score with any of the three independent variables: Pre-Instructional Design score $(t(26)=-.43, p=.67)$, PostInstructional Design score $(t(26)=.83, p=.42)$, and Change-in-Instructional Design score $(t(26)=-1.51, p=.14)$. 
Table 4.17

Trek-21 Participants: Predicting Pre-Level of Computer Use Scores

\begin{tabular}{llllll}
\hline & \multicolumn{5}{c}{ Criterion Variable: Pre-Level of Computer Use Score } \\
\cline { 2 - 6 } Variable & $B$ & SE B & $\beta$ & $t(26)$ & Sign. \\
\hline Pre-Instructional Design Score & -.24 & .54 & -.07 & -.43 & .67 \\
Post- Instructional Design Score & .35 & .42 & .16 & .83 & .42 \\
Change-in-Instr. Design Score & .77 & .51 & .29 & 1.51 & .14 \\
\hline$* p<.05,{ }^{*} p<.01, * * * p<.001,{ }^{\dagger}=$ trend $(.05<p<.15)$ &
\end{tabular}

In Table 4.18, the Post-Computer Use score was regressed against the three scores of Instructional Design (Pre, Post, and Change). No significant relationships were found against each one of the independent variables: Pre-Instructional Design score $(t(26)=$ 0.25, $p=.81)$, Post-Instructional Design score $(t(26)=1.51, p=.14)$, and Change-inInstructional Design score $(t(26)=1.65, p=.11)$.

Table 4.18

Trek-21 Participants: Predicting Post-Level Computer Use Scores

\begin{tabular}{lccccc}
\hline & \multicolumn{5}{c}{ Criterion Variable: Post-Level of Computer Use Score } \\
\cline { 2 - 6 } Variable & $B$ & $S E ~ B$ & $\beta$ & $t(26)$ & Sign. \\
\hline Pre-Instructional Design Score & .14 & .57 & .05 & .25 & .81 \\
Post- Instructional Design Score & .64 & .43 & .29 & $1.51 \dagger$ & .14 \\
Change-in-Instructional Design Score .87 & .53 & .31 & $1.65 \dagger$ & .11 \\
\hline
\end{tabular}

$* p<.05,{ }^{* *} p<.01,{ }^{* * *} p<.001, \dagger=$ trend $(.05<p<.15)$

Table 4.19 shows the regression results between the Change-in-Computer Use score was regressed against the three scores of Instructional Design (Pre, Post, and Change). There was no significant relationship found when the dependent variable Change-in-Computer Use score was regressed against the independent variables: Pre- 
Instructional Design score, $t(26)=1.06, p=.30)$, Post-Instructional Design score, $t(26)=$ $.60, p=.56$, and Change-in-Instructional Design score, $t(26)=-.27, p=.79$.

Table 4.19

Trek-21 Participants: Predicting Change in Level Computer Use Scores

\begin{tabular}{|c|c|c|c|c|c|}
\hline \multirow[b]{2}{*}{ Variable } & \multicolumn{5}{|c|}{$\begin{array}{l}\text { Criterion Variable: Change-in Level of Computer Use } \\
\text { Score }\end{array}$} \\
\hline & $B$ & $S E B$ & $\beta$ & $t(26)$ & Sign. \\
\hline Pre-Instructional Design Score & 1.29 & 1.22 & .21 & 1.06 & .30 \\
\hline Post- Instructional Design Score & .58 & .978 & .12 & .60 & .56 \\
\hline Change-in-Instructional Design Score & -.33 & 1.22 & -.05 & -.27 & .79 \\
\hline
\end{tabular}

Therefore, from the findings above, it can be concluded that participants’ instructional design (extent of IT integration) was not associated with their level of computer use and skills.

$R Q 3 c$ - Level of Computer vs. Evaluation: What is the relationship between participants' changes in teacher level of computer use and participants' Evaluation score, a key factor of the Trek-21 professional development model?

A series of nine simple regression analyses was conducted to investigate the relationship between teachers’ Level of Computer Use score and the Evaluation score. The Evaluation score was the independent variable in this question. The Evaluation score comes from the Final Daily Evaluation Questionnaire. Nine simple regression analyses were conducted between the dependent variable and the independent variable. Below, $t$ values for pre and post tests are reported in Table 4.20, 4.21, and 4.22.

When the dependent variable, Pre-Level of Computer, was regressed against the three independent variables of the Evaluation score, their $p$-values were less than alpha = 
.05. The results indicated a positive significant relationship between the dependent variable Pre-Computer Use score and Pre-Evaluation score, $t(26)=7.64, p<.01$ and Post-Evaluation score, $t(26)=4.71, p<.01$. There emerged a significant negative relationship between Pre-Computer Use score and Change-in-Evaluation score, $t(26)=$ 3.51, $p<.01$ (Table 4.20).

Table 4.20

Trek-21 Participants: Predicting Pre-Level of Computer Use Scores

\begin{tabular}{lccccc}
\hline & \multicolumn{5}{c}{ Criterion Variable: Pre-Computer Use Score } \\
\cline { 2 - 6 } Variable & $B$ & $S E B$ & $\beta$ & $t$ & Sign. \\
\hline Pre-Evaluation Score & .42 & .06 & .84 & $7.64^{* * *}$ & .01 \\
Post-Evaluation Score & .39 & .08 & .69 & $4.71^{* *}$ & .01 \\
Change-in-Evaluation Score & -.20 & .06 & -.58 & $-3.51^{* *}$ & .01 \\
\hline
\end{tabular}

${ }^{*} p<.05,{ }^{* *} p<.01,{ }^{* * *} p<.001,{ }^{\dagger}=$ trend $(.05<p<.15)$

When the dependent variable, Post-Level of Computer Use, was regressed against the three independent variables of the Evaluation score, two of the analyses had $p$-values that were less than significant alpha level of .05. The results indicated a significant positive relationship between the dependent variable Post-Computer Use score and PreEvaluation score, $t(26)=4.05, p<.01$ and Post-Evaluation score, $t(26)=3.05, p<.01$. There was no relationship between Pre-Computer Use score and Change-in-Evaluation score, $t(26)=-.87, p=.39$ (Table 4.21). 
Table 4.21

Trek-21 Participants: Predicting Post-Level of Computer Use Scores

\begin{tabular}{lccccc}
\hline & \multicolumn{5}{c}{ Criterion Variable: Post-Computer Use Score } \\
\cline { 2 - 6 } Variable & $B$ & SE B & $\beta$ & $t$ & Sign. \\
\hline Pre-Evaluation Score & .33 & .08 & .63 & $4.05^{* *}$ & .01 \\
Post-Evaluation Score & .39 & .08 & .69 & $3.05^{* *}$ & .01 \\
Change-in-Evaluation Score & -.11 & .12 & -.17 & -.87 & .39 \\
\hline
\end{tabular}

$* p<.05,{ }^{* *} p<.01, * * * p<.001,{ }^{\dagger}=$ trend $(.05<p<.15)$

When the dependent variable, Change-in-Level of Computer Use, was regressed against the three independent variables of the Evaluation score, their $p$-values were compared to significant alpha level of .05. The results indicated a significant negative relationship between the dependent variable Change-in-Computer Use score and PreEvaluation score, $t(26)=-2.60, p<.01$ and Post-Evaluation score, $t(26)=-2.70, p<.01$. There was no relationship between Pre-Computer Use score and Change-in-Evaluation score, $t(26)=.11, p=.91$ (Table 4.22).

Table 4.22

Trek-21 Participants: Predicting Change-in-Level Computer Use Scores

\begin{tabular}{lccccc}
\hline & \multicolumn{5}{c}{ Criterion Variable: Change-in-Computer Use Score } \\
\cline { 2 - 6 } Variable & $B$ & SE B & $\beta$ & $t$ & Sign. \\
\hline Pre-Evaluation Score & -.53 & .20 & -.46 & $-2.60 *$ & .02 \\
Post-Evaluation Score & -.58 & .22 & -.48 & $-2.70 *$ & .01 \\
Change-in-Evaluation Score & .03 & .27 & .02 & .11 & .91 \\
$* p<.05, * * p<.01, * * * p<.001,{ }^{\dagger}=$ trend $(.05<p<.15)$ & &
\end{tabular}

In the regression model containing the Pre-Evaluation as the independent variables, the slope for Pre-Evaluation was negative and significant $(t(26)=-2.60, p<$ .05) in both cases, indicating that the higher the Pre-Evaluation score, the smaller the 
Change-in-Level of Computer Use score. In the regression model containing PostEvaluation score as the independent variable, the slope for the Post-Evaluation was negative and significant $(t(26)=-2.70, p<.05)$, indicating that the higher the PostEvaluation score the smaller the Change in Level of Computer Use score.

The simple regression model containing Change-in Evaluation as the independent variable, the slope for the Change-in-Evaluation was positive, but not significant, indicating that there was no significant relationship between the Change-in Evaluation and change-in Level Computer Use score.

The results displayed in Table 4.22, also indicate that the Pre-Evaluation score and Post-Evaluation both have significant relationships with Change-in level of Computer Use scores after participants attended Trek-21 professional development program.

The findings above indicate that Evaluation was a key factor in relation to participants' computer use and skills. Participants' IT knowledge was positively related to the level of their computer use and skills.

\section{Summary of RQ3}

Level of Computer Use versus Duration. When mean scores were computed for each period (Pre- and Post-test) on participants' computer use scores, the results (Table 4.16) indicated a significant statistical difference in the level of computer use score from the beginning of the training to the end of the Trek-21 professional development. The results indicate a significant increase in the participants' Level of Computer Use score from the beginning (pre) to the end of the Trek 21 training (post)Statistically significant results were found for participants' Level of Computer Use (pre-training to post-training). 
Pre-test mean was $43.26(S D=15.87)$ and posttest mean was $54.48(S D=16.49)$ with $t(26)=-5.10, p<.05$ indicating increased Level of Computer Use.

Therefore, the significant increase in the level of computer use from the beginning to the end of training indicates that Duration of training was sufficient enough to effectively allow participants to gain computer skills during training. The findings also depicts a positive relationship between participants’ Level of Computer Use and Duration of the professional development training.

Level of Computer versus Instructional Design. The independent variable, Instructional Design, was regressed against the Level of Computer Use score, the dependent variable. The results indicated that there was no significant relationship between Instructional Design score and participants’ Level of Computer Use.

No significant relationship was also found between Pre-Computer Use scores and Change-in-instructional Design. Again, no significant relationship was found between Change-in Computer Use scores and percentage Change-in-Instructional Design.

Therefore, from the findings, it can be concluded that participants’ instructional design (extent of IT integration) was not associated with their level of computer use and skills.

Level of Computer Use versus Evaluation. When Computer Use scores were regressed against Evaluation scores, there was a significant positive relationship between Pre-Evaluation score and Computer Use scores at both the pre-treatment and the posttreatment stages. Those participants with higher Pre-Evaluation scores also had higher Computer Use scores at both pretest and posttest points. Higher Pre-Evaluation scores were related to higher computer scores before and after the Trek-21 training. 
A regression analysis was conducted between the Change-in-Computer Use score against the Pre-Evaluation and the Change-in-Computer score against the PostEvaluation score. A significant negative relationship was found between the two variables at both pre and post-test scores. The more the participant knew about IT integration in the beginning of the training, the smaller the changes they had in their computer use at the end of the training. The same relationship was observed between the Post-Evaluation scores and Change-in-Computer use. The findings indicate that those participants who knew less about IT integration reported more gains in their level of computer use and skills by the end of the training than those who knew more about IT integration. 


\section{Research Question 4 (RQ4)}

RQ4 addressed in this study was: What is the relationship between changes in teachers' extent of instructional technologies (ITs) integration into their units and key factors (Duration and Evaluation) of Trek-21 professional development model? In answering this question, data obtained from the Indicators of Instructional Change Instrument - Random Lesson Sweep instrument were scored for the pre- and postinstitute periods by Trek-21 teacher-leaders and evaluators. The purpose of the instrument was to assess various indicators of instructional change by comparing elements of the pre- and post-institute participants' units. These indicators included active student engagement, increased integration of instructional technologies, and the inclusion of instructional strategies variables. The instrument (Appendix E) evaluates three main areas, namely, instructional procedures with 7 items, instructional strategies with 13 items, and IT integration with 13 items. Duration of the training and evaluation score data were used as independent variables.

Table 4.23

RQ4: Dependent and Independent Variables

RQ4: What is the relationship between changes in teachers' extent of instructional technologies (ITs) integration into their units and key factors (Duration and Evaluation) of the Trek-21 professional development model?

\begin{tabular}{|c|c|c|}
\hline $\begin{array}{l}\text { Independent } \\
\text { variable }\end{array}$ & Data Sources & Hypothesis \\
\hline $\begin{array}{l}\text { Duration of } \\
\text { Training }\end{array}$ & $\begin{array}{c}\text { Indicators of } \\
\text { Instructional Change }\end{array}$ & $\begin{array}{l}\mathrm{H}_{0} \text { : Duration of training does not affect participants' } \\
\text { extent of ITs in their units }\end{array}$ \\
\hline Evaluation & $\begin{array}{c}\text { Indicators of } \\
\text { Instructional Change } \\
\end{array}$ & $\begin{array}{l}\mathrm{H}_{0} \text { : Evaluation does not affect participants' extent of ITs } \\
\text { in their units }\end{array}$ \\
\hline
\end{tabular}


RQ4a- IT Integration vs. Duration: What is the relationship between participants' extent of instructional technologies (IT) integration and Duration of training, a key factor of the Trek-21 professional development model?

Paired $t$ tests were computed to investigate the differences in the mean scores between the pre and post-test of IT Integration score. The Duration of Training was determined as being the independent variable in this question. $t$ values for pre, post-tests are reported in Table 4.24 .

Mean scores were computed for each period (Pre- and Post-test) on participants' IT Integration scores. Participants' pre- and post-test mean scores were compared using paired t-tests and analyzed for significant at an alpha level of .05. The results (Table 4.24) indicate a significant statistical increase in the teachers' extent of IT integration score from the beginning of the training to the end of the Trek-21 professional development. The analysis found participants' scores increased significantly. Pre-test mean was $14.00(S D=5.81)$ and posttest mean was $20.70(S D=7.43)$ with $t(26)=-5.88$, $p=.00$, indicating teachers' increased extent of instructional technologies use from pre to post period of the training.

Table 4.24

Comparison of IT integration Score Before and After Professional Development

\begin{tabular}{|c|c|c|c|c|c|}
\hline & $\begin{array}{c}\text { Pre-Test } \\
\text { Mean }(S D) \\
\end{array}$ & $\begin{array}{c}\text { Post-Test } \\
\text { Mean }(S D) \\
\end{array}$ & $t$-Value & $d f$ & $\begin{array}{c}p \text {-value } \\
\text { (2-tailed) }\end{array}$ \\
\hline IT Integration & $14.00(5.81)$ & $20.70(7.43)$ & $-5.88 * *$ & 26 & .01 \\
\hline
\end{tabular}


The t-test for the pre- to post-data $(t(26)=-5.88, p<.05)$ indicated teachers had a statistically significant increase in extent of instructional technologies integration over the period of training. Therefore, the Trek-21 professional development model was effective in helping the participants to integrate more ITs into their web units and that the duration of the training was sufficient enough to allow the integration to take place.

RQ4b- IT Integration vs. Evaluation: What is the relationship between participants' extent of instructional technologies (IT) Integration and participants' Evaluation score, a key factor of the Trek-21 professional development model?

A set of three regression analyses were conducted to investigate the relationship between teachers' change in IT Integration scores and the Evaluation scores. The Evaluation score was determined as being the independent variable in this question. The Evaluation score comes from the Final Daily Evaluation Questionnaire. Three regression analyses were run between the dependent variable and each of the three independent variables (Pre-, Post-, Change-in-Evaluation scores). Below, $t$ values for the three regression analyses are reported in Table 4.25.

There was no significant relationship between the dependent variable, Change-inIT integration score and Pre-Evaluation score $t(26)=1.56, p=.13$. However, there was a significant positive relationship between Post-Evaluation score and Change-in-IT Integration score, $t(26)=2.13, p=.04$. No significant relationship did emerge between Change-in-Evaluation score and Change-in-IT Integration score, $t(26)=.40, p=.70$. 
Table 4.25

Trek-21 Participants: Predicting Change in Instructional Design Score

\begin{tabular}{lccccc}
\hline & \multicolumn{5}{c}{ Criterion Variable: Change in Instructional Design Score } \\
\cline { 2 - 6 } Variable & $B$ & SE B & $\beta$ & $t(26)$ & Sign. \\
\hline Pre-Evaluation Score & .06 & .04 & .30 & $1.56 \dagger$ & .13 \\
Post-Evaluation Score & .08 & .04 & .39 & $2.13^{*}$ & .04 \\
Change-in-Evaluation Score & .02 & .04 & .08 & 0.40 & .70 \\
$* p<.05, * * p<.01, * * * p<.001,{ }^{\dagger}=$ & trend $(.05<p<.15)$
\end{tabular}

The relationship between change in IT Integration and the change in the evaluation score was positive, although not significant $(t(26)=.40, p=0.70)$. However, the post-evaluation score and the change-in-IT Integration score relationship was determined to be a significant positive relationship $(t(26)=2.13, p=0.04)$. High increases in instructional design score were associated with higher post-evaluation scores and small increases in instructional design were associated with small post-evaluation scores.

The positive relationship findings between change in IT integration and IT knowledge indicate that the more teachers know about IT tools the more likely they will integrate these tools into their web units.

\section{Summary of RQ4}

Instructional Design Score vs. Duration. Participants’ pre- and post-test mean scores were compared using paired t-tests and analyzed for significant at an alpha level of .05 (Table 4.21). Statistically significant results were found for participants' extent of ITs integration into their units and duration of the training. Analysis of IT integration scores found participants’ scores increased significantly. Pre-test mean was $14.00(S D=5.81)$ 
and posttest mean was $20.70(S D=7.43)$ with $t(26)=-5.88, p<.01$, indicating teachers' increased extent of instructional technologies use.

Therefore, the Trek-21 professional development model was effective in helping the participants to integrate more ITs into their web units and that the duration of the training was sufficient enough to allow the integration to take place.

Instructional Design Score vs. Evaluation. The relationship between change-in Instructional Design (Extent of IT Integration) score and the change-in the Evaluation (IT Knowledge) score was generally negative, although not significant. However, the postevaluation scores and the change-in instructional design relationship was a significant positive relationship. Higher increases in instructional design were associated with higher post-evaluation scores and small increases in instructional design were associated with small post-evaluation scores. The relationship between IT Integration score and PostEvaluation score was generally positive and significant.

The positive relationship findings between change-in IT integration and IT knowledge indicate that the more teachers know about IT tools the more likely they will integrate these tools into their web units. 


\section{Research Question 5 (RQ5)}

RQ5 addressed in this study was: What is the relationship between changes in teachers’ instructional technologies (ITs) knowledge and key factors (Duration and Instructional Design) of Trek-21 professional development model? In answering this question, teacher responses to the Final Daily Training Evaluation Questionnaire were collected. These responses described participants’ sustained achievement of training objectives and reflect the knowledge gained through professional development. Final Daily Training Evaluations were administered on the final day (July 12, 2002) of the Trek 21 Summer institute (Appendix D). The final daily training instrument combined 24 Likert-scale, forced-choice items assessing participants’ durability of daily training objectives. The change in the evaluation score before and after training was computed to provide the dependent variable, the Evaluation Score, which will be called the IT

Knowledge score for the purpose of this question. Duration of the training and

Instructional Design score were the two independent variables.

Table 4.26

RQ5: Dependent and Independent Variables

RQ.5: What is the relationship between changes in participants' IT knowledge and key factors (Duration and Instructional Design) of the Trek-21 professional development model?

\begin{tabular}{|c|c|c|}
\hline Independent variable & Data Sources & Hypothesis \\
\hline Duration of Training & Final Daily Evaluation & $\begin{array}{l}\mathrm{H}_{0} \text { : Duration of training does not affect } \\
\text { participants' change in IT knowledge }\end{array}$ \\
\hline Instructional Design & Final Daily Evaluation & $\begin{array}{l}\mathrm{H}_{0} \text { : Instructional Design does not affect } \\
\text { participants' change in IT knowledge }\end{array}$ \\
\hline
\end{tabular}


RQ5a - IT Knowledge vs. Duration: What is the relationship between

participants' Instructional Technologies (IT) Knowledge and Duration of training, a key factor of the Trek-21 professional development model?

Paired $t$-tests were computed to investigate the differences in the mean scores between the pre and post-test of IT Knowledge score. The Duration of Training was determined as being the independent variable in this question. Below $t$ values for pre, post-tests are reported in Table 4.27.

Mean scores were computed for each period (Pre- and Post-test) on participants IT Knowledge scores. Participants’ pre- and post-test mean scores were compared using paired t-tests and analyzed for significant at an alpha level of .05.

Table 4.27

Comparison of Participants' IT Knowledge Before and After Professional Development

\begin{tabular}{|c|c|c|c|c|c|}
\hline & $\begin{array}{c}\text { Pre-Test } \\
\text { Mean }(S D) \\
\end{array}$ & $\begin{array}{c}\text { Post-Test } \\
\text { Mean }(S D) \\
\end{array}$ & $t$-Value & $d f$ & $\begin{array}{c}\text { p-value } \\
\text { (2-tailed) }\end{array}$ \\
\hline IT knowledge & $98.44(31.75)$ & $155.96(29.56)$ & $-11.17 * * *$ & 26 & .01 \\
\hline
\end{tabular}

The results (Table 4.27) indicate a significant statistical increase in the teachers' extent of IT Knowledge score from the beginning of the training to the end of the Trek-21 professional development. The analysis found participants’ IT knowledge scores increased significantly. After the analysis was run on the participants’ IT Knowledge scores, participants’ scores increased significantly (Pre-test mean $=98.44$, Post-test mean $=155.96, t(26)=-11.17 p=.01)$ in the post-test analysis as compared to the scores prior to Trek-21 training. Therefore, teachers' IT knowledge increased significantly from the Pre period to Post period of the training as a result of an effective professional development 
program indicating once more that Duration of training was sufficient enough to allow the increase in participants IT knowledge.

RQ5b - IT Knowledge vs. Instructional Design: What is the relationship between participants' Instructional Technologies (IT) Knowledge and Instructional Design score, a key factor of the Trek-21 professional development model?

A set of three regression analyses were conducted to investigate the relationship between teachers’ Change in IT Knowledge score (the dependent variable) and the IT Integration score (independent variable). The IT Integration score came from the Lesson Sweep instrument. Three regression analyses were run between the dependent variable and an independent variable. Below, $t$ values for pre and post tests are reported in Table 4.28 .

There was no significant relationship between Change-in-IT Knowledge score and three independent variables: Pre-Instructional Design score $t(26)=.40, p=.70$, Post-Instructional Design score $t(26)=.28, p=.79$, and Change-in-Instructional Design score $t(26)=-.051, p=.960$.

Table 4.28

Trek-21 Participants: Predicting Change in Evaluation Score

\begin{tabular}{lccccc}
\hline & \multicolumn{5}{c}{ Criterion Variable: Change in Evaluation Score } \\
\cline { 2 - 6 } Variable & $B$ & $S E B$ & $\beta$ & $t(26)$ & Sign. \\
\hline Pre-Instructional Design Score & .36 & .90 & .08 & .40 & .70 \\
Post-Instructional Design Score & .20 & .72 & .06 & .28 & .79 \\
Change-in- Instructional Design Score & -.04 & .92 & -.01 & -.05 & .96 \\
\hline$* p<.05,{ }^{* *} p<.01,{ }^{* * *} p<.001,{ }^{\dagger}=$ trend $(.05<p<.15)$ & & &
\end{tabular}


The above findings indicate that participants’ IT knowledge was not associated with the way participants designed instruction. Trek-21 participants were trained not to change their instructional design, but to improve on it.

\section{Summary of RQ5}

Evaluation Score vs. Duration. After mean scores were computed for each period (Pre- and Post-test) on participants IT Knowledge scores (Evaluation score), the results indicated that participants’ post-test mean (155.96) scores increased significantly after training from the pre-test means (98.44). As illustrated in Table 4.27, statistically significant results were found for participants' IT knowledge score and duration of the training (pre-training to post-training) for $p=.01(p<.05)$. Pretest mean was 98.44 (31.75) and posttest mean was 155.96 (29.56) with $t(26)=-11.172$, indicating teachers’ increased knowledge of instructional technologies.

Evaluation Score vs. Instructional Design Score. When IT Knowledge score was regressed against IT Integration score, no significant relationship was found between any of the three independent variables (Pre, Post- and Change-in-IT Integration) scores and Change-in-IT Knowledge score. 


\section{Research Question 6 (RQ6)}

RQ6 asks: What key factors (Duration, Instructional Design, and Evaluation) of the Trek-21 Professional Development are crucial to facilitating changes in P-12 participants’ instructional practices (adoption) with respect to integration of ITs? In answering this question, Bivariate correlations were computed to investigate those factors (Duration, Instructional Design, and Evaluation) discussed in the earlier research questions RQ1, RQ2, RQ3, RQ4, and RQ5. The correlation results are presented in Tables 4.29, 4.30, 4.31, 4.32, 4.33 and 4.34.

\section{Duration of Training.}

The results from research questions RQ1a, RQ2a, RQ3a, RQ4a, and RQ5a demonstrated that Duration of Training is a key factor of the professional development training. Duration of the Training affected the mean scores of the following dependent variables significantly: the SoC scores, Teaching Styles scores, Level of Computer Use score, Instructional Design, and Evaluation (IT Knowledge). Duration of Training was significant in relation to Informational $(t(26)=8.07, p<.01)$, Personal $(t(26)=4.51, p$ $<.01)$, and Management $(t(26)=2.31, p<.01)$ between pre and post- 1 tests. Duration of Training was significant in relation to Informational $(t(26)=-2.27, p<.01)$ and Refocusing $(t(26)=-3.79, p<.01)$ between post-1 and post-2. The significance between each of the five dependent variables and the independent variable yielded the following $t$ values: Teaching Styles $(t(26)=3.06, p<.01)$, Level of Computer Use $(t(26)=-5.11, p$ $<.01)$, Instructional Design $(t(26)=-5.88, p<.01)$, and IT Knowledge $(t(26)=-11.17, p$ $<.01)$. 
The significant changes in the five Dependent Variables in relation to Duration of Training indicated that the length of time that the Trek-21 participants spent designing and implementing their web-based units was effective. Given the cycle of the professional development that lasted 12 months, participants increased their knowledge about the ITs, the ways in which they implemented ITs in their classrooms, and their teaching styles.

Instructional Design (Extent of IT Knowledge).

The Instructional Design score was significantly correlated with three of the SoC scores: post-1 Consequences $(r=.55, p<.01)$, post-1 Refocusing $(r=.61, p<.01)$, and post-2 Informational $(r=.41, p<.05)$. The Instructional Design was also correlated with post Evaluation score $(r=.40, p<.05)$. All the three significant relationships ranked as moderate correlations $(.39<r<.70)$. This means participants' extent of IT integration increased following the training. These significant scores are presented in Table 4.29. Table 4.29

Bivariate Correlations Between Stages of Concern and Instructional Design.

\begin{tabular}{|c|c|c|c|}
\hline Independent Variable & Dependent Variable & $\begin{array}{c}\text { SoC score by } \\
r\end{array}$ & $\begin{array}{c}p- \\
\text { value }\end{array}$ \\
\hline Change in Instructional & Pre-Consequences & & \\
\hline \multirow[t]{5}{*}{ Design } & Concerns & $.40 *$ & .04 \\
\hline & Post1-Consequences & & \\
\hline & $\begin{array}{c}\text { Concerns } \\
\text { Post1-Refocusing }\end{array}$ & $.55^{* *}$ & .01 \\
\hline & $\begin{array}{c}\text { Concerns } \\
\text { Post2-Informational }\end{array}$ & $.61^{* *}$ & .01 \\
\hline & Concerns & $.41 *$ & .04 \\
\hline
\end{tabular}

$r=$ Pearson Correlation.

${ }^{*} p<.05,{ }^{* *} p<.01, * * * p<.001,{ }^{\dagger}=$ trend $(.05<p<.15)$

Table 4.29 indicates the value of the Pearson correlation between the Stages of Concern score and the Change-in-Instructional Design score. It is noted that there was a 
positive moderate correlation between the Consequences concern score and participants' Instructional Design score $(r=.40)$ at the pre-test, and at the post1-test $(\mathrm{r}=.55)$; at the post-1 period between Consequences concern score $(r=.55)$, Refocusing concerns score $(r=.61)$ and Change-in-Instructional Design score; and at the post-2test between Informational concerns $(r=.41)$ and Change-in-Instructional Design score.

Table 4.30

Bivariate Correlations between Teaching/Learning Styles (PALS) Score and Instructional Design score

\begin{tabular}{|c|c|c|c|}
\hline Independent Variable & Dependent Variable & $r$ & $p$-value \\
\hline Pre-Instructional Design & Pre-PALS score & .12 & .57 \\
\hline Post-Instructional Design & Pre-PALS score & .07 & .72 \\
\hline Pre-Instructional Design & Post-PALS score & .02 & .94 \\
\hline Post-Instructional Design & Post-PALS score & .02 & .91 \\
\hline Pre-Instructional Design & Change in PALS Score & -.14 & .50 \\
\hline Post-Instructional Design & Change in PALS Score & -.07 & .74 \\
\hline Change in Instructional Design & Change in PALS Score & .05 & .80 \\
\hline
\end{tabular}

Table 4.30 indicates the value of the Pearson correlation between Teaching Styles score and the Instructional Design score. The Pearson correlation coefficient revealed no statistically significant (at alpha $=.05$ ) relationship between participants' Teaching Styles score and Instructional Design score. This finding was not surprising based on the nature of the Principles of Adult Learning Scale (PALS) questionnaire, which recorded teachers teaching styles as opposed to the Instructional Design elements with regards to teachers' units developed during the training. 
Table 4.31

Bivariate Correlations between Level of Computer of Use and Instructional Design

\begin{tabular}{llcc}
\hline \multicolumn{1}{c}{ Independent Variable } & Dependent Variable & $\begin{array}{l}\text { Computer Use Score } \\
\text { by } r\end{array}$ & p-value \\
\hline Pre-Instructional Design & Pre-Computer Use & $.40^{*}$ & .04 \\
Pre-Instructional Design & Post-Computer Use & .05 & .81 \\
Post-Instructional Design & Pre-Computer Use & .16 & .42 \\
Post-Instructional Design & Post-Computer Use & .29 & .14 \\
Change in Instructional Design & Change in Computer Use & -.14 & .50 \\
\hline
\end{tabular}

$r=$ Pearson Correlation

$* p<.05, * * p<.01, * * * p<.001, \dagger=$ trend $(.05<p<.15)$

Stages Of Concern vs. Instructional Design. Instructional Design was found to be positively related to Consequences concerns and Refocusing concerns at the during the 4week period. At the Post-2 period, Instructional design was found to be positively related to Informational Concerns.

Teaching Styles versus Instructional Design. There was no significant relationship between teachers Extent of IT integration and Teacher's Teaching Styles.

Computer Use vs. Instructional Design. There was no significant relationship found between teachers’ level of computer use and Extent of IT integration.

Evaluation vs. Instructional Design. There was a significant positive relationship between change in IT integration and IT knowledge at the end of the training. The higher the evaluation score, the larger the change in IT integration at the end of training. Change in IT integration was positively related to IT knowledge.

This makes sense because participants with more experience in IT knowledge showed a lot of gains IT integration in their web units at the end of the training. 
When regressed against Evaluation score, no significant relationship found between teachers’ IT knowledge and Instructional Design.

Evaluation Score (IT knowledge).

Stages of Concern vs. Evaluation Score. Evaluation was found to be positively related to two levels of participants' concerns at the Pre period, Awareness and Informational. The IT Knowledge score was significantly correlated with post-1 Collaboration $(r=.48, p<.05)$ and post-1 Refocusing $(r=.43, p<.05)$. The IT knowledge was correlated with pre Computer Level of Use $(r=.-58, p<.01)$ and post Computer Level of Use $(r=.-49, p=.01)$. As the IT Knowledge score referred to the self-evaluation of the participants' knowledge about ITs and IT integration at the end of the training, the significant correlation indicated the changes in participants' IT knowledge were related to the consequences of the innovation. These significant scores are presented in Table 4.32.

Table 4.32

Bivariate Correlations between Stages of Concern and Evaluation Score

\begin{tabular}{cccc}
\hline Independent Variable & Dependent Variable & $\begin{array}{c}\text { SoC Score by } \\
r\end{array}$ & $p$-value \\
\hline \multirow{2}{*}{ Change in Evaluation } & Pre-Awareness Concerns & $.40^{*}$ & .04 \\
& Pre-Informational Concerns & $.48^{*}$ & .01 \\
& Post1-Collaboration Concerns & $.48^{*}$ & .01 \\
& Post1-Refocusing Concerns & $.43^{*}$ & .03 \\
\hline
\end{tabular}

$r=$ Pearson Correlation

$* p<.05, * * p<.01, * * * p<.001,^{\dagger}=$ trend $(.05<p<.15)$

Table 4.32 indicates the value of the Pearson correlation between the Stages of Concern score and the change in the Evaluation. It is noted that there was a positive 
moderate correlation between Pre-Awareness concerns and participants' Change-inEvaluation score $(r=.40)$. There was a correlation between Pre-Informational concerns and participants' change in Evaluation score $(r=.48)$. Soon after training, a positive correlation emerged between the independent variable, Change in Evaluation score and Collaboration $(r=.48)$ and Refocusing $(r=.43)$ concerns.

Teaching Styles vs. Evaluation. There was no significant relationship between teachers’ Evaluation score and Teacher’s Teaching Styles.

Computer Use vs. Evaluation. There was a significant positive relationship between level of computer use and IT knowledge at the PRE period, but a negative relationship with the change in IT knowledge. This makes sense because people with more computer experience did not experience a larger magnitude in term of the gains.

Table 4.33 indicates the value of the Pearson correlation between the level of Computer Use score and the Evaluation score. It is noted that there was a negative correlation between pre-test level of Computer Use and participants' change in Evaluation score $(\mathrm{r}=-.58)$, post-test level of Computer Use and participants' change in Evaluation score $(\mathrm{r}=-.49)$. 
Table 4.33

Bivariate Correlations between Level of Computer of Use and Evaluation score

\begin{tabular}{lccc}
\hline Independent Variable & Dependent Variable & $r$ & $p$-value \\
\hline Pre-Evaluation & Pre-Computer Use & $.84^{* *}$ & .01 \\
Post-Evaluation & Pre-Computer Use & $.69^{* *}$ & .01 \\
Change in Evaluation & Pre-Computer Use & $-.58^{* *}$ & .01 \\
Pre-Evaluation & Post-Computer Use & $.63^{* *}$ & .01 \\
Post-Evaluation & Post-Computer Use & $.52^{* *}$ & .01 \\
Change in Evaluation & Post-Computer Use & $-.49^{* *}$ & .01 \\
Pre-Evaluation & Change in Computer Use & $-.46^{*}$ & .03 \\
Post-Evaluation & Change in Computer Use & $-.48^{*}$ & .01 \\
Change in Evaluation & Change in Computer Use & .23 & .24 \\
\hline
\end{tabular}

$r=$ Pearson Correlation

$* p<.05, * * p<.01, * * * p<.001, \dagger=$ trend $(.05<p<.15)$

Instructional Design vs. Evaluation. There was no significant relationship between change in IT integration and IT knowledge.

\section{Table 4.34}

Bivariate Correlations between Change- in-Instructional Design and Evaluation score

\begin{tabular}{lcc}
\hline Independent Variable & $\begin{array}{c}\text { Change in Instructional } \\
\text { Design by } \\
\text { Pearson Correlation }\end{array}$ & p-value \\
\hline
\end{tabular}

$\begin{array}{lll}\text { Pre-Evaluation Score } & .30 & .13 \\ \begin{array}{l}\text { Post-Evaluation Score (IT } \\ \text { knowledge) }\end{array} & .40 * & .04 \\ \begin{array}{l}\text { Change in Evaluation Score (IT } \\ \text { knowledge) }\end{array} & -.16 & .43 \\ * p<.05, * * p<.01, * * * p<.001, \dagger=\text { trend }(.05<p<.15) & \end{array}$

Summary of RQ6 
This chapter described the results obtained from the Stages of Concern, PALS questionnaire, Survey of Computer Use, Lesson Sweep, and the Final Daily Evaluation Questionnaire. The twenty-seven participants were teachers in West Virginia schools participating in the second year of the Trek-21 Professional Development. The analysis focused on the relationship between five dependent variables and three independent variables. The five dependent variables were participants' Stages of Concern score, PALS score, Computer Use scores, change in IT Integration and Change in IT knowledge. The three independent variables were Duration of the Training, Instructional Design, and Evaluation.

Duration of Training as a Key Factor. Duration of the training affected the mean scores of the following dependent variables significantly: some of the SoC scores, Teaching Styles scores, Level of Computer Use scores, Instructional Design score, and Evaluation (IT Knowledge) scores. Therefore, Duration of Training was a crucial key factor in the Trek-21 professional development program.

Instructional Design as a Key Factor. Participants’ Evaluation score was found to be positively related to two levels of participants Awareness and Informational concerns at the before Trek-21 training. A significant relationship was also found between Evaluation score and participants’ level of Computer Use. Evaluation did not have a significant relationship with Teaching Styles score or Instructional Design.

Evaluation as a Key Factor. Participants’ Evaluation score was found to be positively related to two levels of participants Awareness and Informational concerns at the before Trek-21 training. A significant relationship was also found between Evaluation score and participants’ level of Computer Use. Evaluation did not have a significant 
relationship with Teaching Styles score or Instructional Design. Therefore, Evaluation was a crucial key factor of the professional development model. 


\section{CHAPTER V - CONCLUSIONS AND IMPLICATIONS}

This chapter has been divided into two sections. This first section presents a conclusion of the study. Conclusions are based on the research questions and the interpretation of significant findings. The second and final section of this chapter outlines the implications of this study and suggestions for future research.

\section{Conclusion}

This study investigated the relationship between key factors of Trek-21 professional development model and resulting changes in teacher practices with respect to integration of instructional technologies in study participants’ classrooms.

This section is organized according to the questions addressed throughout this study. The following research questions were evaluated quantitatively to estimate the effectiveness of the Trek-21 project key factors for producing change in teacher practice.

Research Question 1: What is the relationship between changes in teachers concerns toward instructional technologies (ITs) and key factors (Duration, Instructional Design and Evaluation) of the Trek-21 professional development model?

The first part of the research question hypothesizes that there would be a relationship between the integration of instructional technologies, and the level of concerns as measured by the Stages of Concern Questionnaire (SoCQ) over time. In order to gain insights about this research question, the stages of concern about the innovation questionnaire (Hall, et al., 1977) was used. As discussed in Chapter three, the questionnaire looks at different stages that a user passes through when adopting an innovation, such as IT. Hall et al. (1998) and Hord et al. (1987) suggested that there would be a linear trend over time predicting each of the levels of concern in the SoCQ. 
Prior to learning a new innovation, participants would exhibit concerns in Awareness, Information, Personal, and Management Stages as measured by the SoCQ. After training and over time, the intensity of concerns prior to training would diminish and then shift to concerns of Consequences, Collaboration, and refocusing. The data confirmed participants’ levels of concern shifted as predicted by Hall et. al. (1998) and Hord et al. (1987).

As discussed in Chapter IV, the analysis of data supported the potential effect of the Trek-21 professional development project on the stages of concern (SoCQ) related to Duration of Training, Instructional Design and Evaluation.

RQ1a: SoC versus Duration. This research question was designed to answer if the duration of the training was a key factor in teachers' concerns toward IT integration. Results of the SoCQ for all 27 teachers indicated that both Internal and External concerns of the participants moved toward the direction expected after an effective training (post1). The changes in their concerns were not as significant after implementation as they were after training. This may be due to differences of IT implementation experiences of the participants in the contexts of their teaching practices.

Findings for RQ1a indicate that duration of training was a key factor in the changes of teachers’ concerns toward IT integration. Following a four-week-long training, participant teachers' concerns changed towards an expected directions. After implementation, however, participant teachers’ scores did not change significantly, perhaps, due to their IT implementation experiences in their teaching context. 
Therefore, Duration of training was sufficient enough to significantly affect participants' SoC scores. Duration was a key factor in lowering participants’ Internal Concerns and increasing External Concerns after 4-week training.

RQ1b: SoC versus Instructional Design. This study found that Instructional Design score was positively related to Consequences concerns and Refocusing concerns at the Post-1 period. A significant positive relation was also found between Informational concerns and Instructional Design score at the end of implementation period. This finding indicated that participants who integrated more ITs in their web units also had higher External concerns.

RQ1c: SoC versus Evaluation. This study found that the Evaluation score was significantly positively related to Awareness and Informational at the Post-1 period. There were no other significant relationships between Evaluation score and any of the participants' seven levels of concern toward ITs. Therefore, participants who were more concerned internally were more likely to gain more IT knowledge than participants who were less concerned coming into the Trek-21 training. Research Question 2: What is the relationship between changes in participants teaching/learning styles and key factors (Duration, Instructional Design and Evaluation) of Trek-21 professional development model?

Three independent variables were regressed against the Teaching/Learning Styles scores. The variables included in this analysis were: Duration of training, Instructional Design, and Evaluation.

RQ2a: PALS versus Duration. A $t$-test analysis revealed a significant difference in participants' teaching style scores from the beginning to the end of training indicating 
that Duration of the training was sufficient enough to significantly increase participants’ teaching style scores. The findings indicated a slight change in participants’ teaching style from teacher-centered style before training towards learner-centered at the end of the professional development. The results can be interpreted in two ways. First, its meaning might be that participants, at least in part, showed some internalization of the constructivist approach to teaching where technology may be used as a tool to put student at the center of the learning process. Second, this trend could be the result of either chance, or any other variables that were not predicted or measured by this study. Statistically speaking, the latter reason is the most viable, though.

This trend may have been due to the fact that not being comfortable with technology may be a big restriction when trying to integrate it into teaching. As the OTA (1995) report suggested, teachers are at the center of effective use of instructional technology. Therefore, helping teachers use ITs comfortably may be the most important step in helping students succeed in their technology endeavors.

RQ2b: PALS versus Instructional Design. The simple regression analysis of Instructional Design score on Teaching Styles score revealed no statistically significant relationship. When PALS Score were regressed against Pre-Instructional Design Score, there was no significant relationship between Pre-instructional Design score and PALS score at either the pre-treatment stage, or the post-treatment stage. When PALS Score were regressed against Post-Instructional Design Score, there was no significant relationship observed between Post-instructional Design score and PALS score at either the pre-treatment stage, or the post-treatment stage. When PALS Score were regressed against Post-Instructional Design Score there was no significant relationship between 
Change-in-instructional Design score and Principle of Adult learning scores at either the pretreatment stage, or the post-1 treatment stage.

The findings revealed that teachers' teaching styles were independent of the extent to which participants integrate ITs into their web units.

RQ2c; PALS versus Evaluation. The simple regression analysis of Evaluation score on Teaching Styles score revealed no statistically significant relationship. This finding was not surprising based on what is known about the way teachers teach. The amount of IT knowledge the participants gained during training was not related to their teaching styles and that integration of new IT tools into web units did not change the way teachers teach. Factors brought out in the training process could explain this inconsistency. While teachers may not choose to integrate IT in their classrooms, these same teachers may not view ITs as overly complex.

Research Question 3: What is the relationship between changes in teacher level of computer use and key factors (Duration, Instructional Design and Evaluation) of Trek-21 professional development model?

RQ3a: Level of Computer Use versus Duration. When mean scores were computed for each period (Pre- and Post-test) on participants' computer use scores, the results (Table 4.16) indicated a significant increase in the participants’ Level of Computer Use score from the beginning (pre) to the end of the Trek 21 professional development training (post). Pre-test mean was $43.26(S D=15.87)$ and posttest mean was $54.48(S D=16.49)$ with $t(26)=-5.10, p<.05$ indicating increased Level of Computer Use. 
As noted in Chapter IV, the duration of training did emerge as a significant predictor of level of computer use. This finding is consistent with prior research studies that have found duration of training to positively affect the adoption of an innovation. Although there was no data collected concerning the length of each individual training module involved in the study, the results of this study imply two possibilities: the duration of training associated with IT integration was enough time for the participant to learn how to integrate ITs.

RQ3b: Level of Computer versus Instructional Design. The independent variable, Instructional Design, was regressed against the Level of Computer Use score, the dependent variable. The results indicated that there was no significant relationship between Instructional Design score and participants’ Level of Computer Use. Therefore, participants' instructional design (extent of IT integration) was not associated with their level of computer skills.

Of interest, however, was a significant negative relationship that was found between Pre-Computer Use scores and Change-in-instructional Design. Participants with higher pre-evaluation scores had smaller changes in computer use scores from the beginning to the end of the Trek-21 training. Higher post-evaluation scores were related to smaller change in computer use from the beginning to the end of Trek-21 training. There was no significant relationship between Change-in-Computer Use scores and Change-in-Instructional Design.

RQ3c: Level of Computer Use versus Evaluation. When computer use scores were regressed against Evaluation scores, there was a significant positive relationship between Pre-Evaluation score and Computer Use scores at both the pre-treatment and the post- 
treatment stages. Participants with higher pre-evaluation scores also had higher computer use scores at both pretest and posttest points. Higher pre-evaluation scores were related to higher computer scores before and after Trek-21 training.

After regressing Change-in-Computer Use Score against Post-Evaluation Score, a significant negative relationship was found between the two variables. Those participants with higher pre-evaluation scores had smaller changes in computer use scores from the beginning to the end of the Trek-21 training. Higher post-evaluation scores were related to smaller change in computer use scores from the beginning to the end of Trek-21 training.

Those participants with higher pre-evaluation scores had lower percentage change in computer use scores from the beginning to the end of the Trek-21 training. Higher post-evaluation scores were related to lower change in computer use scores from the beginning to the end of Trek-21 training. Therefore, Evaluation was a key factor in relation to participants’ computer skills. Participants’ IT knowledge was positively related to the level of their computer skills.

Research Question 4: What is the relationship between changes in teachers’ extent of instructional technologies (ITs) integration into their units and key factors (Duration and Evaluation) of Trek-21 professional development model?

RQ4a: Instructional Design Score versus Duration. As noted in Chapter IV, the duration of training did emerge as a significant predictor of teachers' extent of IT integration. After the analysis was conducted on the Lesson Sweep scores, participants’ scores increased significantly in the post-test analysis as compared to the scores prior to Trek-21 training (Table 4.24). The results indicate a significant statistical increase in 
teachers' extent of IT integration from the beginning of the training to the end of the professional development. Again, duration of training showed evidence of positively affecting the adoption of an innovation in terms of an increase in teachers' extent of IT integration. Therefore, Duration of training was sufficient enough to significantly increase participants' extent of IT integration in their web units.

RQ4b: Instructional Design Score versus Evaluation. The relationship between change in teachers' extent of instructional design and the change in the evaluation score was generally negative, although not significant. However, the post-evaluation scores and the change in extent instructional design relationship was determined to be a significant positive relationship. Higher increases in teachers’ extent of instructional design were associated with higher post-evaluation scores and small increases in extent of instructional design were associated with small post-evaluation scores. Post-evaluation score did emerge as a significant predictor of changes in teachers' extent of instructional design. Therefore, the significant positive relationship between change in IT integration and IT knowledge meant that the more teachers know about IT tools the more likely they will integrate these tools into their web units.

Research Question 5: What is the relationship between changes in teachers’ instructional technologies (ITs) knowledge and key factors (Duration and Instructional Design) of Trek-21 professional development model?

RQ5a: Evaluation Score versus Duration. This question sought to address those discrepancies between larger and smaller changes (gains) in teachers’ instructional technologies knowledge over the period of the training and determine if those discrepancies actually influenced the teachers’ integration of ITs. 
As mentioned in Chapter IV, Duration of training did emerge as a significant factor of teachers' instructional technologies knowledge. The analysis of pre- and postFinal Daily Evaluation instruments showed a statistically significant increase in the posttest scores (Table 4.27). In fact, the duration of training actually had a positive affect on teachers' instructional technologies knowledge. The results indicate a significant statistical increase in teachers' instructional technologies knowledge from the beginning of the training to the end of the professional development. The findings indicate that Duration of training was sufficient enough to significantly increase participants IT knowledge during the Trek-21 professional development.

RQ5b: Evaluation Score versus Instructional Design Score. When Evaluation Score was regressed against Instructional Design score, no significant relationship emerged between the two variables. Therefore, participants IT knowledge was not associated with the way participants designed their instruction.

Research Question 6: What key factors (Duration, Instructional Design and Evaluation) of the Trek-21 professional development are crucial to facilitating changes in P-12 participants’ instructional practices (adoption) with respect to integration of instructional technologies (ITs)?

Duration of Training as a Key Factor. Duration of the training affected the mean scores of the following dependent variables significantly: some of the SoC scores, Teaching Styles scores, Level of Computer Use scores, Instructional Design score, and Evaluation (IT Knowledge) scores. Therefore, Duration of Training was a crucial key factor in the Trek-21 professional development program. 
Instructional Design as a Key Factor. Participants’ Instructional Design score (also known as Extent of IT Integration) was found not to be a crucial key factor of Trek21 professional development model. No significant relationships were found between Instructional Design score and the following independent variables: PALS score, participants’ Level of Computer Use, and participants’ IT knowledge.

Evaluation as a Key Factor. Participants’ Evaluation score was found to be positively related to two levels of participants Awareness and Informational concerns at the beginning of Trek-21 training. A significant relationship was also found between Evaluation score and participants’ level of Computer Use. Although Evaluation did not have a significant relationship with Teaching Styles score or Instructional Design, still it was found to be a crucial key factor of the professional development model.

\section{Summary of Conclusions}

Based on the findings of this study, conclusions were drawn with respect to the three key factors of professional development model, two conclusions for Duration of training, four conclusions each for Instructional Design and Evaluation.

The findings stated in this study lead to the following two conclusions with respect to Duration of training. The first conclusion is that Duration was a crucial key factor in relation to dependent variable scores: SoC, PALS, Instructional Design, Level of Computer Use, Extent of IT integration and IT knowledge. The second conclusion is that the dependent variable scores changed significantly over the course of the duration of training.

The findings stated in this study lead to the following three conclusions with respect to Instructional Design as a key factor of professional development. The first 
conclusion is immediately following Summer Institute teachers with higher external concerns also had integrated more ITs into their web units than those with lowers concerns. The second conclusion is that teachers' teaching styles were independent of participants' extent of IT integration in their web units. The third conclusion is that teachers' extent of IT integration was not associated with their level of computer skills.

Based on the findings stated in this study, the following four conclusions with respect to Evaluation as a key factor of professional development were made. The first conclusion is that participants who were more concerned internally were more likely to gain more IT knowledge than those who were less concerned at the beginning of the Trek-21 training. The second conclusion is that the amount of IT knowledge participants gained during training was not related to their teaching styles. Integration of new ITs into web units did not change the way teachers teach. The third conclusion is that teachers with higher level of computer skills indicated more confidence in integrating ITs than those with lower level of computer skills. The fourth conclusion is that the more teachers know about IT tools the more likely they will integrate these tools into their web units.

\section{Implications}

This section outlines implications, recommendations, and offered suggestions for future research. The implications for the findings of this study extend from the state level down into individual schools. Perhaps the greatest implication centers on the innovation (IT) and change in teacher practice. School administrators and state officials must realize that change in teacher practice is not a chance occurrence. Change in teacher practice cannot be mandated from top-down: this approach will lead to frustration and failure. Change in teacher practice must be recognized as an emotional event. As such, 
educational administrators must be prepared to deal with the frustration and resentment that any type of change is sure to invoke. Further, change in teacher practice cannot take place without a reason. Regardless of the innovation in question, be ITs or any other, change in teacher practice is a form of communication involving a two-way interaction. Without interaction, the odds of an innovation being accepted decreases. As Rogers (1962) points out, an innovation may be rejected during any stage of the adoption process.

However, educational administrators can take steps to minimize the frustration and resentment associated with change in teacher practice and maximize the possibility that an innovation will be accepted. First, educational administrators can give teachers an opportunity to witness an innovation in use, which corresponds to Rogers' (1962) first stage of adopting an innovation. Education administrators must look for opportunities to show all potential users of an innovation like ITs the benefits of such an innovation. This can be accomplished by taking teachers to tour other schools currently using the innovation in question. Whether it is a PDA, an electronic grade book program, a simulation program, or video editing software, or another new IT, the best way to show teachers the potential of an innovation is to show other teachers actually using the innovation. When teachers have an opportunity to see others actually integrating the innovation such as ITs, communications channels will be opened.

Second, these same potential users must be given a chance to try an innovation in an environment where they can feel comfortable, this step corresponding to Rogers’ (1962) Fourth stage of adoption. Education administrators must do their best to look for opportunities when it comes to change. By confiding in their teachers that an innovation 
is not being forced, then an opportunity exists to integrate the innovation. An atmosphere of trust must be established between administrators and teachers who intend to integrate an innovation so that teachers can have the opportunity to establish a sense of ownership toward that innovation. However caution still has to be exercised in this situation. Educational leaders must recognize that some individuals will eagerly accept an innovation while others will not. Creating such a friendly environment for users and nonusers of an innovation will enhance the chance that more nonusers will accept the innovation.

Third, educational leaders should not assume that key factors such as duration of training, instructional design, technical support, or other intrinsic factors will influence the use of an innovation. Instead, each individual should be treated as a potential user of the innovation. Consequently, educational leaders must work to determine the motivating factors for each individual: what works for one may not work for another. This concept is not far removed from the motivating factors that teachers are expected to use in their classrooms. If administrators expect teachers to cater to the individual needs of students, then these same administrators must be role models when it comes to introducing innovations.

Fourth, the benefits that are offered by an innovation, the degree of difficulty in using that innovation, and the ability to integrate that innovation are dependent on the individual him/herself. It is the user's perceptions of the innovation that matter; and, the characteristics of an innovation do influence its acceptance and the way it will be integrated in to the classroom. To jump start the change process, administrators therefore, must recognize that two individuals will always perceive an innovation differently. What 
may be complex to one, may be easier to the another. One teacher's advantage, is another teacher's limitation. Taking these differences into consideration is important in understanding how change can occur. Therefore, a good plan will take these points into consideration to avoid frustration and failure. Surry (1995) suggested that if administrators understand the adoption of an innovation, they will be more prepared to work effectively with potential adopters or users of ITs (Surry, 1995).

Finally, as mentioned previously, a friendly environment to integrate ITs must exist for change in teacher practice to occur. If such an environment is missing, any plan will be too difficult to execute.

In summary, this study has laid the foundation for a follow up study. Future research on professional development to help teachers integrate instructional technologies in the classroom should focus on the integration of ITs at both public school and collegiate levels. IT integration in the classroom is an area that has picked up steam since the turn of the century. While the potential is immeasurable, guidance must come from solid and sound research efforts on the subject. Without this research base, use of ITs is at risk of becoming just another statistical trend in education. This study has therefore, included several recommendations for the development and continuance of revitalizing professional development models involved in training of teachers who are integrating instructional technologies into their classrooms. Instructional technologies are a part of K-12 teachers' lives at all levels and will continue to be an integral part of the school system as longs as school administrators are looking for ways to enhance student learning by using ITs. 
With respect to professional development and the 3 key factors in this study the following recommendations can be made:

1. Participants need to be given sufficient time and opportunities for them to integrate ITs. Time is an important factor that must be addressed and respected when designing professional development training. Professional development must provide the amount of time necessary for ownership and sustained change to take place. It does not happen in four weeks. It does not happen in two months. It takes more than a Summer Institute period for an innovation to be owned. Teachers must therefore be afforded the time to learn new skills and practice new behaviors and strategies when learning to integrate ITs while being supported by a knowledgeable, available, resource person.

2. Professional Development should be an ongoing process not a one-time-only workshop with availability of both curriculum and technical support to make teachers comfortable when integrating ITs.

3. Evaluation of training objectives must be incorporated into the professional development as a form of assessment of participants’ performance and of the effectiveness of the training program if teachers are to integrate ITs appropriately to promote learning in the classrooms.

\section{Recommendations Regarding Future Research}

Suggestions for future training programs include more visits to participants during implementation phase, evaluating not only written lessons, but also videotapes and self- 
reflection of participants. The changes in methods and evaluation strategies should then be studied in relationship to levels of implementation over time.

One of the premises of the Trek-21 Professional development model was the inclusion of key factors which affect integration of ITs. Results from research question one (RQ1a) suggested that teacher groups (by level of computer use) could help paint a much clearer picture of analyzing research data. Therefore, a more direct evaluation of the teacher groups by level of computer use and their impact on implementation of Trek21 methodologies in the classroom following training needs to be investigated.

Future research also is needed to investigate the impact of Trek-21 training on the students of Trek-21 teachers. The ultimate goal of education reform is to increase and enhance student performance and learning. Changes in students’ attitudes towards instructional technologies and its integration results will be evaluated and compared to the implementation of Trek-21 methodologies in participants’ classrooms. An ethnographic study would also be valuable to study the impact of Trek-21 on teachers and students over a longer period of time. A study of all PK-12 teachers trained during the 3 years of Trek-21 professional development training could also be done. Participants’ surveys, Daily and Final evaluations, Stages of Concerns Questionnaires, PALS, the Lesson Sweep were completed during each of the 3 years of training. Looking at pre- and post-training results for the whole year of the study, various evaluations can be completed based on the data collected from these similar instruments. Comparisons could be made based on the differences implemented in the training methods during the 4-week training. A larger sample population (i.e. $N>100$ ) would also increase the power of the results. 
The data collected for 2001 Trek-21 program could also be further analyzed using multiple linear regression or run as repeated measures design.

The design of the study supported and revealed deeper insights and other factors that impacted the Trek-21 professional development and results of the study. Information obtained in the Post-1 and Post-2 period of the project evaluation provides a realistic indication of the long-term impact of Trek-21 training. Without the post- 1 and post-2 data, far more optimistic results would have been obtained, but the results would have not been an accurate indication of implementation of Trek-21 methodologies over time. Information obtained from the analysis of the quantitative methods provided a complete picture of the results and implication of the study. Use of multiple instruments in the study revealed deeper insights and other factors that impacted the Trek-21 professional development and results of the study.

Future research is needed to determine whether providing knowledge and skills through a well designed professional development program like Trek-21 will actually increase integration of ITs in education. Internal and external factors relevant to integration must be identified and closely monitored so the variables that effect Integration of ITs can be clearly defined. A state wide study of professional development plan for the purpose of integrating Instructional technologies into the classroom is needed to determine the key elements necessary for success.

This study also focused on the extent of IT integration into teachers' web units. Through the analysis, some ideas emerged as to how teachers are integrating ITs in their classroom. Questions that need to be address include: Are teachers integrating ITs to provide authentic, active-learning, problem-solving situations for students? Are teachers 
integrating ITs to compensate for a lack of classroom materials or teaching tools? Or, are teachers simply integrating ITs to provide rewards and recreation for students? Research on these questions, and others is needed in the near future. 


\section{REFERENCES}

Abdal-Haqq, I. (1996). Making Time for Teacher Professional Development. ERIC Digest. ERIC Clearinghouse on Teaching and Teacher Education Washington DC.ERIC document No. ED4000259. [Available Online] http://www.ericfacility.net/ ericdigests/ed400259.html.

Byrom, E. (1998). Factors influencing the effective use of technology for teaching and learning: Lessons learned from the SEIR-TEC intensive site schools. Retrieved May 20, 2003 from http://www.serve.org/seir-tec/publications/lessons.html

Chu, J.L. (2000). Assessment of the Integration of technology into the curriculum by middle and high school teachers. UMI Dissertation Publication No.: 9983692. Pepperdine University: Los Angeles, CA.

Cattagni, A. and Westat, E.F. (2001). Internet access in U.S. public Schools and Classrooms: 1994-2000. NCES 2001-071. Washington, DC: U.S. Department of Education, National Center for Education Statistics.

Crandler, J. (1996). Implementing technology in education: Recent findings from research and evaluation studies. [On-line]. Retrieved December 2002 from: http://www.wested.org/techpolicy/recapproach.html.

Coburn, J. (1999) The Center for Interactive Learning: An Incubator for Hatching Technology. College Planning and Management. 2(3), 44-46.

Conti, G. J. (1978). Principles of adult learning scale: An instrument for measuring teacher behavior related to the collaborative teaching-learning mode. Unpublished doctoral dissertation, Northern Illinois University, DeKalb. 
Conti, G. J. (1979). Principles of adult learning scale. Proceedings of the Twentieth Annual Adult Education Research Conference. Ann Arbor, MI: Adult Education Program, University of Michigan.

Conti, G. J. (1982). The Principles of Adult learning scale. Adult Literacy and Basic Education, 6, 135-150.

Corcoran, T. B. (1995, June). Helping teachers teach well: Transforming professional development (CPRE Policy Brief). Retrieved May 20, 2003, from http://www.ed.gov/pubs/CPRE/t61/

Darling-Hammond, L. and Berry, B. (1998). Investing in Teaching: The Dividend is Student Achievement. Education Week. May 27, 1998, p. 48.

Darling-Hammond, Linda. (January, 2000). Teacher Quality and Student Achievement: A Review of State Policy Evidence. Education Policy Analysis Archives 8. Retrieved April 15, 2003, from http://epaa.asu.edu/epaa/v8n1.

Davenport, M. K. (1995). Factors related to the Tennessee PK-12 educators' implementation of the Internet into classroom activities and professional development. Dissertation Accession No.: AAI9527944. East Tennessee State University: Tennessee.

DeWert, M. and Cory, S. (1996). Becoming Partners: Building a School/University Collaboration Focused on Teaching and Learning with Technology. Journal of Computing in Teacher Education. 12(3), 8-12.

Educational Testing Service (2002, June). The No Child Left Behind Act: A Special Report. Retrieved from http://ftp.ets.org/pub/corp/nclb.pdf. 
Ealy, D. (1999). The effects of an Internet Skill-Building Module on Safety and Environmental Graduate Students' Internet Anxiety, Likelihood to Use the Internet, and Learning Internet/Intranet. Dissertation Abstract. West Virginia University: Morgantown, WV.

Fahey, M. (1989, December). Long-Distance Learning. Network World, 6(49), pp. 3942, 49-50.

Fatemi, E. (1999, September 23). , Building the digital curriculum. Education Week on the Web [Online]. Retrieved June 16, 2003, from http Available: http://www.edweek.org/sreports/tc99/articles/summary.htm

Fatt, J. P. (2002-2003). Perception of Information Technology in Higher Education, Journal of Educational Technology Systems, 31(2), 115-142.

Fay, D. (1994, December). Internet and the Electronic Classroom. Microprocessing \& Microprogramming, 40 (12), pp. 847-850.

Foley, M. (1996). The Internet as a communications innovation: Effects on communication among K-12 teachers. Dissertation Accession No.: AAG9723643. The American University: Washington, D.C.

Federal Communications Commission. About the FCC: A Consumer Guide to Our organization, Functions and Procedures. Retrieved August 20, 2003, from http://hraunfoss.fcc.gov/edocs_public/attachmatch/DOC-229127A1.pdf

Fuchs, B.F. (1997). The Impact of the Internet on educators at North Rockland High School. Unpublished doctoral dissertation. UMI Microfilm No.: 9734060. Columbia University Teachers College: New York, NY. 
Fullan, M. G. (1996, June). Coordinating top-down and bottom-up strategies for educational reform [On-line]. Retrieved June 27, 2003, from http://www.ed.gov/pubs/EdReformStudies/SysReforms/fullan1.html

Fullan, M. with Steigelbauer, S. (1991). The new meaning of educational change. New York: Teachers College Press.

Gay, S. M. (1997). Teaching with technology: A case study of teachers' perceptions of implementing computers into the classroom (Instructional Technology. Dissertation Accession No.: AAG9805505. The University of Nebraska: Lincoln, NB.

Guskey, T. and Huberman, M. (1995). Professional development in education: New paradigms and practices. New York. NY: Teachers College Press.

Haensly, P.A., Lupkowski, A. \& McNamara, J. F. (1987). The chart essay: A strategy for communicating research findings to policymakers and practitioners. Education Evaluation and Policy Analysis, 9(1), 63-75.

Hall, G.E. (1978). The study of teachers' concerns and consequent implications for staff development. Austin, TX: Research and Development Center for Teacher Education, The University of Texas.

Hall, G. E., George, A. A., Rutherford, W. L. (1979). Measuring stages of concern about the innovation: A manual for use of the SoC questionnaire. Austin, TX: The University of Texas at Austin, The Research and Development Center for Teacher Education. (ERIC document Reproduction No. 147 342). 
Hall, G., George, A., \& Rutherford, W. (1998). Measuring stages of concern about the innovation: A manual for use of the SoC Questionnaire. Austin, TX: Southwest Educational Development Laboratory.

Heaviside, E., Malitz, G., and Carpenter, J. (1995). Advanced telecommunication in U.S. Public School, K-12 (Report No. NCES 95-731). Rockville, MD: The National Center for Educational Statistics. (ERIC Document Reproduction Service No. ED 378 959)

Hensley-Marschard, L. E. (1996). How the Jason Project triggers teacher participation and professional development. Dissertation Accession No.: AAG9704750. Indiana University: Indiana.

Herbert, J. (1999). An Online Learning Community. American School Board Journal. 186 (3), 39-41.

Hord, S.M., Rutherford, W.L., Huling-Austin., L., and Hall, G.E. (1987). Taking charge of change. Alexandria, VA: ASCD.

Howley, A. A., and Howley, C. B. (1994). Receptivity to telecommunications among K12 teachers in a rural state: Results of a West Virginia Survey. Paper presented at annual meeting of the national Rural Education Association, Tuscalosa, AL. (ERIC Document Reproduction Service No. ED 374 958)

Jaber, W.E. (1997). A Survey of Factors Which Influence Teachers' Use of Computerbased Technology. Dissertation URN No.: etd-71997-02347. Virginia Polytechnic Institute and State University: Blaskburg, VA. Retrieved June 22, 2003, from http://scholar.lib.vt.edu/theses/available/etd-7199702347/unrestricted/ wjaber2.pdf. 
Joint Committee on Standards for Educational Evaluation. (1994). The program evaluation standards ( $2^{\text {nd }}$ ed.). Thousand Oaks, CA: Sage Publications, Inc.

Joyce, B., \& Showers, B. (1995). Student achievement through staff development: Fundamentals of school renewal. White Plains, NY: Longman Publishers USA. Kachigan, S.K. (1992). Multivariate statistical analysis. New York, NY: Radius Press. Kemp, C. R. (2002). Urban school teachers' self-efficacy beliefs and practices, innovation practices, and related factors in integrating technologies. Indiana, PA: Indian University of Pennsylvania. (UMI Reproduction Number 3043340).

Lewis, L., Parsad, B., Carey, N., Bartfai, N., Farris, E., and Smerdon, B. (1999). Teacher quality: A report on the preparation and qualification of public school teachers (NCES 1999-080). U.S. Department of education. Washington, DC: National Center for Education Statistics.

Lane, E. \& Summerhill, C.(1993a). An Internet Primer for Information Professionals : A Basic Guide to Internet Networking Technology. Westport, CT: Meckler.

Lane, E. \& Summerhill, C. (1993a). The Public-Access. Computer Systems Review 4, No. 3, 27-29.

Loucks-Horsley, S. (1995, November). What the professional developer/designer does. Paper presented at the Education Development Center's Conference for Professional Development Teams for the 25 Statewide Systemic Initiatives, Baltimore, MD.

Market Data Retrieval. (1999). New teachers and technology: Examining perceptions, habits, and professional development experiences. Shelton, CT: Author. (ED 438787). 
McKenzie, J. (1998, April). Adult technology learning: Creating learning cultures with just-in-time support. ESchool News [Online]. Available: http://staffdevelop.org/adult.html.

Milken Exchange on Education Technology. (1999). Will new teachers be prepared to teach in a digital age? A national survey on information technology in teacher education. Santa Monica, CA: Author. (ED 428 072). Retrieved May 15, 2003, from http://www.mff.org/publications/

Mohaiadin, J. (1995). Utilization of the Internet by Malaysian students who are studying in foreign countries and factors that influence its adoption. Dissertation Accession No.: AAG9829184. University of Pittsburgh: Pittsburgh, PA.

Mueller, D. J. (1986). Measuring social attitudes: A handbook for researchers and practitioners. New York, NY: Teachers College Press, Columbia University.

Mullens, J., Leighton, M., Laguarda, K., and O'Brien, E. (1996). Student Learning, Teaching Quality, and Professional Development: Theoretical Linkages, Current Measurement, and Recommendations for Future Data Collection (NCES 96-28). U.S. Department of Education. Washington, DC: National Center for Education Statistics Working Paper.

National Staff Development Council. (n.d.). Standards for staff development [Online]. Retrieved June 22, 2003, from http://www.nsdc.org/list.htm Office of Technology Assessment, U.S. Congress. (1995). Teachers and technology: Making the connection. OTA-HER-616. Washington, DC. Retrieved June 22, 2003, from http://www.wws.princeton.edu/ ota/disk1/1995/9541.html. O'Leary, M. (1989). Online Flea Markets from Uncle. Information Today, 6(9), 13-14. 
Panel on Educational Technology, President's Committee of Advisors on Science and Technology. (1997, March). Report to the President on the use of technology to strengthen K-12 education in the United States [Online]. Available: http://www.ostp.gov/PCAST/k-12ed.html.

Payne, J. A. (1998). The Impact of state-of-the-art communications technology on instructional and learning behaviors and teacher/student perceptions. Dissertation Accession No.: AAG9829184. Ohio University: Athens, Ohio.

President's Committee of Advisors on Science and Technology, Panel on Educational Technology. (1997). Report to the President on the use of technology to strengthen K-12 education in the United States. Washington, DC: Executive Office of the President of the United States. (ED 410 950) Avail.: http://www.ostp.gov/PCAST/k-12ed.html

Reeves, Douglas B. (2000). Accountability in Action: A Blueprint for Learning Organizations. Denver, Colo.: Advanced Learning Press.

Renyi, J. (1996). Teachers take charge of their learning: Transforming professional development for student success. Washington, DC: National Foundation for the Improvement of Education. Available online: http://www.nfie.org/publications/takecharge.htm

Rutherford, F. J., and T. R. Koballa Jr. (1992). A decade of attitude research based on Hovland's learning Theory Model. Science Education, Vol. 76, No. 1: 17-42. Roberts, P. A. (1998). Characteristics of Early Adopters using educational Internet networks. Dissertation Accession No.: AAG9908561. Pepperdine University: California. 
Roblyer, M.D. (2003). Integrating educational technology into teaching ( $3^{\text {rd }}$ ed.). New Jersey: Prentice-Hall, Inc.

Rogers, E.M. (1995). Diffusion of Innovations (4 ${ }^{\text {th }}$ Ed.). New York, NY: The Free Press. Rogers, E.M. (1976, March). The New Product Adoption and Diffusion. Journal of Consumer Research. Volume 2, March 1976, pp. 290-301.

Schavelson, R. J. (1988). Statistical reasoning for the behavioral sciences. Boston: Allyn and Bacon.

Sheingold, K., and Hadley, M. (1990). Accomplished teachers: integrating computers into classroom practice. New York: Center for Technology in Education, Bank Street College of Education. (ERIC Document Reproduction Service no. ED 322900).

Shoemaker, T. L. (1997). Factors affecting the implementation of Internet use in Michigan K-12 Schools. Dissertation Accession No.: AAG9725867. Wayne State University: Michigan.

Showers, B., Joyce, B., and Bennett, B.(1987, November). Synthesis of Research on Staff Development: A Framework for Future Study and a State-of-the-Art Analysis. Educational Leadership, November 1987: 77-87.

Sparks, D. \& Hirsh, S. (1997). A new vision for staff development. Oxford, OH: National Staff Development Council.

Sprinthall, N. A., Reiman, A. J., and Theis-Sprinthall, L. (1996). “Teacher professional development,” in J. P. Sikula, T. J. Buttery, and E. Guyton (Eds.), Handbook of research on teacher education (pp. 666-703). New York: Simon \& Schuster Macmillan. 
Smerdon, B., Cronen, S., Lanahan, L., Anderson, J., Iannotti, N., and Angeles, J.(2000). Teachers' Tools for the $21^{\text {st }}$ Century: A report on Teachers' Use of Technology (NCES 2000-102). U.S. Department of education. Washington, DC: National Center for Education Statistics.

Smith, W.S. (1997). Technology versus/and science. Unpublished manuscript, University of Akron at Akron, $\mathrm{OH}$.

Surry, D.W. (1997). Diffusion theory and instructional technology. Retrieved August 20, 2003 from the World Wide Web: http://www.gsu.edu/ wwwitr/diffusion/index.html

U.S. Department of Education, National Center for Education Statistics (NCES). (2000a). Teachers' tools for the 21st Century: A report on teachers' use of technology. Washington, DC: Author. (ED 444 599). Retrieved June 26, 2003, from http://nces.ed.gov/spider/webspider/2000102.shtml.

U.S. Department of Education, Web-Based Education Commission. (2000b). The power of the Internet for learning: Moving from Promise to Practice. Washington, DC: Author. (ED 444 603) Available: http://www.ed.gov/offices/AC/WBEC/FinalReport/.

Walston, D (May-June,2001). Improving the Quality of Teaching Using Collaborative Professional Development: The Teachers Teaching with Technology (T) Institutes. Mathematics Education Dialogue. Retrieved June 22, 2003, from http://www.nctm.org/dialogues/2001-05/20010507.htm.

Wells, J. (1999). Trek 21 - Educating Teachers as Agents of Technological Change. Proposal document for PT3 Grant Program, U. S. Department of Education. 
Wenglinsky, H. (1998). Does it compute? The relationship between educational technology and student achievement in mathematics.Educational Testing Service. Retrieved June 5, 2003, from http://www.ets.org/research/pic/dic/techtoc.html

Wheeler, J.R. (1996). A descriptive study of small enrollment, northeast Kansas schools: Local area networks, Internet and teacher's levels of concern toward Internet as a tool for teaching and learning. Dissertsation Accession No.: AAI9634401. DAI, 57, no. 06A (1996): p. 2439. University of Kansas: Missouri, KS.

Lane, E. \& Summerhill, C. (1993). The Public-Access. Computer Systems Review 4, No. 3, 27-29.

Williams, C. (2000). Internet access in public school: 1994-1999 (NCES 2000-086). U.S. Department of education. Washington, DC: National Center for Education Statistics. 


\section{APPENDIX A:}

The Stages of Concern about IT Integration Questionnaire 
Trek 21 Participant Code:

\section{Stages of Concern Instrument}

\section{ATTITUDES TOWARD INSTRUCTIONAL TECHNOLOGY}

DIRECTIONS: Answer as completely and truthfully as you possibly can when thinking how each of the following statements applies to your PRESENT attitude toward integrating instructional technology. Circle the number that best reflects your present attitude. The higher the number, the better the statement reflects your present attitude.

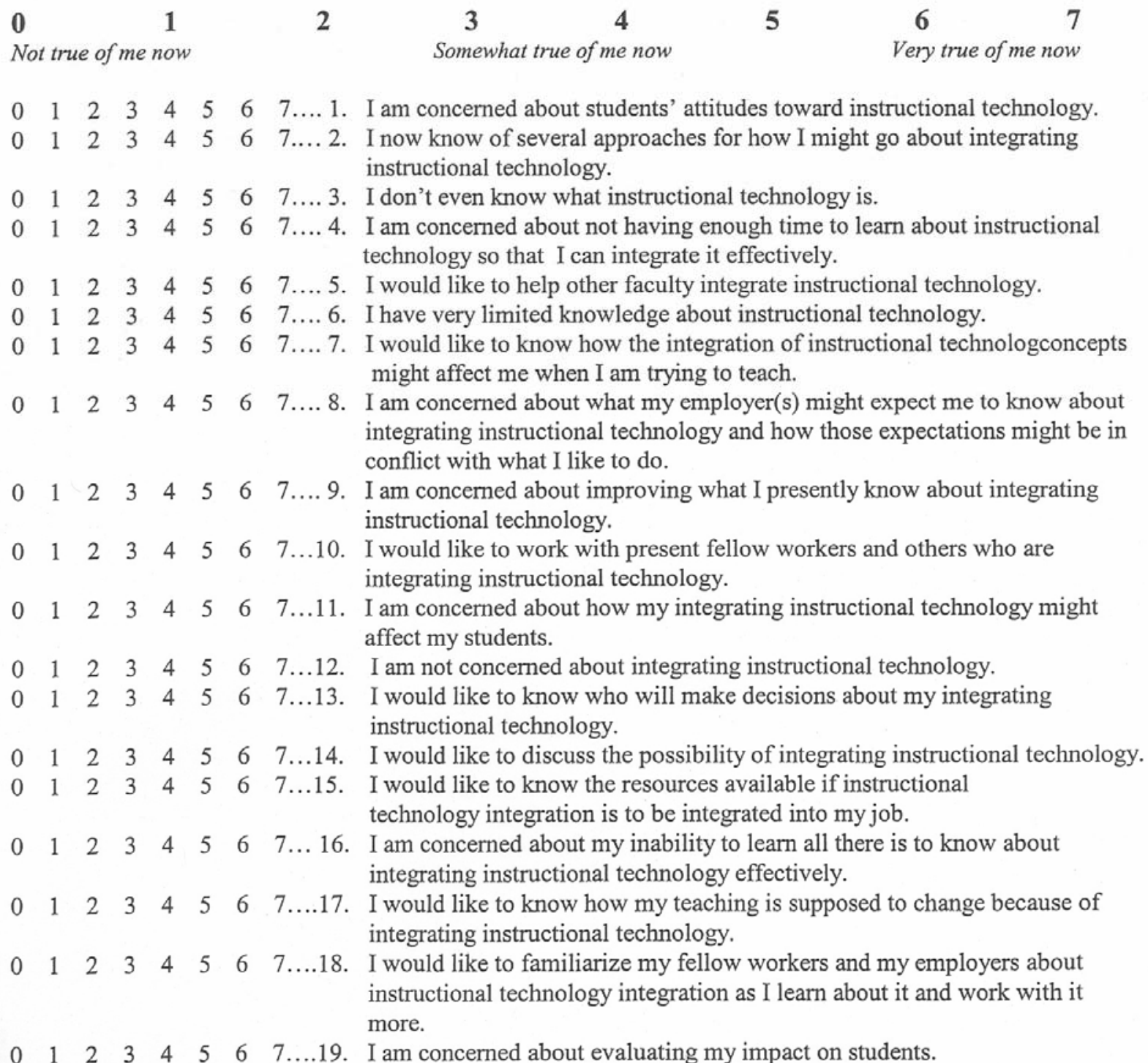




$\begin{array}{cccccccc}0 & 1 & 2 & 3 & 4 & 5 & 6 & 7 \\ \text { Not true of me now } & & \text { Somewhat true of me now } & & \text { Very true of me now }\end{array}$

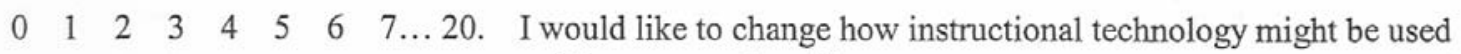
as I learn more about it.

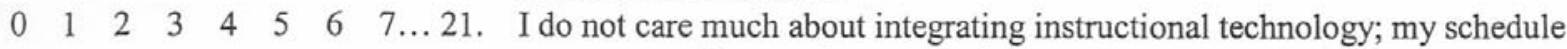
prevents me from caring too much.

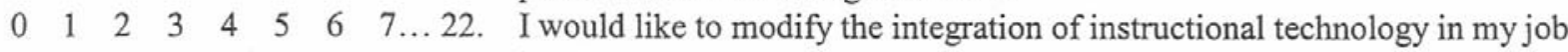
based on students' experiences.

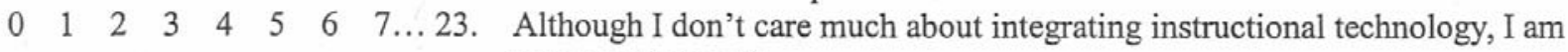
concerned about it.

$\begin{array}{llllllllll}0 & 1 & 2 & 3 & 4 & 5 & 6 & 7 \ldots & 24\end{array}$. I would like to excite my students or fellow teachers about integrating instructional technology concepts.

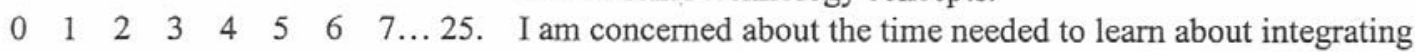
instructional technology that will keep me away from doing what I am supposed to be doing as part of my job.

$\begin{array}{llllllllll}0 & 1 & 2 & 3 & 4 & 5 & 6 & 7 \ldots & 26\end{array}$. I would like to know what integrating instructional technology will require in the immediate future.

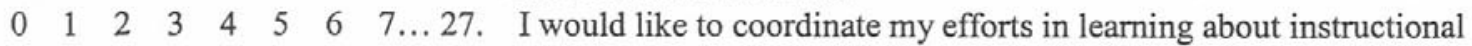
technology integration with fellow workers.

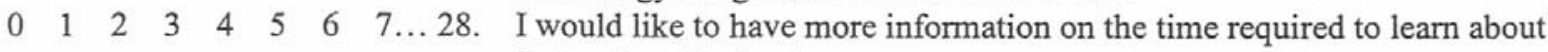
instructional technology.

$\begin{array}{llllllllll}0 & 1 & 2 & 3 & 4 & 5 & 6 & 7 \ldots 2 & 29\end{array}$. I would like to know what other people are doing in relation to integrating instructional technology.

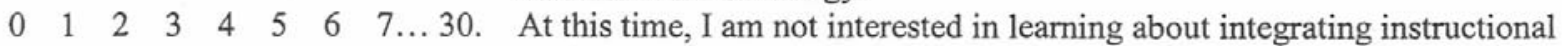
technology concepts.

$\begin{array}{lllllllllll}0 & 1 & 2 & 3 & 4 & 5 & 6 & 7 \ldots & 31\end{array}$. I would like to determine how to supplement and enhance instructional technology integration.

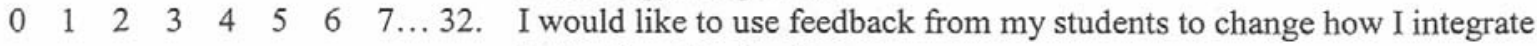
instructional technology.

$\begin{array}{llllllllll}0 & 1 & 2 & 3 & 4 & 5 & 6 & 7 \ldots & 33\end{array}$. I would like to know how my job will change when $\mathrm{I}$ begin integrating instructional technology.

$\begin{array}{llllllllll}0 & 1 & 2 & 3 & 4 & 5 & 6 & 7 \ldots & 34\end{array}$. My present schedule is preventing me from learning too much about integrating instructional technology.

$\begin{array}{llllllllll}0 & 1 & 2 & 3 & 4 & 5 & 6 & 7 \ldots & 35\end{array}$. I would like to know how the integration of instructional technology instruction is better than the methods I presently use or plan to employ when I do my job. 


\section{APPENDIX B:}

Principles of Adult Learning Scale (PALS) Questionnaire 
Trek 21 Participant Code:

\section{Learning Strategies Survey}

The following survey contains several things that a teacher might do in a classroom. You may personally find some of them desirable and find others undesirable. For each item, respond to the way you most frequently practice the action described by circling the appropriate number as given below:

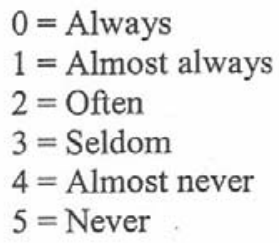

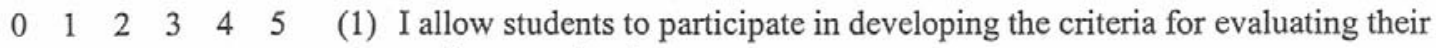
performance in class.

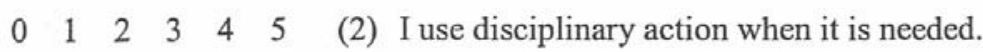

$\begin{array}{lllllll}0 & 1 & 2 & 3 & 4 & 5 & \text { (3) I allow some students more time to complete assignments when they need }\end{array}$ it.

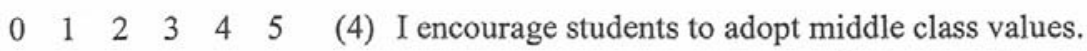

$\begin{array}{llllllll}0 & 1 & 2 & 3 & 4 & 5 & \text { (5) I help students diagnose the gaps between their goals and their present }\end{array}$ level of performance.

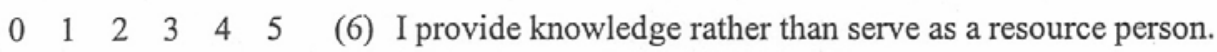

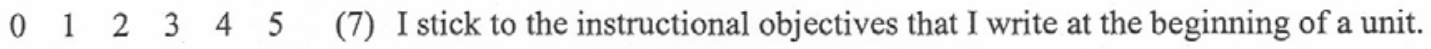

$\begin{array}{llllllll}0 & 1 & 2 & 3 & 4 & 5 & \text { (8) I participate in the informal counseling of students. }\end{array}$

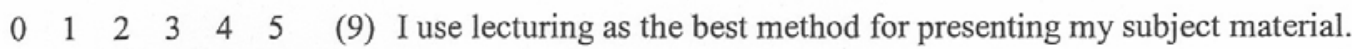

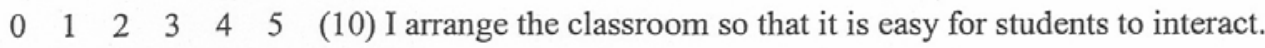

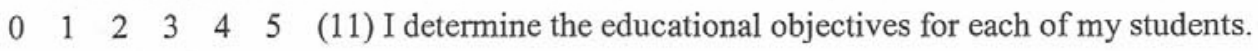

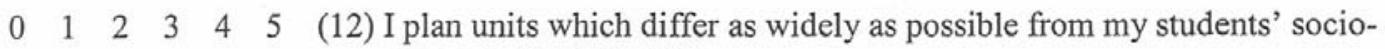
economic backgrounds.

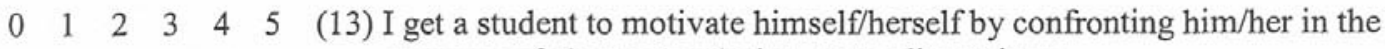
presence of classmates during group discussions.

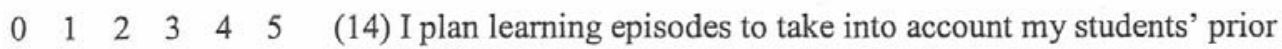
experiences. 
$\begin{array}{lllllll}0 & 1 & 2 & 3 & 4 & 5 & \text { (15) I allow students to participate in making decisions about the topics that will }\end{array}$ be covered in class.

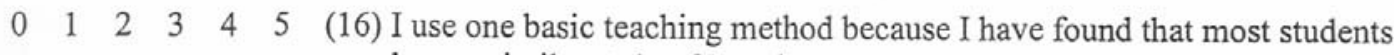
have a similar style of learning.

$\begin{array}{lllllll}0 & 1 & 2 & 3 & 4 & 5 & \text { (17) I use different techniques depending on the students being taught. }\end{array}$

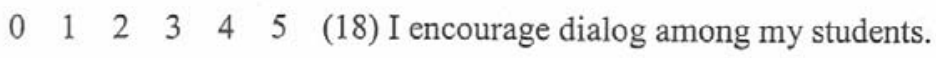

$\begin{array}{lllllll}0 & 1 & 2 & 3 & 4 & 5 & \text { (19) I use written tests to assess the degree of academic growth rather than to }\end{array}$ indicate new directions for learning.

$\begin{array}{lllllll}0 & 1 & 2 & 3 & 4 & 5 & \text { (20) I utilize the many competencies that most students already possess to }\end{array}$ achieve educational objectives.

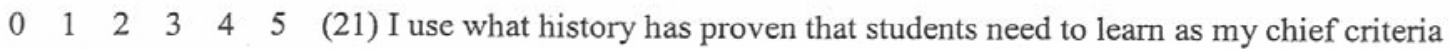
for planning learning episodes.

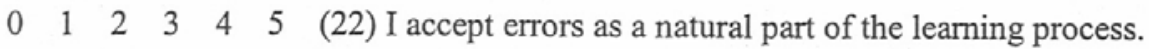

$\begin{array}{lllllll}0 & 1 & 2 & 3 & 4 & 5 & \text { (23) I have individual conferences to help students identify their educational }\end{array}$ needs.

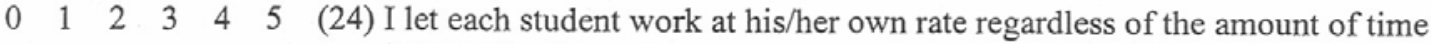
it takes him/her to learn a new concept.

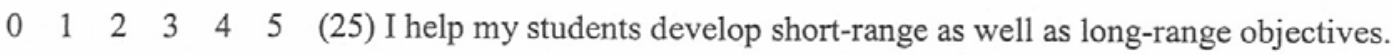

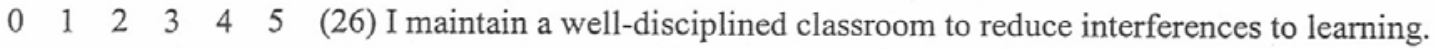

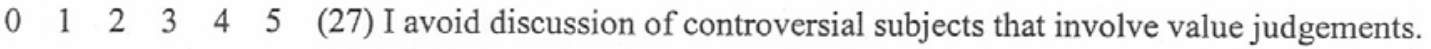

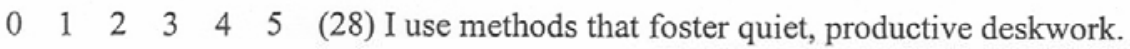

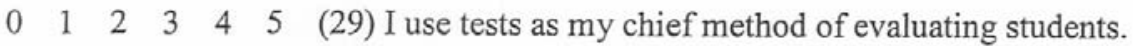

$\begin{array}{lllllll}0 & 1 & 2 & 3 & 4 & 5 & \text { (30) I plan activities that will encourage each student's growth from dependence }\end{array}$ on others to greater independence.

$\begin{array}{lllllll}0 & 1 & 2 & 3 & 4 & 5 & \text { (31) I gear my instructional objectives to match the individual abilites and needs }\end{array}$ of the students.

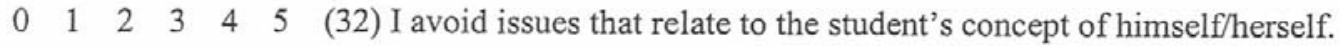

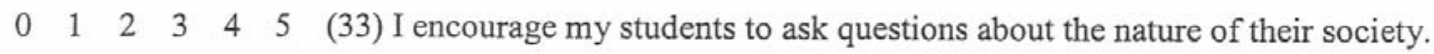




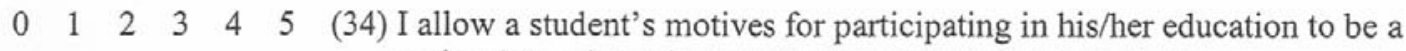
major determinant in the planning of learning objectives.

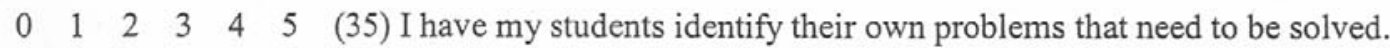

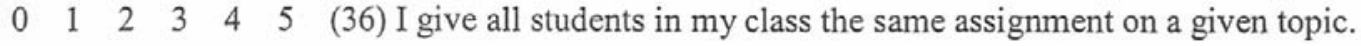

$\begin{array}{lllllll}0 & 1 & 2 & 3 & 4 & 5 & \text { (37) I organize learning episodes according to the problems that my students }\end{array}$ encounter in everyday life.

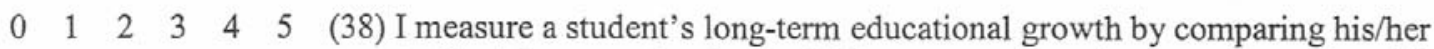
total achievement in class to his/her expected performance as measured by national norms from standardized tests.

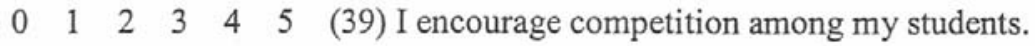

$\begin{array}{lllllll}0 & 1 & 2 & 3 & 4 & 5 & \text { (40) I use different materials with different students. }\end{array}$

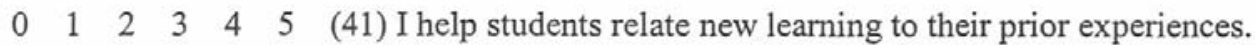

$\begin{array}{lllllll}0 & 1 & 2 & 3 & 4 & 5 & \text { (42) I teach units about problems of everyday living. }\end{array}$ 


\section{APPENDIX C:}

The Survey of Computer Use Questionnaire 


\section{Survey of Computer Use}

Participant Code:

Directions: Complete sections A-D of the survey by checking $(\checkmark)$ the appropriate response.

\section{Part A: Your Technology Background}

How often have you used the following technologies?

CODE: $\quad 1=$ frequently $\quad 2$ = rarely $\quad 3=$ never $\quad 4=$ not available

\begin{tabular}{|c|c|c|c|c|c|}
\hline Applications & Examples & 1 & 2 & 3 & 4 \\
\hline 1. IBM Compatible computer & Windows 3.11 , Windows $95 / 98$, Windows NT & & & & \\
\hline 2. Apple Macintosh computer & Performa, Quadra, PowerMac, G3, G4 & & & & \\
\hline 3. Other Computer & DOS, Apple Ile, UNIX, etc. & & & & \\
\hline 4. VCR & Recorder, player & & & & \\
\hline 5. Laserdisc Player or DVD Player & & & & & \\
\hline 6. Video Camcorder & & & & & \\
\hline 7. Digital Camera & & & & & \\
\hline 8. LCD Panel or Computer Projector & & & & & \\
\hline 9. Internet Web Browser/Online Service & Netscape, Internet Explorer, AOL, etc. & & & & \\
\hline 10. Fax Machine & & & & & \\
\hline 11. Modem & & & & & \\
\hline 12. CD-ROM & & & & & \\
\hline 13. Scanner & & & & & \\
\hline 14. Network File/Print Sharing & & & & & \\
\hline
\end{tabular}

Part B: Staff-Centered Technology

How often have you used the following applications?

CODE: $\quad 1=$ frequently $\quad 2$ = rarely $\quad 3=$ never $\quad 4=$ not available

\begin{tabular}{|l|l|l|l|l|}
\hline \multicolumn{1}{|c|}{ Applications } & \multicolumn{1}{|c|}{ Examples } & \multicolumn{1}{|c|}{2} & 3 & 4 \\
\hline 1. Student Management Systems & Grading/attendance/assessment programs & & & \\
\hline 2. Student Information Systems & Student records, discipline, health systems & & & \\
\hline 3. School Management Systems & Budget, personal scheduling/calendar & & \\
\hline 4. Word Processing & Word, WordPerfect, ClarisWorks, Microsoft Works & & & \\
\hline 5. Spreadsheets/Databases & Excel, Lotus 1-2-3, Filemaker Pro, Access & & \\
\hline 6. Desktop Publishing & Pagemaker, QuarkXpress, Print Shop Deluxe & & & \\
\hline 7. Authoring/Multimedia & Hyerstudio, Authorware, Director & & \\
\hline $\begin{array}{l}\text { 8. Instructional } \\
\text { Demonstration/Tutorial }\end{array}$ & PowerPoint, Persuasion & & \\
\hline 9. Informational Retrieval & Infrotrac, SIRS, Library Circulation & & \\
\hline $\begin{array}{l}\text { 10. Audio/Video Capture or } \\
\text { Digitizing }\end{array}$ & Premiere, Videoshop & & \\
\hline
\end{tabular}


Part B: Continued....

\begin{tabular}{|l|l|l|l|}
\hline 11. Art/Graphic Development & Photoshop, Painter, Illustrator, Canvas, Draw & & \\
\hline 12. Computerized Testing & Microtest & & \\
\hline 13. Internet/Online Service Access & Netscape, Internet Explorer, AOL, Compuserv & & \\
\hline 14. Web Page Development & FrontPage, HomePage, Pagemill, BB Edit & & \\
\hline 15. E-mail & Eudora, Outlook, Exchange, Emailer & & \\
\hline
\end{tabular}

\section{Part C: Student-Centered Technology}

In your classes, how often do you have students use the following applications?

CODE: $\quad 1=$ frequently $\quad 2$ = rarely $3=$ never $\quad 4=$ not available

\begin{tabular}{|c|c|c|c|c|c|}
\hline Applications & 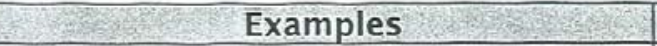 & 1 & 2 & 3 & 4 \\
\hline 1. CAI: Drill \& Practice/Tutorial & & & & & \\
\hline 2. Simulation/Educational Games & Sim City, Sim Life, Civilization & & & & \\
\hline 3. Word Processing & Word, WordPerfect & & & & \\
\hline 4. Informational Retrieval & & & & & \\
\hline 5. Internet Searches & & & & & \\
\hline 6. E-mail & & & & & \\
\hline 7. Bulletin Boards, Listserves & & & & & \\
\hline 8. MUD/MOO & Multi User Domains & & & & \\
\hline $\begin{array}{l}\text { 9. Authoring/Multimedia } \\
\text { Development }\end{array}$ & Hyperstudio, Authorware, Director & & & & \\
\hline 10. Desktop Publishing & Pagemaker, QuarkXpress, Publisher, etc. & & & & \\
\hline 11. Electronic Presentations & PowerPoint, Persuasion & & & & \\
\hline 12. Video Development & & & & & \\
\hline 13. Open Lab Access & 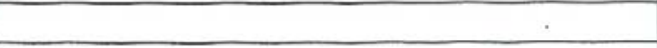 & & & & \\
\hline 14. Web Page Development & 0 & & & & \\
\hline
\end{tabular}

\section{Part D: Learning Strategies}

In your current classes, to what extent are students engaged in the following?

$$
\text { CODE: } \quad 1=\text { frequently } \quad 2 \text { = rarely } \quad 3 \text { = not engaged }
$$

\begin{tabular}{|l|l|l|}
\hline $\begin{array}{l}\text { 1. Problem-Solving: The application of principles to the solution of a problem that is new to } \\
\text { the student. }\end{array}$ & $\mathbf{2}$ & 3 \\
\hline $\begin{array}{l}\text { 2. Task Analysis: The process used for identifying the step-by-step procedures needed to } \\
\text { accomplish something. }\end{array}$ & & \\
\hline $\begin{array}{l}\text { 3. Discovery Learning: The student must induce concepts or principles fairly } \\
\text { independently, but may be guided by the teacher. }\end{array}$ & & \\
\hline $\begin{array}{l}\text { 4. Critical Thinking: Evaluating the credibility of information, distinguishing relevant from } \\
\text { irrelevant, recognizing bias, and deciding what to do by reasoning from the available } \\
\text { evidence. }\end{array}$ & \\
\hline $\begin{array}{l}\text { 5. Concept Scaffolding: Seeing the larger picture into which a new experience will fit, using } \\
\text { imagery, pictorial representation, a diagram, or other organization to facilitate relationships } \\
\text { within the knowledge structure. }\end{array}$ & & \\
\hline
\end{tabular}


Part D: Continued...

6. Higher-order Thinking: Challenging students to interpret, analyze, or manipulate information in response to a question or problem that cannot be resolved through routine application of previously learned knowledge.

7. Metacognition: The mental processes whereby one monitors one's cognitive processes in thinking, learning, and remembering self-understanding and regulation.

8. Computer-Assisted Instruction: Instruction mediated by a computer which presents content, asks questions, and reacts to responses.

9. Cooperative Learning: An approach to learning, arranged by the teacher, that requires two or more students to work together to achieve an educational objective, as opposed to individual learning.

10. Constructivist Learning: Emphasis on student development of new knowledge through active engagement processes that link new knowledge to prior understanding. 11. Intrinsic Motivation: Motivation due to satisfaction that is inherent in performing activity.

12. Conceptual Change: Construction of new understandings that involves abandoning or revising some of one's existing conceptions, not just adding new ones.

Directions: For sections E-G of the survey please judge your level of achievement in each of the following competencies. Circle the number which best reflects your current level of skill attainment (Level 3 is considered mastery.)

\section{Part E: Self Evaluation of Basic Computer Use}

\section{Basic computer operation}

Level 1 I do not use a computer.

Level 2 I can use the computer to run a few specific, preloaded programs. It has little effect on either my work or home life. I am somewhat anxious I might damage the machine or its programs.

Level 3 I can set-up my computer and peripheral devices, load software, print, and use most of the operating system tools like the scrapbook, clock, note pad, find command, and trash can (recycling bin). I can format a data disk.

Level 4 I can run two programs simultaneously and have several windows open at the same time. I can customize the look and sounds of my computer. I use techniques like shift-clicking to work with multiple files. I look for programs and techniques to maximize my operating system. I feel confident enough to teach others some basic operations.

II. File management

Level I I do not save any documents I create using the computer.

Level 2 I save documents I've created but I cannot chose where they are saved. I do not back-up my files.

Level 3 I have a filing system for organizing my files, and can locate files quickly and reliably. I back-up my files to floppy disk or other storage device on a regular basis.

Level 4 I regularly run a disk-optimizer on my hard drive and use a back-up program to make copies of my files on a weekly basis. I have a system for archiving files which I use on a regular basis to conserve my computer's hard drive space.

\section{Word processing}

Level 1 I do not use a word processor, nor can I identify any uses or features it might have which would benefit the way I work.

Level 2 I occasionally use the word processor for simple documents which I know I will modify and use again. I generally find it easier to hand write or type most written work I do.

Level 3 I use the word processor for nearly all my written professional work: memos, tests, worksheets, and home communication. I can edit, spell check, and change the format of a document. I can arrange the pages, preview and print my work. I feel my work looks professional.

Level 4 I use the word processor not only for my work, but have used it with students to help them improve their own communication skills. 


\section{Spreadsheet use \\ Level 1 I do not use a spreadsheet, nor can I identify any uses or features it might have which would benefit the way I work. \\ Level 2 I understand the use of a spreadsheet and can navigate within one. I can create a simple spreadsheet which adds a column of numbers. \\ Level 3 I use a spreadsheet for several applications. These spreadsheets use labels, formulas and cell references. I can change the format of the spreadsheets by changing column widths and text style. I can use the spreadsheet to make a simple graph or chart. \\ Level 4 I use the spreadsheet not only for my work, but have used it with students to help them improve their own data keeping and analysis skills.}

\section{Database use}

Level 1 I do not use a database, nor can I identify any uses or features it might have which would benefit the way I work.

Level 2 I understand the use of a database and can locate information within one which has been pre-made. I can add or delete data in a database.

Level 3 I use databases for a personal applications. I can create an original database - defining fields and creating layouts. I can find, sort and print information in layouts which are clear and useful to me.

Level 4 I can use formulas with my database to create summaries of numerical data. I can use database information to mail merge in a word processing document. I use the database not only for my work, but have used it with students to help them improve their own data keeping and analysis skills.

\section{Graphics use}

Level I I do not use graphics in my word processing or presentations, nor can I identify any uses or features they might have which would benefit the way I work.

Level 2 I can open and create simple pictures with the painting and drawing programs. I can use programs like PrintShop or SuperPrint.

Level $3 \quad$ I use both pre-made clip art and simple original graphics in my word processed documents and presentations. I can edit clip art, change its size, and place it on a page. I can purposefully use most of the drawing tools, and can group and un-group objects. I can use the clipboard to take graphics from one application for use in another. The use of graphics in my work helps clarify or amplify my message.

Level $4 \quad$ I use graphics not only for my work, but have used it with students to help them improve their own communications. I can use graphics and the word processor to create a professional looking newsletter.

\section{Hypermedia use}

Level I I do not use hypermedia (HyperStudio), nor can I identify any uses or features it might have which would benefit the way I work.

Level 2 I can navigate through a pre-made hypermedia program.

Level 3 I can create my own hypermedia stacks for information presentation. These stacks use navigation buttons, sounds, dissolves, graphics, and text fields. I can use an LCD projection device to display the presentation to a class.

Level $4 \quad$ I use hypermedia with students who are making their own stacks for information keeping and presentation.

\section{Network use}

Level 1 I do not use the on-line resources available in my building, nor can I identify any uses or features they might have which would benefit the way I work.

Level 2 I understand that there is a large amount of information available to me as a teacher which can be accessed through networks, including the Internet. With the help of the media specialist, I can use the resources on the network in our building.

Level 3 I use the networks to access professional and personal information from a variety of sources including networked CD-ROM reference materials, on-line library catalogs, the ERIC database, and the World Wide Web. I have an e-mail account that I use on a regular basis.

Level 4 Using telecommunications, I am an active participant in on-line discussions, can download files and programs from remote computers. I use telecommunications with my students. 
IX. Student Assessment

Level 1 I do not use the computer for student assessment.

Level 2 I understand that there are ways I can keep track of student progress using the computer. I keep some student produced materials on the computer, and write evaluations of student work and notes to parents with the word processor.

Level 3 I effectively use an electronic grade book to keep track of student data and/or I keep portfolios of student produced materials on the computer. I use the electronic data during parent/teacher conferences.

Level 4 I rely on the computer to keep track of outcomes and objectives individual students have mastered. I use that information in determining assignments, teaching strategies, and groupings.

\section{$X$. Ethical use understanding}

Level 1 I am not aware of any ethical issues surrounding computer use.

Level 2 I know that some copyright restrictions apply to computer software.

Level 3 I clearly understand the difference between freeware, shareware, and commercial software and the fees involved in the use of each. I know the programs for which the district or my building holds a site license. I understand the school board policy on the use of copyrighted materials. I demonstrate ethical usage of all software and let my students know my personal stand on legal and moral issues involving technology. I know and enforce the school's technology policies and guidelines, including its Internet Acceptable Use Policy. I have a personal philosophy I can articulate regarding the ethical use of technology in education.

Level 4 I am aware of other controversial aspects of technology use including data privacy, equitable access, and free speech. I feel comfortable talking about these issues.

\section{Part F: Self-Evaluation for Advanced Teacher Computer Use}

\section{Instructional software use}

Level 1 I do not use instructional software as a part of my instructional program, nor am I aware of any titles which might help my students meet their learning goals.

Level 2 I use a few computer programs as an instructional supplement, as a reward, or with special needs children.

Level 3 I use several programs (drill and practice, simulations, tutorials, etc.) chosen by my department or grade level to help all my students meet specific learning objectives. The software allows me teach and/or reinforce concepts more effectively than traditional methods. When it is available, I use the software's management system to help assess individual student performance. I use technological resources to meet the needs of students who do not respond to traditional methods of instruction.

Level 4 I seek out new programs for evaluation and adoption. I know sources of software reviews and keep current on new developments in computer technologies through professional reading and conference attendance. I share my findings with other professionals.

\section{Information literacy skills}

Level 1 I am not familiar with the term information literacy, nor do I know why such skills are important.

Level 2 As a part of my curriculum, I have library research projects and I support the library skills taught by the media specialist. I am aware that there are electronic resources available to my students.

Level 3 My curriculum includes multiple projects that have an information literacy component. These are team taught with the media specialist. I understand the Big Six or a similar information literacy process and design student projects so that they require higher level thinking skills, use electronic information sources, require the use of computer productivity software, and are authentically assessed. I guide my students in accessing, evaluating and using information and experts from world-wide sources through the Internet and video conferencing.

Level $4 \quad$ I am involved in curriculum planning teams and advocate the use of multidisciplinary activities which require-information literacy skills. I share successful units with others through print, electronic publishing, presentations and workshops. 


\section{Modification of instructional delivery}

Level 1 I have one or two effective methods of teaching content to my students. I do not use technology which requires that I change my instructional methodology.

Level 2 I have tried units or projects that are student-directed, use small groups, or are highly individualized, but I primarily use teacher-directed, whole group instruction.

Level 3 I use a variety of instructional delivery methods and student grouping strategies routinely throughout the year. I can design activities and approaches which best fit the learning objectives and the availability of the technology available to me. I can use small groups working cooperatively or in rotation to take advantage of student to equipment ratios of greater than one to one. I modify instructional methods to take advantage of the learning styles of individual students.

Level 4 | continuously try new approaches suggested by research or observation to discover the most effective means of using technology to engage my students and meet curricular goals.

I work with a team of fellow teachers to create, modify and improve my practices in this area.

\section{Assessment of student performance}

Level 1 I evaluate my students using objective tests only,

Level 2 I evaluate some student performances or projects using subjective criteria. I save some student work for cumulative folders and parent conferences, and print some electronically produced student work.

Level 3 I use a wide range of assessments to evaluate student projects and performances. I can create assessment tools like checklists, rubrics and benchmarks which help the student assess his own performance and allow me to objectively determine the quality of student work. I ask students to keep both a physical and electronic portfolio of their work. Students and their parents have the means to continuously access the recorded progress students are making toward their learning goals through networked grade books and portfolios. Students are given the opportunity to demonstrate skills through performance to a wide audience via data and video networks. I have means of aggregating performance data for my class which I use to modify my teaching activities and strategies.

Level 4 I continuously try new approaches suggested by research or observation to discover the most effective means of using technology to help assess student learning. I work with a team of fellow teachers to create, modify and improve my work in this area.

V. Individualization of the educational program

Level 1 I modify my curriculum or instructional methods only for students with identified special needs.

Level 2 I occasionally give students the choice of assignments in my class, but all class members (unless they are in special education) must meet the same learning objectives within the same time frame. Skill remediation is done during summer school or informally during or after school.

Level 3 With the assistance of the student, parents and appropriate specialists, I create an individualized learning plan for each of my students. I track the accomplishment of learning goals in the plan using a computerized tool. I use this tool during parent conferences and for school or state reporting. Students and their parents have networked access to this tool for continuous monitoring of progress and plan modification.

Level 4 I provide suggestions about the content and design of the individualized computerized planning and report tools.

\section{Professional growth and communication}

Level 1 I do not use electronic resources for professional growth or communication.

Level 2 I can find lesson plans and research in on-line data bases. I correspond with parents and other teachers using e-mail.

Level 3 I use the Internet and other on-line resources to obtain research findings, teaching materials and information related to the content of my classes. I read electronic newsletters and journals to keep current on educational practices. I participate in electronic discussion groups and chat rooms which are related to my area of education, and contribute to and use the best practices discussed there. I use a computerized presentation program when giving workshops or speaking at conferences. I use technology to take part in distance learning opportunities for my own professional development.

Level 4 I organize professional growth opportunities for other teachers and feel comfortable teaching other staff members about the use of technology. 
VII. Research and evaluation of technology use

Level 1 I have not attempted to determine whether the use of instructional technology has made a difference in my students' learning or classroom climate.

Level 2 I gather, use and share anecdotal information and observations about student use of technology in my classroom.

Level 3 I use action research and aggregated data to accurately determine whether the technology and methodology I am using has an impact on how well my students learn and on school climate.

Level 4 I participate in formal studies of the impact of technology on student learning conducted by professional groups and academics. I have designed such studies as part of my own professional education. I report electronically and in print the findings of my research to other professionals.

\section{Part G: Self-Evaluation for Teacher Internet Use}

\section{Internet basics}

Level I I do not understand how networks work, nor can I identify any personal or professional uses for networks, including the Internet. I do not have an account on any network nor would I know how to get one.

Level 2 I can identify some personal or professional uses for networks, and understand the potential value to my students and me. I've read some articles about the Internet in the popular press. I can directly use network access to a library catalog or CD-ROM.

Level 3 I can describe what a computer network does and how it can be useful personally and professionally. I can distinguish between a local area network, a wide area network, and the Internet and can describe educational uses for each. I have personal access to the Internet that allows me to receive and send email, download files, and access the World Wide Web. I know that I must protect my password, and should restrict access by others to my account.

Level 4 I use networks on a daily basis to access and communicate information. I can serve as an active participant in a school or organizational planning group, giving advice and providing information about networks. I can recommend several ways of obtaining Internet access to others.

\section{Email and electronic mailing lists}

Level 1 I do not use email.

Level 2 I understand the concept of email and can explain some administrative and educational uses for it.

Level 3 I use email regularly and can:

- read and delete messages

- send, forward and reply to messages to

- create address books, mailing lists, and a signature file

- send and receive attachments

- use electronic mailing lists and understand the professional uses of them

- read and contribute to a professional electronic mailing list

Level 4 I can send group mailings and feel confident that I could administer an electronic mailing list. I use activities that require email in my teaching. I can locate lists of subject oriented mailing lists.

\section{The World Wide Web}

Level 1 I do not use the World Wide Web.

Level 2 I am aware that the World Wide Web is a means of sharing information on the Internet. I can browse the Web for recreational purposes.

Level 3 I can use a Web browser like Explorer or Netscape to find information on the World Wide Web, and can list some of the Web's unique features. I can explain the terms: hypertext, URL, http, and html. I can write web pages to share information locations with others. I can use Web search engines to locate specific information and can create bookmarks to Web sites of educational value.

Level 4 I can configure my web browser with a variety of helper applications. I understand what "cookies" do and whether to keep them enabled. I can speak about the security issues of online commerce and data privacy. 


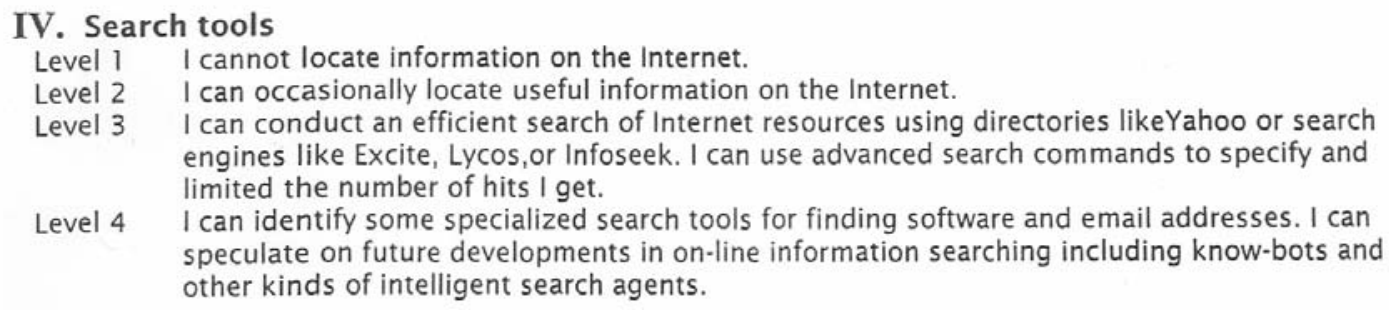

\section{Newsgroups, gophers and telnet}

Level 1 I have no knowledge of newsgroups, gophers, or telnet functions.

Level 2 I know that there are resources in a variety of formats available on the Internet, but can not confidently access them.

Level 3 I read the newsgroups that interest me on a regular basis, and I can contribute to newsgroups. I understand the use of gophers and can locate several that help me. I can write directions for locating a gopher so that others can find it as well. I can access a remote computer through the telnet command, including remote library catalogs. I can find the help screens when emulating remote computers and can log off properly.

Level 4 I know how to find, configure, and use the specialized tools for newsgroups, gophers, and telnet access. I use the resources found in these areas with my students.

\section{Obtaining, decompressing, and using files \\ Level 1 I cannot retrieve files from remote computers. \\ Level 2 I know that documents and computer programs that are useful to my students and me are stored on computers throughout the world. I can retrieve these files. \\ Level 3 I understand the concept and netiquette of "anonymous FTP" sites. I can transfer files and programs from remote locations to my computer, and can use programs or plug-ins that help me do this. I can extract compressed files, and know some utilities that help me view graphics and play sounds and movies. I understand the nature and danger of computer viruses, and know how to minimize my risk of contracting a computer virus. \\ Level 4 I use information I have retrieved as a resource for and with my students. I understand the concept of a network server, and the functions it can serve in an organization. I can use an $\mathrm{ftp}$ client to upload files to a server.}

\section{Real-time and push technologies}

Level 1 I use only static documents and files I retrieve from the Internet.

Level 2 I have some information sent to me on a regular basis through e-mail and I check some sites on a regular basis for information.

Level 3 I use chat-rooms and customized news and information feeds. I can listen to audio streamed from the web. I know the hardware and software requirements for web-based videoconferencing.

Level 4 I can use real-time applications to design a "virtual" classroom or interactive learning experience. My students use videoconferencing for communication with experts and project collaboration with other students.

\section{Web page construction}

Level 1 I can not create a web page.

Level 2 I can save text I have created as an html file with a command in my word processor. I know a few, simple html commands.

Level 3 Using hand-coded html or a web page authoring tool, I can:

- view web pages as a source documents

- create a formatted web page that uses background color, font styles and alignment, graphics, and tables

- include links to other parts of my document or other Internet sites in my page

- know basic guidelines for good web page construction and the district's web policies

Level 4 I can use the web as an interface to databases. When appropriate, I can register my pages with search engine sites. I can help write web creation policies for design, content, and use. 


\section{Learning opportunities using the Internet}

Level 1 I am not aware of any ways the Internet can be used with students in my classroom.

Level 2 I occasionally allow my students to use the Internet to find information.

Level $3 \quad$ I know a variety of projects and activities that effectively use the Internet to instruct and involve students. I know a source for collaborative projects, can direct students to on-line tutorials and learning resources, and encourage a variety of key-pal activities.

Level 4 I can design and implement an Internet project or maintain an educational Internet site.

\section{Netiquette, On-line Ethics, and Current Issues Surrounding Internet Use in K-12 Schools}

Level I I am not aware of any ethics or proprieties regarding the Internet nor am I aware of any issues dealing with Internet use in a school setting.

Level 2 I understand a few rules that my students and I should follow when using the Internet. I understand that the Internet is sometimes a controversial resource that many educators and parents do not understand.

Level 3 I have read a guideline for Internet use such as Rinaldi's "The Net: User Guidelines and Netiquette" or other source, and follow the rules outlined. I know and read the FAQ files associated with sources on the Internet. I am aware that electronic communication is a new communications medium that may require new sensitivities. I can identify printed and online resources that speak to current Internet issues like:

- censorship/site blocking software

- copyright

- legal and illegal uses

- data privacy

- security I can list some of the critical components of a good Acceptable Use Policy and know and use our district's.

Level 4 I can use my knowledge of the Internet to write good school policies and activities that help students develop good judgment and good information skills.

Please add any additional comments or concerns that you would like to share:

Thank you for your participation in Trek 21! 


\section{APPENDIX D:}

Indicators of Instructional Change Instrument (Random Lesson Sweep) 
Effective Integration of Instructional Technologies 1

\section{Indicators of Instructional Change Instrument—Random Lesson Sweep Pre-Implementation}

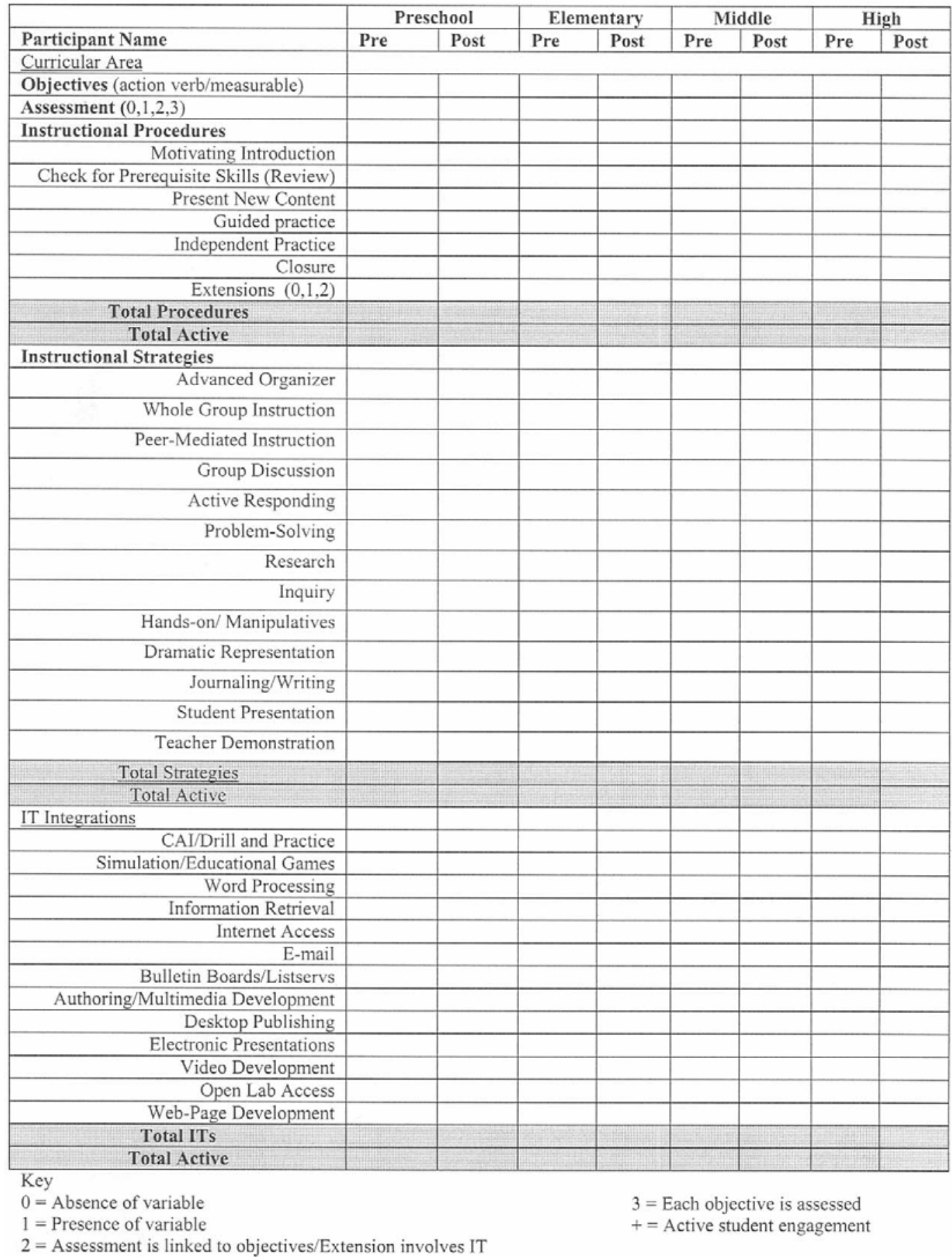


Indicators of Instructional Change Instrument-

Random Comprehensive Evaluation-Pre-Implementation

\begin{tabular}{|c|c|c|c|c|c|c|c|c|c|c|}
\hline \multirow[t]{3}{*}{ Participant Name } & \multicolumn{10}{|c|}{ Preschool Elementary Middle High } \\
\hline & \multicolumn{2}{|c|}{ Lesson 1} & \multicolumn{2}{|c|}{ Lesson 2} & \multicolumn{2}{|c|}{ Lesson 3} & \multicolumn{2}{|c|}{ Lesson 4} & \multicolumn{2}{|c|}{ Lesson 5} \\
\hline & Pre & Post & Pre & Post & Pre & Post & Pre & Post & Pre & Post \\
\hline \multicolumn{11}{|l|}{ Curricular Area } \\
\hline \multicolumn{11}{|l|}{$\begin{array}{l}\text { Objectives (action } \\
\text { verb/measurable) }\end{array}$} \\
\hline \multicolumn{11}{|l|}{ Assessment $(0,1,2,3)$} \\
\hline \multicolumn{11}{|l|}{ Instructional Procedures } \\
\hline \multicolumn{11}{|l|}{ Motivating Introduction } \\
\hline \multicolumn{11}{|l|}{$\begin{array}{r}\text { Check for Prerequisite Skills } \\
\text { (Review) }\end{array}$} \\
\hline \multicolumn{11}{|l|}{ Present New Content } \\
\hline \multicolumn{11}{|l|}{ Guided practice } \\
\hline \multicolumn{11}{|l|}{ Independent Practice } \\
\hline \multicolumn{11}{|l|}{ Closure } \\
\hline \multicolumn{11}{|l|}{ Extensions $(0,1,2)$} \\
\hline \multicolumn{11}{|l|}{ Total Procedures } \\
\hline \multicolumn{11}{|l|}{ Total Active } \\
\hline \multicolumn{11}{|l|}{$\begin{array}{l}\text { Instructional } \\
\text { Strategies }\end{array}$} \\
\hline \multicolumn{11}{|l|}{ Advanced Organizer } \\
\hline \multicolumn{11}{|l|}{ Whole Group Instruction } \\
\hline \multicolumn{11}{|l|}{ Peer-Mediated Instruction } \\
\hline \multicolumn{11}{|l|}{ Group Discussion } \\
\hline \multicolumn{11}{|l|}{ Active Responding } \\
\hline \multicolumn{11}{|l|}{ Problem-Solving } \\
\hline \multicolumn{11}{|l|}{ Research } \\
\hline Inquiry & & & & & & & & & & \\
\hline Hands-on/ Manipulatives & & & & & & & & & & \\
\hline Dramatic Representation & & & & & & & & & & \\
\hline Journaling/Writing & & & & & & & & & & \\
\hline Student Presentation & & & & & & & & & & \\
\hline Teacher Demonstration & & & & & & & & & & \\
\hline Total Strategies & & & & & & & & & & \\
\hline Total Active & & & & & & & & & & \\
\hline
\end{tabular}




\section{APPENDIX E:}

Final Daily Training Evaluation Questionnaire 
PK-12 2001 Institute

Day 1- Daily Evaluation Form

Welcome to the "Trek 21 Daily Evaluation Form". Please follow the steps outlined below to complete the survey.

Step 1: Type your participant code in the box provided.

Step 2: Please read each statement and rank your understanding at the present time (After Training). Next, think back to your understanding before the training today (Before Training). Use the pull down menu to select your responses.

Step 3: Respond to each question (use Not Applicable where you are unwilling or unable to respond). Your form will not submit with blank items.

OPTIONS: $1=$ No understanding; 2 = A little understanding; $3=$ Moderate understanding; $4=$ Quite a bit of understanding; $5=$ Almost complete understanding; $0=$ Not applicable

Participant Code:

\begin{tabular}{|c|c|c|}
\hline Question & After this session ... & Before this session ... \\
\hline 1. The purpose of trek 21 & (0) (1) (2) (3) (4) (5) & (4) (1) (2) (3) (4) (5) \\
\hline 2. The different types of ITs & (0) (1) (2) (3) (4) (5) & (4) (1) (2) (3) (4) (5) \\
\hline 3. How other teachers use ITs & (a) (1) (2) (3) (4) (5) & (4) (1) (2) (3) (4) (5) \\
\hline $\begin{array}{l}\text { 4. How I can use ITs to enhance my } \\
\text { teaching }\end{array}$ & (1) (1) (2) (3) (4) (5) & (1) (1) (2) (3) (4) (5) \\
\hline $\begin{array}{l}\text { 5. How ITS can be used to encourage } \\
\text { student engagement }\end{array}$ & (1) (1) (2) (3) (4) (5) & (4) (1) (2) (3) (4) (5) \\
\hline $\begin{array}{l}\text { 6. How to assess the effectiveness of } \\
\text { ITs }\end{array}$ & (0) (1) (2) (3) (4) (5) & (1) (1) (2) (3) (4) (5) \\
\hline
\end{tabular}

Daily Open-ended:

Please give us your thoughts in response to the following questions:

a) Things I learned today:

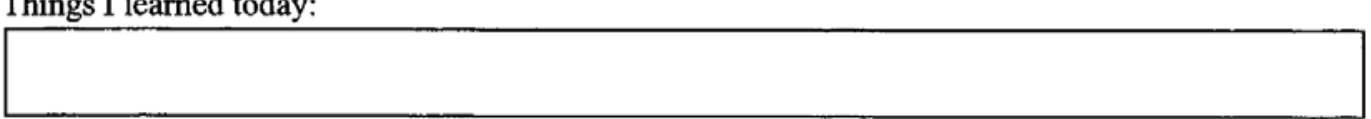

b) A strength of the session today is:

c) Something that would have improved today's session is:

d) Today I accomplished: 
PK-12 2001 Institute

Daily Evaluation Items

Day 15 - July 13 Final Daily Evaluation

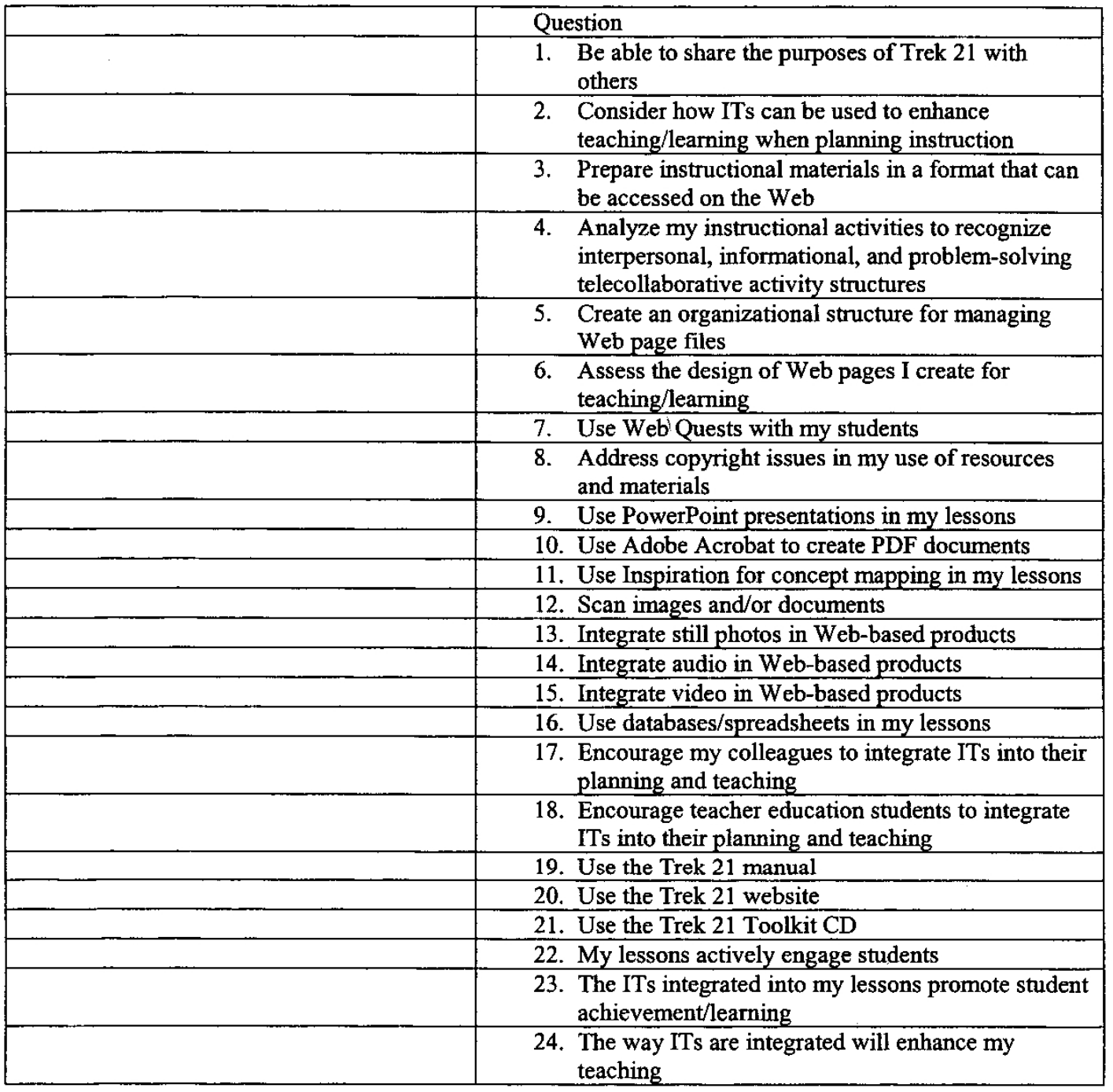

Final Open-ended:

Describe the anticipated impact (if any) of your participation in the Institute on:

a) your own personal/professional use of ITs

b) the learning experiences of your students

c) the teaching/learning experiences of the teacher education students you work with

Please share your general reactions to the Trek21 Institute: 